\title{
Reflections on Water: \\ Community Productions in Cai Lay, Vietnam
}

\author{
By \\ Tam Tran, B.A.S.

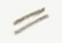 \\ A thesis submitted to \\ The Faculty of Graduate Studies \\ In partial fulfillment of the requirements for the degree of
}

\section{Master of Architecture}

\author{
Carleton University \\ Ottawa, Ontario \\ June 142005
}

CCopyright

2005, Tam Tran 


\begin{abstract}
This thesis considers the role of the architect in the stewardship of water as both a physical resource and cultural symbol, essential to human existence. It argues that architects are well positioned to enable a positive transformation in the way that the population approaches the integration of water into their lives and that they should be deeply implicated in the preservation, management and celebration of water in its poetic traditions and the practices of everyday life.

The specific context for this study is the country of Vietnam. The first part of the thesis defines the current water crisis in Vietnam that led to the author's interest in this topic, and establishes a theoretical basis regarding the role of the architect in Vietnam and the role that water can play in the architectural project. The subsequent sections of the thesis explore the specific conditions surrounding the physical and cultural incorporation of water into the riverfront community of Cai Lay, Vietnam.
\end{abstract}




\section{Acknowledgements}

Special thanks to my parents for the unconditional love and support to make this possible. I wish to express my gratitude to my advisor, Lucie Fontein for her continuous guidance and constructive criticisms throughout the project. I am grateful for the constant support of family and friends who freely gave their time and ideas for

discussion. My thanks also go to Rob, Mai Anh, Eric, Mandy, and Jen for their amazing contributions. 


\section{Table of Contents}

Abstract

Acknowledgments

ii

List of Illustrations

iii

1 Introduction

2 Setting the Theoretical Stage

2.1 The Role of the Architect

2.2 History of Water in Design

2.3 Changing Water: A History of Meaning

2.4 Changing Social Perspective: Sustainable Design 2.4.1 The Integrated System

2.4.2 Natural Water Treatment Gardens

2.5 Case Study: The Living Water Garden

3 Site Research: Cai Lay, Vietnam

3.1 Geographical Background

3.2 The Current Water Resource for Living

3.3 Water Consumption

3.4 Site Remediation Opportunities

4 Cultural Research: Cai Lay, Vietnam

4.1 Water Culture

4.2 Traditional Water Puppetry

5 Design Proposal

5.1 Urban Renewal Objectives

5.2 Site Remediation

5.3 Development of the Riverfront

5.4 The Water Puppet Theatre

5.5 The Residential Infrastructure

6 Conclusions

Appendices

A The Living Machine Fact Sheet 78

B Site Interview Data $\quad 86$

$\begin{array}{ll}\text { Works Cited } & 91\end{array}$

$\begin{array}{lr}\text { Selected Bibliography } & 93\end{array}$ 


\section{List of Illustrations}

All images by author unless otherwise noted.

Figure 1: Site Panorama View

Figure 2: Site Elevation View

Figure 3: River View, looking north

Figure 4: River View, looking south 4

Figure 5: City Gate $\quad 4$

Figure 6: Main Street Intersection $\quad 4$

Figure 7: Typical Rural House $\quad 6$

Figure 8: Aluminum Sheathing House $\quad 6$

Figure 9: The Trevi Fountain 11

Figure 10: Large Basins at Versailles $\quad 12$

Figure 11: Mosque at Cordoba $\quad 13$

Figure 12: The Alhambra in Granada $\quad 13$

Figure 13: The Integrated Urban Water System 24

Source: Neil S. Grigg, Urban Water Infrastructure: Planning,

Management, and Operations (New York: Wiley, 1986) 15.

Figure 14: Living Water Garden Map

Source: The Living Water Garden. Keepers of the Waters website. 14 February $2005<\mathrm{http}: / /$ keepersofthewaters.org/lwg.cfm>.

Figure 15: Constructed Wetlands

Source: The Living Water Garden. Keepers of the Waters website. 14 February $2005<$ http://keepersofthewaters.org/lwg.cfm>.

Figure 16: Clean Water Fountain

Source: The Living Water Garden. Keepers of the Waters website. 14 February $2005<\mathrm{http}: / /$ keepersofthewaters.org/lwg.cfm>. 
Figure 17: Living Water Garden Detailed Map

Source: The Living Water Garden. Keepers of the Waters website. 14

February $2005<$ http://keepersofthewaters.org/lwg.cfm>.

Figure 18: Water Tower

Figure 19: Site Analytical Drawing 1

Figure 20: Site Analytical Drawing 2

Figure 21: Water Puppet Theatre

Figure 22: Thay Pagoda

Source: Hong Huy Nguyen and Chinh Trung Tran, Vietnamese

Traditional Water Puppetry, (Vietnam: The Gioi Puplishers, 2001) 15.

Figure 23: Thay Pagoda Plan

Source: Nguyen, 16.

Figure 24: Thay Pagoda Elevation

Source: Nguyen, 17.

Figure 25: Site drawing of land uses (1:5000)

Figure 26: Site Model (1:250)

Figure 27: Proposed Site Plan (1:1000)

Figure 28: Water Level Diagram

Figure 29: Proposed Waterfront Plan (1:250)

Figure 30: Proposed Foundation Section (1:10)

Figure 31: Section A - Washroom and Dock (1:50)

Figure 32: Section B - Theatre and Market (1:50)

Figure 33: Section C - House and Market (1:50)

Figure 34: Section D - Water Reclamation (1:50)

Figure 35: Detail, water spout (1:5) 
Figure 37: Detail, stair with water (1:20)

Figure 38: Section E - Market/Theatre/Pathway (1:50) 60

Figure 39: Detail Section - water screen (1:10) 62

Figure 40: Water Puppet Theatre Elevation 63

Figure 41: Water Puppet Theatre Plan (1:50) 64

Figure 42: Water Puppet Theatre Perspective 65

Figure 43: Water Puppet Theatre Axonometric Drawing 66

Figure 44: Section - House 1 (1:50) 68

Figure 45: Section - House 2 (1:50) 68

Figure 46: Proposed Plumbing (1:50) 69

$\begin{array}{ll}\text { Figure 47: Water Placement and Collection Studies } & 70\end{array}$

$\begin{array}{ll}\text { Figure 48: Conceptual House Model } 1 & 70\end{array}$

Figure 49: Conceptual House Model $2 \quad 70$

$\begin{array}{ll}\text { Figure 50: Conceptual House Model } 3 & 70\end{array}$

$\begin{array}{ll}\text { Figure 51: Conceptual House Model } 4 & 70\end{array}$

Figure 52: Conceptual House Model $5 \quad 70$

$\begin{array}{ll}\text { Figure 53: Analytical Painting } 1 & 71\end{array}$

$\begin{array}{ll}\text { Figure 54: Analytical Painting } 2 & 71\end{array}$

Figure 55: Analytical Painting 3 72

Figure 56: Analytical Painting 4 72

Figure 57: Analytical Painting 5

Figure 58: Moment 1

Figure 59: Moment 2 
Figure 60: Moment 3

Figure 61: Moment 4

Figure 62: Moment 5 


\section{Introduction}

Many cities in under-developed countries are facing enormous difficulties providing healthy environments (which are contingent upon the supply of clean water and the appropriate management of solid and liquid waste) for their growing populations. The combined factors of population growth, urbanization, industrialization, and economic development continue to exert pressures and higher demands on water resources. If trends continue, incompetent water management will endanger the lives of future generations.

This situation is likely to deteriorate even further in the future for three main reasons. First of all, the global population is increasing rapidly and is likely to continue to do so. This means more and more water will be required for domestic and industrial uses as well as agricultural production for the expanding population. Secondly, as more and more people attain a higher standard of living, per capita water demand will also continue to increase. Finally, as the global population (and production activities) increase, more and more waste products will contaminate existing water sources. The contaminants are seriously affecting the quality of available sources of both surface and groundwater. Thus, water quality management is becoming an increasingly important concern all over the world, and especially in developing countries.

Vietnam is a pertinent illustration of this regrettable phenomenon. Vietnam has a long history of water management control issues that have developed in response to water shortages during the dry season, a monsoon climate that regularly causes extensive flood 
damage, and the desire to intensify agricultural production. ${ }^{1}$ Historically, droughts have been seasonal and localized, but recently these have become a more serious problem. Much of the coastal environment is polluted and is increasingly being degraded by the compounding factors of population growth, urbanization, rapid and largely uncoordinated economic development, and inadequate resource management. Over the past decade, these problems are overwhelming the capacity of the existing political and institutional regime and, in turn, are undermining the effectiveness of numerous governmental interventions. Given this history and context, water resource management still remains one of the most critical issues in Vietnam today. For these reasons, architectural and urban design strategies must be found to reduce the strain on and abuse of this valuable resource.

The site chosen for the critical analysis and proposed remediation strategy is Cai Lay, Vietnam. Cai Lay is a medium-sized city with a population of approximately 24,500 people. Like many other cities in Vietnam, the river is the backbone in the development and growth of the city, yet it is currently polluted and unable to sustain a healthy environment for the city's inhabitants. Excrement ends up in ponds, streams and ditches and on open ground because waste water is discharged directly into streams, open drains, rivers, lakes and coastal waters without treatment. The proposed urban renewal strategy aims to develop a long-term vision for a hydrological community with access to a safe, affordable and sustainable water supply and waste water management systems. It calls for the immediate cessation of the exploitation of water resources and urges public awareness and involvement in the preservation of this precious resource.

\footnotetext{
${ }^{1}$ The Ministry of Environment and Natural Resource, Vietnam Environment Monitor 2003: Water (Ho Chi Minh City: World Bank Report) 1.
} 
This thesis argues that architects should be fundamentally implicated in the preservation, management and celebration of water, both at the community and dwelling scales. In their multi-faceted roles, that straddle the realms of cultural identity (spirituality, poetic traditions and the practices of everyday life) and technological innovation, architects are well positioned to enable a positive transformation in the way that the population approaches the integration of water into their lives.

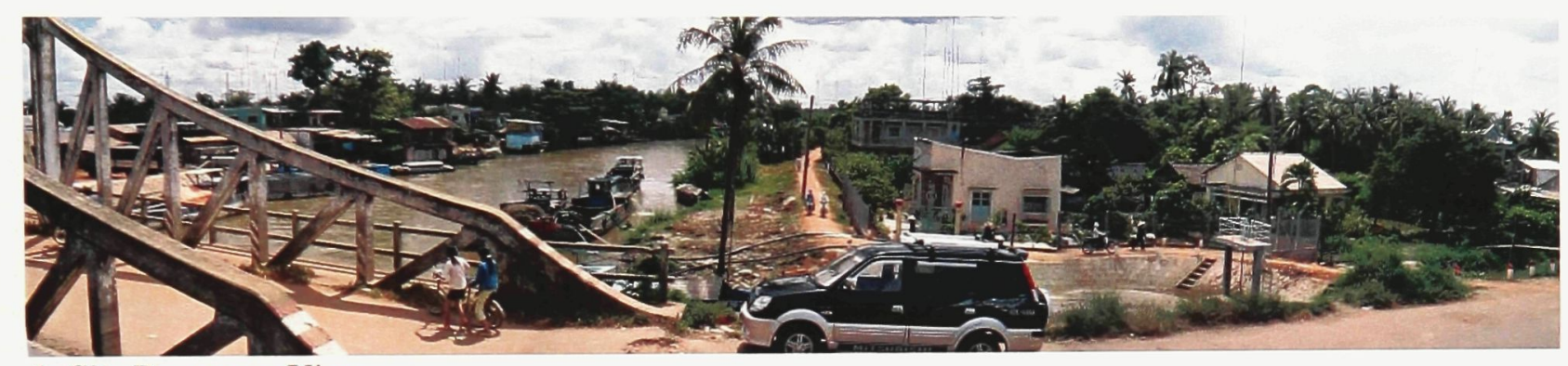

1: Site Panorama View

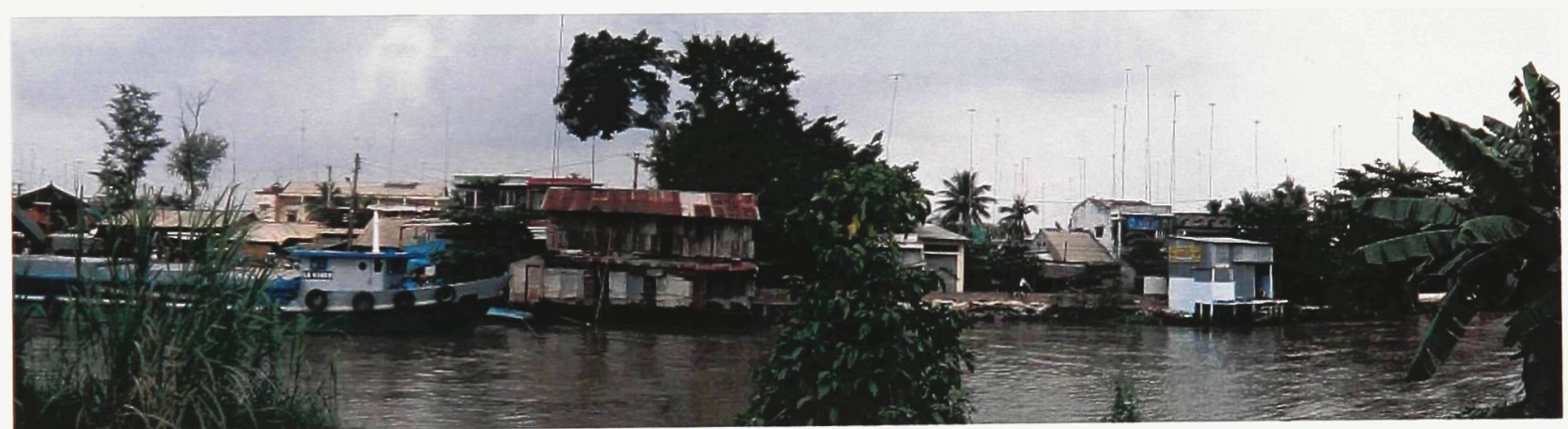

2: Site Elevation View 


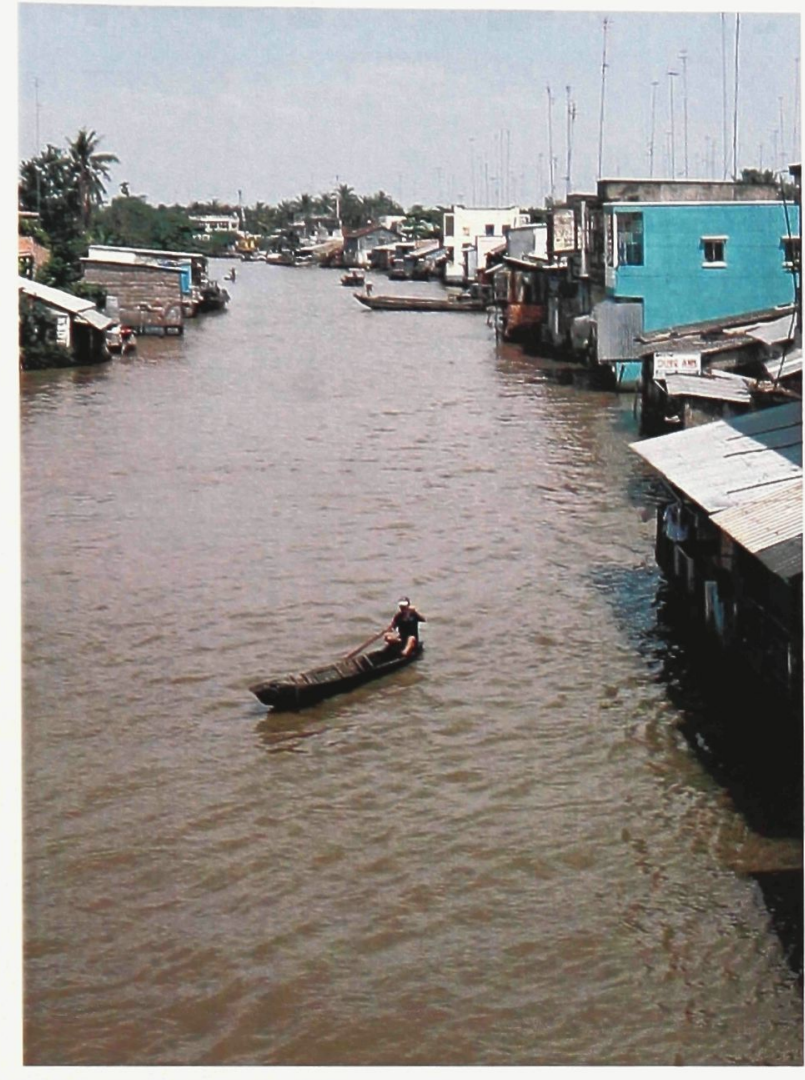

3: River View, looking north

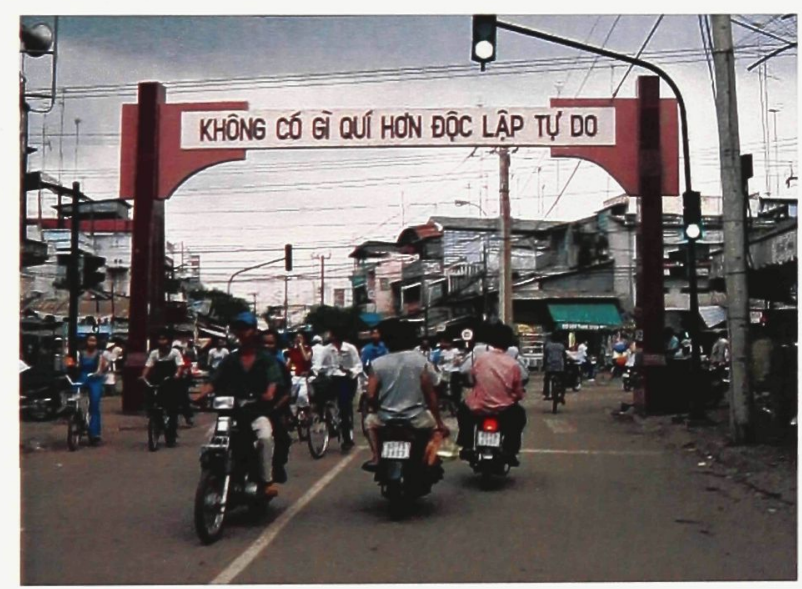

5: City Gate

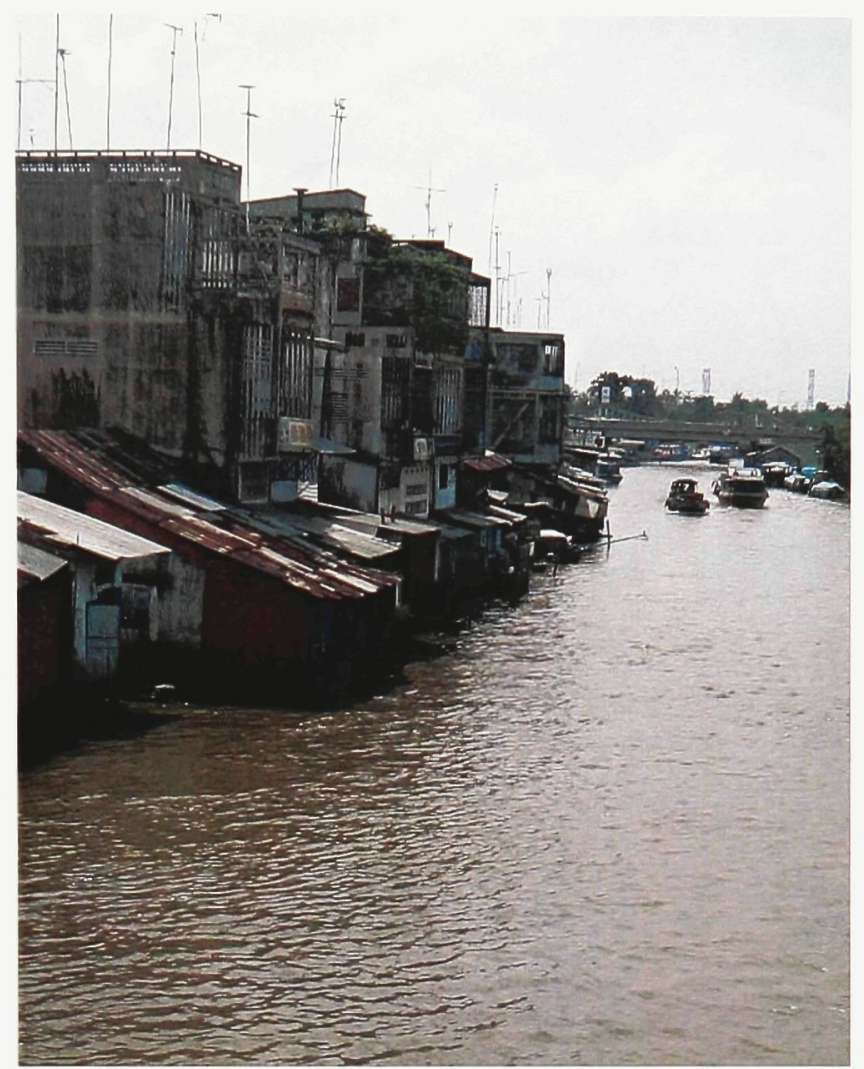

4: River View, looking south

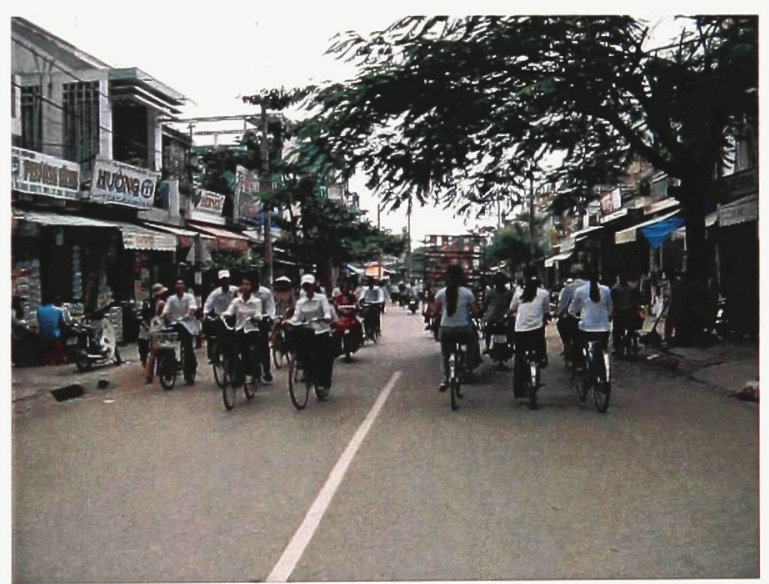

6: Main Street Intersection 


\section{$2 \quad$ Setting the Theoretical Stage}

\subsection{The Role of the Architect}

The role of the architect in a small Vietnamese city like Cai Lay is quite different from that of an architect in North America. The construction of an average dwelling will not involve an architect at all and will be carried out by local tradesmen and builders. Traditionally, the owner is responsible for his or her own hiring and managing of all the trades in the construction of a typical house. In this case, the owner is fulfilling the role of the manager, developer and architect in the North American sense. In a small Vietnamese city, the architect is sometimes involved in providing the design and construction drawings for wealthier clients, however that is the utmost extent of the architect's involvement in terms of housing in Cai Lay and many other small cities in Vietnam. In most cases, the construction of a typical dwelling requires no construction drawings at all and the owner simply coordinates a design/build type of process with the tradesmen and builders directly on site.

The typical dwelling construction in Cai Lay is very different from that of a North American suburb. Due to the favorable tropical weather, the building envelopes are much less complicated than those developed for more extreme weather conditions. Major concerns in typical dwelling constructions are rain, wind and heat from the sun. As a result, the typical dwelling utilizes traditional natural ventilation methods with a very simple building envelope. The construction methods and materials in Cai Lay vary depending on the type of occupancy and the available capital from the owner. 
The cheapest and most affordable type of construction is wood-framing with coconut leaf sheathings utilized for wall partitions, siding and roofing. This type of construction is mainly used in rural areas where the entire construction and design will involve only the family and friends of the owner. The aesthetics of coconut leaf sheathing are typically romanticized for rural farm houses and traditional rural homes. These houses are symbolic of Vietnam's rural community. In city peripheries, this form of

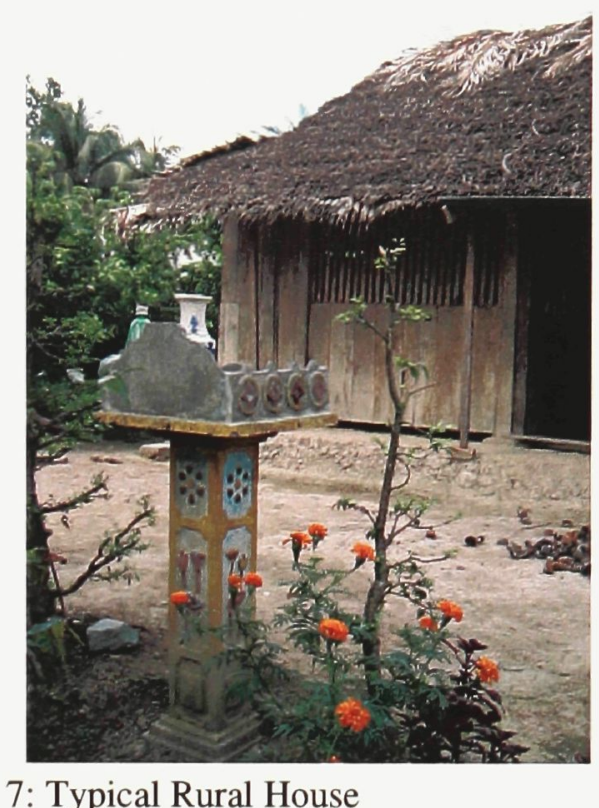

7: Typical Rural House construction is favored for extensions and temporary sheds and shelters such as kitchen and washroom spaces that are separated from the main living spaces. Despite its renewable quality, coconut leaf sheathings are rarely used in urban centers where other materials for construction are readily available.

Another construction method is wood-framing with galvanized aluminum sheathing. The majority of these constructions are for kitchen extensions, shaded patios or large warehouses. Aluminum sheathings are utilized primarily for roofing and sometimes for siding. The utilization of aluminum sheathing is carefully planned for open structure or high ceiling constructions because it reflects extreme heat during hot summer

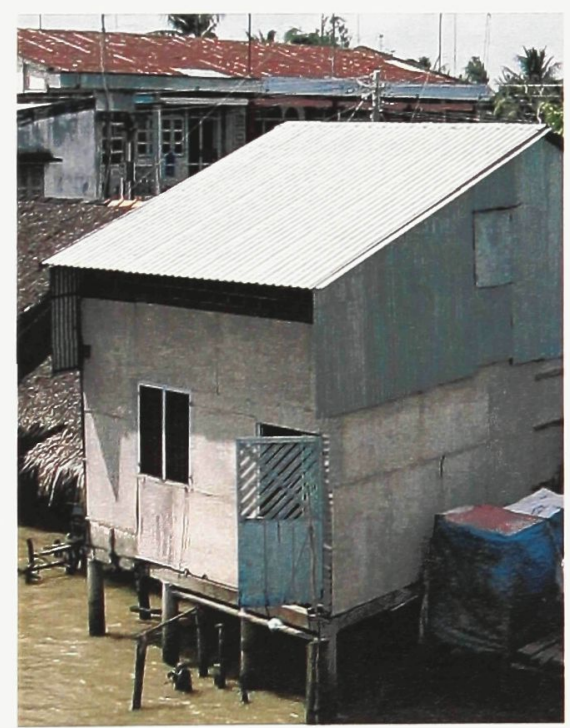

8: Aluminum Sheathing House days. 
In urban centers, the most favoured construction material is concrete. The typical wall construction of an urban center dwelling is comprised of concrete, concrete block or brick with concrete cladding or plaster. Ground floor finishes are either concrete or completed with tiles imported from China. Upper floors are composed of wood beams supporting a wood floor or finished concrete slabs. The roofs are pitched wood-framing with interlocking roofing tiles or concrete slabs.

All these types of constructions are long-established and have been practiced for generations by the local tradesmen and builders. Like most traditional lines of work in Vietnam, construction skills and knowledge are passed on from one generation to the next and thus, the tradesmen are experts at what they do and require no technical assistance from the architect. The tradesmen are in fact the builder/architects in the classical Western sense. Thus architects are rarely involved in typical dwelling construction.

The majority of projects involving architects in Vietnam are currently public projects such as schools, libraries, hospitals and government buildings. Meanwhile, community design from the larger urban scale, down to the individual dwelling is often neglected. As in North America, little stress is placed on the role of the architect as public servant and defender of a cultural ethic.

The current situation in Cai Lay does not require architects to be involved or implicated in such matters as the preservation and management of water resources. The provision and management of water currently falls under the purview of local government officials. In such a situation, the architect has a limited role in directly 
affecting the typical dwelling designs and thus cannot make any immediate changes to the people's attitude towards water resources at either the private or community levels.

This thesis proposes that the architect redefine his/her professional role and act as leader and enabler in this most crucial dimension of human inhabitation. The redesign of the riverfront community of Cai Lay will act as a case study to illustrate the possibility of such a professional emphasis. Specifically an urban design is proposed that includes a natural water treatment facility, an open market and a water puppet theater that are connected by means of a water infrastructure to a variety of dwelling types. In this new role, the architect will take responsibility for the moment of intersection between the urban water infrastructure and the community at the public level and the dwelling at the private level. This responsibility is not merely for the supply of potable water and removal of waste water, but extends also to the celebration of water as a valued spiritual and cultural presence in the life of the city of Cai Lay.

In this sense, the role of the architect becomes one of technical advisor/ facilitator/educator, steward of the environment and protector of culture. The architect must take an ethical stance that weaves together these multiple forces in such a way as to make them inextricably linked. (Appendix A describes similar issues but in the context of North American society.)

Alberto Pérez-Gómez suggests that this ethical concern is difficult to recognize because it is internal to the practice of architecture rather than an external addition to some technical or formalistic activity. He notes that architecture is far from being merely an aesthetic or technical concern, architecture "seeks to set human action within an 'appropriate' frame, fulfilling this reconciliatory role despite man's tendency to control 
and dominate fellow human beings and the environment...If architects are to play a role in the complex world of the twenty-first century - a world conscious of environmental limits and cultural differences while civilization continues to embrace the goal of technological globalization - they must ponder their strategies to disclose their discipline's potential for embodying an ethical intentionality. "2

The main concern for the architectural community in Cai Lay is clear: local architects must adopt a leadership role and work with local government to establish reliable water supplies for every community. Architects can contribute a unique and imaginative gift by making use of the distinctive potential of water in the most creative and diligent way possible.

\footnotetext{
${ }^{2}$ Louise Pelletier, Alberto Pérez Gómez, and Institut de recherche en histoire de l'architecture, Architecture, Ethics, and Technology, (Montréal; Buffalo: Institut de recherche en histoire de l'architecture, Canadian Centre for Architecture, McGill University; Montreal; McGill-Queen's University Press, 1994) 4.
} 


\subsection{History of Water in Design}

Humans have always imitated nature, and nature's effects can be found in almost every piece of human creativity. Many great works of poetry, art, literature, and architecture have been the result of the absolute love and longing for a symbolic relationship with nature. Nature is the source of emotions, moods, and the aura of space and time that touches everything and influences many channels of architectural creativity. As a primary natural element, water is no exception. It is a necessary and basic ingredient in the world and is extremely vital both to life and to a diverse range of aesthetic and recreational pleasures. Each and every culture has its own way of designing with water and including it in architecture.

In some cases, water can be used to establish a particular mood or atmosphere. It can be reflective, crystalline and sparkling, auditory and hypnotic depending upon its setting, the climate, the quality of light, geology, soil, and a multitude of other factors. It produces an endless range of sounds as it sprays or is evaporated into the air and then returns to the surface, as it falls over rocks and into pools, and as it flows calmly over and around obstructions. Water in repose, on the other hand, has quite a different personality. With care and precision of design, water can have a dramatic impact on the experience of a place.

In most cases, the more aesthetic uses of water are combined with a more practical function. The decorative uses of water design can be traced back as early as Egyptian period. There were decorative ponds and canals constructed in Egyptian gardens as pictured in archaeological remains of tombs, sculptural relief and in 
paintings. ${ }^{3}$ The designs were geometric and formal but believed to serve both as irrigation channels or storage ponds such as raising fish for food. ${ }^{4}$

Similarly in Greece there was firm evidence of the existence of numerous fountains that combined religious, utilitarian and aesthetic functions. Many of these springs and fountains in Greece were dedicated to the gods, goddesses, nymphs and heroes. Practically, these fountains served as sources of drinking water and often included a structure to cover and enclose the draw basin. The Hellenistic Greeks produced many brilliant and remarkable cities with pressurized water systems, aqueducts, and definitely ingenious fountains. Renaissance architects later revived and improved these devices after discovering them in ancient literature. ${ }^{5}$

Ancient Rome was decorated with an abundance of fountains and other water features. At the time of the first sacking of the city, it was recorded Rome contained 1,212 public fountains and 926 public baths. ${ }^{6}$ The Trevi Fountain (completed in 1762) is one of Rome's finest

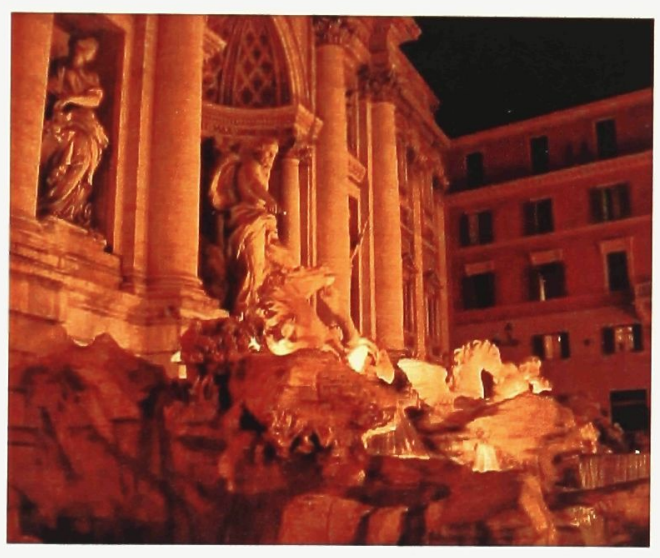

9: The Trevi Fountain examples of the ultimate joining of water and architecture. Architect Nicola Salvi envisioned the fountain as a glorious affirmation of the water cycle. Here, water makes its triumphant entry into the city, commanding attention as it overcomes the piazza with its overwhelming delight. The water collects in the basin and simultaneously squirts back

\footnotetext{
${ }^{3}$ Craig S. Campbell, Water in Landscape Architecture, (New York: Van Nostrand Reinhold Company, 1978) 15.

${ }^{4}$ Craig S. Campbell, Water in Landscape Architecture, (New York: Van Nostrand Reinhold Company, 1978) 15.

${ }^{5}$ Craig S. Campbell, Water in Landscape Architecture, (New York: Van Nostrand Reinhold Company, 1978) 16.

${ }^{6}$ Craig S. Campbell, Water in Landscape Architecture, (New York: Van Nostrand Reinhold Company, 1978) 16.
} 
up in the air, symbolizing the complete water cycle. Akin to the elemental substance of water the fountain is a repository for countless dreams and fantasies. Despite its mythic and grandiose scale, the Trevi never loses its remarkable ability to relate to everyday custom. Local people and

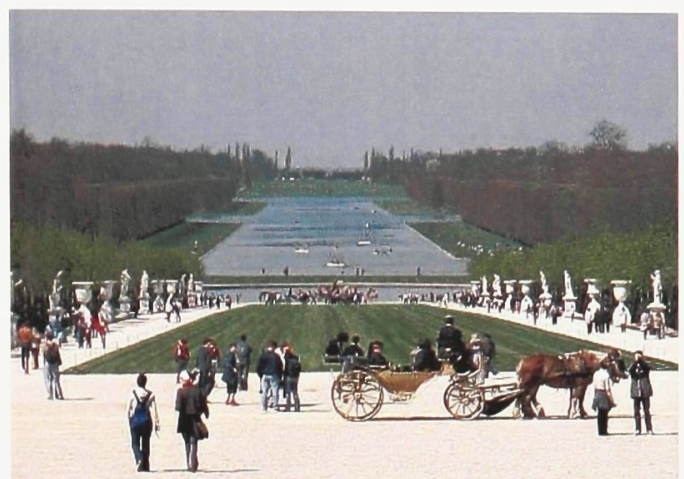

10: Large Basins at Versailles tourists alike gather daily around the fountain to bask in the sun and gossip about everyday activities such as politics or the price of vegetables. The fountain is a mandatory stop for local people during evening walks and for tourists ritually flipping coins over their shoulders into the basin, supposedly guaranteeing them one wish as well as a return trip to the city.

The renaissance period marks the celebration of technological innovation with respect to water. The exuberant water displays in the Italian gardens greatly influenced the French in terms of their size, with the addition of large canals and moats. The rather flat landscape restricted the French to recreate the cascades and vigorous water displays. The water displays in French palace gardens were generally hand-worked or horse-driven pumps to raise water from rivers to reservoirs. ${ }^{7}$ Lead pipes then conveyed the water from the reservoir located at higher level to the garden. At French gardens such as Versailles, architects built enormous basins to distinguish important visual axes and create formal patterns on gazed water that mirror the sky and moving clouds overhead. These large basins at Versailles are carefully positioned to take advantage of their reflective surfaces that are equivalent to natural lakes and ponds.

${ }^{7}$ Craig S. Campbell, Water in Landscape Architecture, (New York: Van Nostrand Reinhold Company, 1978) 44. 
Contrary to the grandness of scale in European

water features, Islamic cultures minimize the amount of water for maximum advantages. In Islamic cultures water was a central feature of garden design with religious symbolism. It defined space and interpenetrated from the open court into the enclosure. The Islamic view of Heaven is a beautiful garden complete with springs and fountains where the Day of Judgment will take place. ${ }^{8}$ In fact, from Persia to Spain water was one of the four essentials in the creation of a

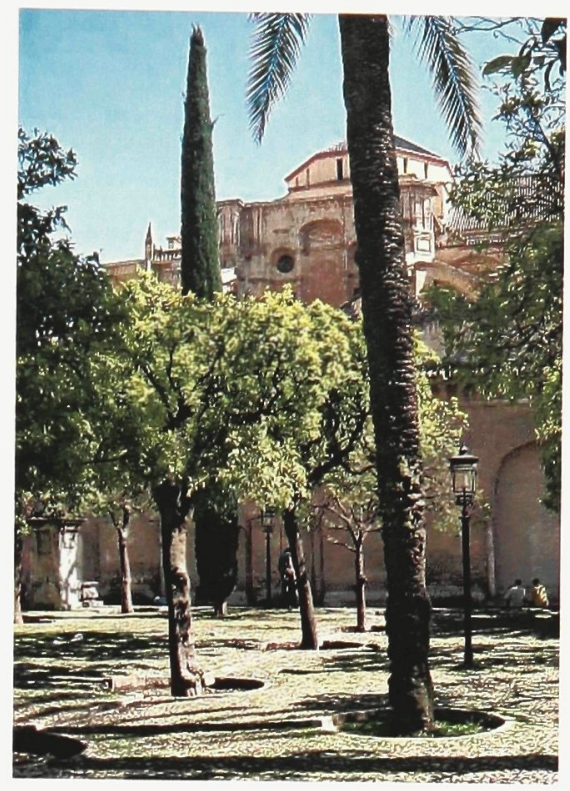

11: Mosque at Cordoba traditional garden including shade trees, flowers, and music.

It is difficult to discuss great water features without mentioning the remarkable achievement in Moorish design such as the Mosque at Cordoba or the Alhambra in Granada. The Moors reintroduced highlevel hydraulics, and irrigation systems, elaborate cisterns and reservoirs. In Moorish Spain garden design, the visual and auditory quality of water was more crucial than plant material. Through cultural style

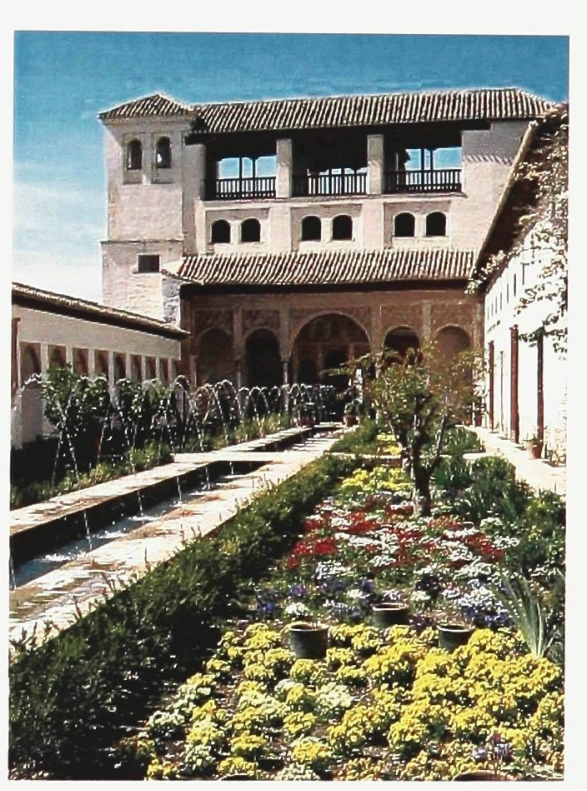

12: The Alhambra in Granada and scarcity of supply the Moors brought to Spain techniques that made a small amount of water appear to be vast. Water was confined to small channels where no waste water was allowed to escape unused. For instance, narrow pools and conduits designed through

\footnotetext{
${ }^{8}$ Craig S. Campbell, Water in Landscape Architecture, (New York: Van Nostrand Reinhold Company, 1978) 18.
} 
interconnected surface channels ran from tree to tree for irrigation. This ingenious method of directing irrigation water to trees in courtyard gardens is now common in Spain. The majority of these channels were open and visible whenever possible. The often-carved lotus patterns of basins were intended to make a small volume of water seem greater. This illusion is further accentuated by basins designed to be continually full to the brim and water overflowing the edges into a secondary channel. The fundamental differences of the Islamic garden to the Renaissance and baroque gardens are the essentially spiritual, poetic, and contemplative purposes. The Western park or garden was completely opposed to nature and concentrated the social, ceremonial, and classical-inspired play areas of the Italian and French aristocracy. In contrast, the Arabic garden often secludes its spaces in hidden courts, with only subtle unframed views.

In some cases, it is the narrative content of water that is exploited. In ancient Asia, the poet, painter, sculptor and monk played an important role in the formation of early gardens, creating ideal images of water, rock and plant forms. The water design of traditional Chinese and Japanese gardens is entirely dependent on its natural settings. These traditional gardens were typically designed by the inhabitant who often installed them as well. It is more likely that these traditional gardens were derived from paintings and sketches that provided the basic ideas whereas the final product was the result of considerable adjustment rather than scaled drawings. Both Chinese and Japanese lake and pond designs can be seen or experienced from many locations. These gardens were never fully framed in totality, but instead unfolded and revealed themselves in progression, always keeping some feature hidden from view. The gardens were places for solitude and contemplation rather than for vast spectacles and social celebrations. 
The history of water in design is so encompassing that one can only touch on it briefly here. There are many spectacular and ingenious designs of water features throughout history and from various cultures. They all share the idea that water is a precious commodity that can give both life and pleasure to our senses. With a relatively small amount of water in design can give one a feeling of immediacy, intimacy, and belonging. Water is a material that can provide the channel for additional meaning in architecture. 


\subsection{Changing Water: A History of Meaning}

In the search for the beginning of the philosophy of water, one realizes that it began in many different cultures, within many texts and anywhere one can find expressions of the latent power and mystery of water. A philosophy of water refers to any wonder, reflection, contemplation, or mediation that explores and articulates some aspect of the world of water that was previously hidden or forgotten. One can only scratch the surface in the history and meaning of water, as it is such an extensive and diverse terrain. Just as the architect Charles W. Moore wrote, "Water is composed of stories, above and beyond its molecular fusion of hydrogen and oxygen." 9

In the account of Thales of Miletus, the sixth-century Greek philosopher expresses wonder at the enormity of water and at its unending potency. ${ }^{10}$ Thales found the water to be the source of all beings, the "arche". ${ }^{11}$ He expresses the "arche" not as some mere formalism, but as the primordial or aquatic matter of which everything is composed. Water is part of everything. Everything has its beginning in water and to water everything returns. Thales believed that water was the most fundamental building block of the universe. It is irreducible and indestructible. Nietzsche noted that Thales' philosophy marks the beginnings of the philosophical doctrine that everything is one. ${ }^{12}$ Thales implies that everything is one because everything is fundamentally related to water. Whenever the source or latent power of nature is explored, water comes to the surface. Evidently, all things that are responsible for the generation and preservation of

\footnotetext{
${ }^{9}$ Charles W. Moore, Water and Architecture, (New York: Harry N. Abrams, Inc., 1994) 15.

${ }^{10}$ Richard D. McKirahan, Philosophy Before Socrates: An Introduction with Texts and Commentary (Cambridge: Hackett Publishing Company, 1994), 23-31.

${ }^{11}$ McKirahan 23-31.

${ }^{12}$ Friedrich Wilhelm Nietzsche, Philosophy in the Tragic Age of the Greeks, trans. Marianne Cowan (Chicago: Regnery, 1962)
} 
living things are moist such as milk, semen, amniotic fluid, blood, and water. It is the immensity of water, as it appears throughout the entire natural world, that Thales articulates by assigning to water the causal power of the original source, the "arche".

Apart form the Western tradition of philosophy and its roots in ancient Greece, water is also contained in the Tao Te Ching, the ancient Chinese text attributed to the legendary Lao Tzu. In this text, there is an apparent sense of amazement and devotion to the Tao of the countless things and their sources, especially in terms of the ways of water. For example, chapter eight of the Tao Te Ching reads as follows:

The best (man) is like water.

Water is good; it benefits all things and does not compete with them.

It dwells in (slowly) places that all distain.

This is why it is so near to Tao. ${ }^{13}$

In this context, Lao Tzu uses water as symbols of Tao from which one can learn moral lessons. Soft and yielding as it is, water is able to slowly change things that appear to be hard and flexible. In chapter 78, one can see the paradoxical way in which water manifests itself:

There is nothing softer and weaker than water, And yet there is nothing better for attacking hard and strong things.

For this reason there is no substitute for it.

All the world knows that the weak overcomes the strong and the soft overcomes the hard.

But none can practice it. ${ }^{14}$

Although it might seem paradoxical that such a soft and gentle thing as water could possess such erosive capabilities, this is indeed true and apparent in many cases around the world, such as the phenomenon of the Grand Canyon.

\footnotetext{
${ }^{13}$ Wing-Tsit Chan, A Source Book in Chinese Philosophy, (Princeton, N.J.: Princeton University Press, 1963) 143.

${ }^{14}$ Wing-Tsit Chan, A Source Book in Chinese Philosophy, (Princeton, N.J.: Princeton University Press, 1963) 174-175.
} 
In chapter 66, governmental concerns and lessons are expressed:

The great rivers and seas are kings of all mountain streams

Because they skillfully stay below them.

That is why they can be their kings.

Therefore, in order to be the superior of the people,

One must, in the use of words, place himself below them.

And in order to be ahead of the people,

One must, in one's own person, follow them.

Therefore the sage places himself above the people and

they do not feel his weight.

He places himself in front of them and the people do not

harm him.

Therefore the world rejoices in praising him without getting tired of it.

It is precisely because he does not compete that the world cannot compete with him. ${ }^{15}$

In this excerpt, there is a clear reflection on the way of the government in terms of the seemingly paradoxical integration of humility and power evoked by the way of water.

Since, the sea is lower than the streams, and higher streams will naturally flow to the lower sea, it is able to do nothing and still receive the power of the streams. The lesson learned here is that those who desire to govern and lead others are urged to let their actions be informed by the people they govern, as water lets its course be informed by the channel it traverses. The actions of the government are encouraged to mimic the actions of water.

In the thirteenth-century, Dōgen, the founder of the Zōtō Zen school of Japanese Buddhism, wrote a sutra in which he uses water to express the very nature of Shō, enlightenment or realization. ${ }^{16}$ Dōgen's writing in "Mountain and Water Sutra" is filled with examples concerning the paradoxical characteristics of water, which reflect a truth

\footnotetext{
${ }^{15}$ Wing-Tsit Chan, A Source Book in Chinese Philosophy, (Princeton, N.J.: Princeton University Press, 1963) 170-171.

${ }^{16}$ Kazuaki Tanahashi, Moon in a Dewdrop: Writings of Zen Master Dōgen, (New York: North Point Press, 1985) 24.
} 
about the way of the world, a truth that Dōgen and Zen Buddhists call emptiness, or Kū. ${ }^{17}$ He suggests that while most humans only see water as continuously flowing, it is not the case that all beings see water in this same way. For example, the living fish in the sea do not perceive their home as something flowing, constantly moving and changing; on the contrary, they see water as an abode, a stable, a palace, or a structured dwelling. On the other hand, the palaces of human beings appear to fish as flowing similarly, to how humans see the home of these fish as flowing water. Therefore, seeing the relative nature of the flowing and non-flowing of water means realizing that no form belongs inherently to water as such, because the material of water is informed according to the situation of the informer, so that it is empty of any inherently existing form.

In modern times, Gaston Bachelard investigates how the water of the physical world is one element of the matter from which we form our dreams, reveries, and images. Bachelard writes, "A leap into the unknown is a leap into water."18 For Bachelard, an exploration that plummets into mystery invokes the image of leaping into water and understanding its fluid depths.

Bachelard comments in the first chapter of "Water and Dreams: An essay on the imagination of matters" that humans try to understand themselves in the way of Narcissus, by reflecting on water. ${ }^{19}$ The image of Narcissus is an image of a human being that knows, loves, and permeates into its own mysterious depths. Water allows Narcissus to participate in his image; it provides the depth and continuity that a static

\footnotetext{
${ }^{17}$ Kazuaki Tanahashi, Moon in a Dewdrop: Writings of Zen Master Dōgen, (New York: North Point Press, 1985) 24.

${ }^{18}$ Gaston Bachelard, Water and Dreams: An essay on the imagination of Matters, trans. Edith R. Farrell (Dallas: The Dallas Institute of Humanities and Culture, 1983) 165.

${ }^{19}$ Gaston Bachelard, Water and Dreams: An essay on the imagination of Matters, trans. Edith R. Farrell (Dallas: The Dallas Institute of Humanities and Culture, 1983) 19-43.
} 
mirror is unable to offer, as a mirror remains a superficial reflection, a barrier that does not allow the self to penetrate inside it through reflection. Only water allows Narcissus to enter into his own image and fathom the mystery beneath the surface.

Bachelard also shows that material imagination sees water as an archetype of purity, having the power to cleanse both matter and form. ${ }^{20}$ While it is evident that water can physically clean a dirty being, it is often forgotten that water has the power to purify an impure soul. Bachelard argues that the purifying power of water lies within the very liquid stuff of water. Therefore, whether in a baptismal ceremony, Fountain of Youth, Exodus of the Israelites, or many rituals performed in the Ganges River, water has the power to purify and bring one out of original sin, old age, or any sort of dirt or impoverishment.

Ivan Illich, following Bachelard, says that water is a living, archetypal fluid, a fertile material that is informed by our imagination and dreams, wherein he looks specifically to the relation between urban water and urban space. Fundamental to Illich's investigation is his distinction between water and $\mathrm{H}_{2} \mathrm{O}$. Water has the ability to both purify form and clean matter, but also to "communicate its purity by touching or waking the substance of a thing and it cleans by washing dirt from its surface."21 On the other hand, $\mathrm{H}_{2} \mathrm{O}$ is water created from the industrial society that has been transmogrified, reduced to a chemically constituted "fluid with which archetypal waters cannot be mixed." 22

\footnotetext{
${ }^{20}$ Gaston Bachelard, Water and Dreams: An essay on the imagination of Matters, trans. Edith R. Farrell (Dallas: The Dallas Institute of Humanities and Culture, 1983) 133-157.

${ }^{21}$ Ivan Illich, $\mathrm{H} 2 \mathrm{O}$ and the Waters of Forgetfulness: Reflection on the History of "Stuff", (Dallas: Dallas Institute of Humanities and Culture, 1985) 27.

${ }^{22}$ Ivan Illich, $\mathrm{H} 2 \mathrm{O}$ and the Waters of Forgetfulness: Reflection on the History of "Stuff", (Dallas: Dallas Institute of Humanities and Culture, 1985) 7.
} 
Illich suggests that the transmogrification of water into $\mathrm{H}_{2} \mathrm{O}$ has brought water into the service of industrial development and technological progress, which has saturated and abstracted the chemical form of water from the heterogeneous mixture of its living flow. Unlike the living, archetypal water, the fluid of $\mathrm{H}_{2} \mathrm{O}$ is in need of cleansing and purification of the diseases and pollutants that often accumulate within it. Therefore, in bringing $\mathrm{H}_{2} \mathrm{O}$ into the modern technocracy, water has been forgotten, abandoned in favor of a formula and a domesticated abstraction. Perhaps the most relevant and important point by Illich is that if one wants to recover water in its living, informed reality, one must also investigate those images that have forgotten their relation to the materiality of water. Therefore, a meaning of water looks at all images, even abstract formulas, with a view of their relationship to the archetypal aquatic material.

Overall, the study of water has a rich history of meaning and tradition in all cultures. The key to understanding water is to recognize the physical laws that govern its behavior, the phenomenological properties that act and react with our senses, and finally, its symbolic value. Beyond its molecular structure, water is composed of many stories and is endlessly appealing. It is simple and familiar, yet intriguingly complex. Above all else, water is essential to life and is the greatest symbol of life. It can indicate chastity when it is pure and clean. It can also offer spiritual cleansing and the possibility of spiritual rebirth. Perhaps these positive symbolic meanings of water throughout different cultures can give hope and new promises to the stark contrast in the modern exploitation of this precious resource. 


\subsection{Changing Social Perspective: Sustainable Design}

There is a growing realization that the resolution of environmental problems involves not merely technical or economic adjustments but a real shift in attitudes and behaviors of all people. Historically, governments have attempted to deal with environmental problems by arguing that technical progress will eliminate the practices that plague the natural environment. However, environmental degradation is now moving at a far faster rate than technological advances can hope to keep pace with. Stewart Barr suggests that the resolution of environmental problems would be best achieved through a change in people's attitudes and behaviors.

One such example is the declining use of coconut leaf sheathing in building construction. The rural imagery of Vietnam is overflowing with coconut leaf sheathed dwellings that romanticize its picturesque beauty. These vernacular dwellings correspond well to their surroundings because the building materials are available in abundance within the vicinity and are also the product of a renewable resource. However, there is a cultural bias against this sustainable construction material that is considered "cheap" and is associated with a rural lack of sophistication. As a consequence, coconut leaf sheathing trades are rapidly disappearing from the outskirts of the city and are being replaced by other less sustainable construction trades. Such trends need to be reversed and it is up to architects to take a leading role in this matter by incorporating materials such as coconut leaf sheathing in the erection not only of private dwellings but in the design of public buildings as well. 
Barr argues that only a shift in attitudes towards the actions one takes everyday will actually have a lasting effect on the environment. ${ }^{23}$ Recognizing the valuable contribution each individual has to make to environmental preservation and sustainability will enable environmental behavior to become socially normative, and thus create positive changes. Barr suggests that government policy can be established more effectively when based around the need to target measures at specific elements of the population, which have behavioral specificity implicit within them. Policy makers need to investigate the underlying factors of each behavioral category and proceed on targeted messages at identified sections of the population. ${ }^{24}$

In the case of the Cai Lay water problem, the targeted sections of the population are the people who are directly dependent on water resources. This includes those people who are directly impacting the water sources everyday. Such populations include waterfront residents, boat inhabitants, and farmers.

\footnotetext{
${ }^{23}$ Stewart Barr, Household Waste in Social Perspective: Values, attitudes, situation and behaviour (Aldershot: Ashgate, 2002) 1.

${ }^{24}$ Stewart Barr, Household Waste in Social Perspective: Values, attitudes, situation and behaviour (Aldershot: Ashgate, 2002) 175.
} 


\subsubsection{The Integrated System}

The proposal discusses several ways to improve the urban water management of Cai Lay but also the unrealized opportunities for improving urban water management in the areas of integration and cooperation. Urban water managers, engineers and designers sometimes consider only the parts of the system where they have direct responsibility for management or design; they do not consider the advantages of approaching management from an integrated viewpoint. Integration and cooperative management offer three main classes of benefits. First, the protection of the quality and against the abuse of the water resources through integrated management and protection of source development and wastewater disposal. Second, is the economy of scale that comes from joint development of projects and services. The third category of benefit is the possibility of offering service where there were none before.

Integration and cooperation management is particularly useful in Cai Lay as by taking advantage of the centralization of the city, officials can introduce urban renewal strategies for all parts of the city. The proposed project will be based on the objective of providing potable water to every citizen in Cai Lay over the next ten years. The new housing development, waterfront rehabilitation, sewage disposal pipelines and natural water treatment provision will be integrated as one large urban renewal project for this centralized objective.

Currently, there is a relatively small number of treatment processes used outside the large cities in developing countries. In areas where the people are more concerned about a community water supply, water treatment is considered as a second stage in development; the first stage is locating a reliable water source. In some development 
programs for drinking water supplies, this policy stems from economic reasons. This can be another integration opportunity where policy makers can make positive changes to the creation of a healthy community.

The hydrological cycle on the right, illustrated by Neil Grigg, shows the three general parts of the urban water system as they fit together. Grigg argues for the integration of the management of the three urban water services together, "since the rain that creates the stormwater can also overload the wastewater system through inflow and infiltration, as well as serving as a source of drinking water

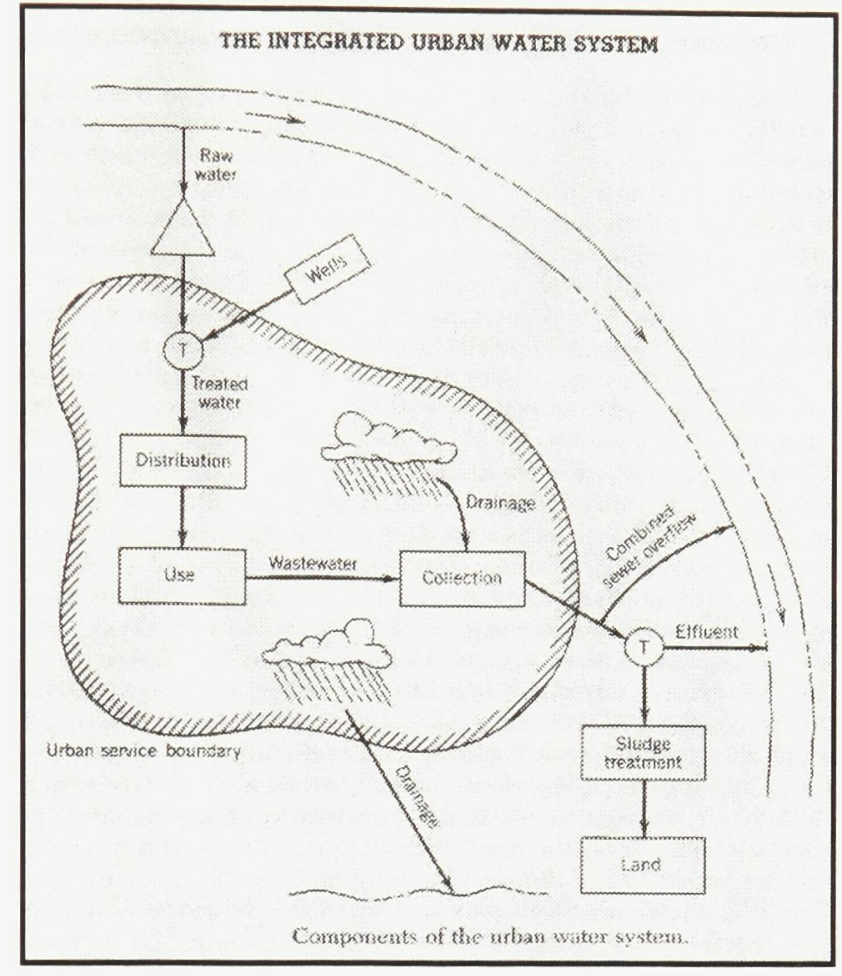

13: The Integrated Urban Water System supply." 25 He adds that if the management authority can be unified, the same information could be used to make coordinating decisions.

The concept of the unified urban water system originated from the work of the Urban Water Resources Research Program of the American Society of Civil Engineers (ASCE), directed by Murray McPherson in the 1970s. ${ }^{26}$ The urban water system consisted of three water programs together: water supply, wastewater, and storm or floodwater. It is logical to look at them together since the same floodwaters that must be controlled can be a beneficial source of water supply. Also, as the wastewater stream for

\footnotetext{
${ }^{25}$ Neil S. Grigg, Urban Water Infrastructure: Planning, Management, and Operations (New York: Wiley, 1986) 15.

${ }^{26}$ Neil S. Grigg, Urban Water Infrastructure: Planning, Management, and Operations (New York: Wiley, 1986) 15.
} 
one city becomes the next city's water supply, they should be considered as part of the system.

The division of tasks into fields with varying value systems is also problematic in the architectural profession. Today architecture is controlled by different professions and businesses and is no longer an integrated process. Programming and feasibility analysis is the domain of sociologists and planners while construction is the domain of the developer-financier or contractor. The problem is the presence of the conflict between these phases of professional agenda. If decisions are made in unity rather than in competition, they can benefit each domain equally in the interest of client/user relationship. This division of the architectural tasks can only serve to accentuate the conflict and weaken comprehensive decision making. Thus, the solution that will benefit the interest of the client/user can only emerge through a process that optimizes or suboptimizes many decisions rather than simply maximizing or minimizing one decision variable. For instance, cost can be minimized at the expense of other values such as comfort or efficiency and thus it may also be at the expense of the client/user.

Today, collaborative rather than individual action has become necessary to intervene effectively in the course of change. Mario G. Salvadori writes, "Architecture is and has always been the fruit of teamwork. But in the past the same man was a team, while today a team must become a single person if good architecture is to be achieved."27

${ }^{27}$ Eugene Raskin, Architecture and People (New Jersey: Prentice-Hall, Inc., 1974) x. 


\subsubsection{Natural Water Treatment Gardens}

The option of introducing a wastewater treatment facility to the city of Cai Lay is restricted due to inadequate financial resources, limited manufacturing capacity, limited skilled labour (but ample unskilled labour), and scarce engineering personnel for construction and maintenance of water and wastewater systems. One outstanding option for the city would be the concept of the Living Machine conceived by Dr. John Todd. The Living Machine treatment facility utilizes a series of tanks, which support vegetation and a variety of other organisms. ${ }^{28}$

Living Machine Inc. describes the Living Machine as being a wastewater treatment system that costs less to operate than conventional systems while at the same time achieving tertiary treatment. As part of its treatment process, it uses plants and animals that do not require chemicals that are harmful to the environment. Its unique characteristic of integrating with the landscape can be aesthetically pleasing. This unique advantage may be helpful for Cai Lay to place the treatment system on the border of the city's edge and farmland. In terms of maintenance, the system has a few additional requirements, such as routine maintenance activities can use unskilled labourers for jobs such as cleaning, removing and disposing sludge, vegetation management, and maintaining organism population. (See Appendix B for The Living Machine fact sheet.)

The Environment Protection Agency (EPA) concluded that Living Machines are typically cost competitive with more conventional wastewater treatment systems and the capacity volume of up to $1,000,000$ gpd $\left(3785 \mathrm{~m}^{3} /\right.$ day) if located in a warm climate. The capacity of the Living Machine exceeds the required projection of $723 \mathrm{~m}^{3}$ per day for Cai

\footnotetext{
${ }^{28}$ United States Environment Protection Agency, Wastewater technology fact Sheet: The Living Machine. (U.S.EPA, 2001) 1.
} 
Lay in the next ten years. This analysis concluded that the Living Machine is a sound water treatment alternative for the city of Cai Lay. The Living Machine is definitely not an absolute answer, but rather an alternative measure to the widely outdated concept of a techno-fix for developing countries. 


\subsection{Case Study: The Living Water Garden}

In Chengdu, China, Betsy Damon designed a water garden that takes a portion of river water and cleans it naturally by filtration through a series of ponds that grow aquatic plants. The wetlands, waterways and fountains help put oxygen back into the water while plants absorb and break down chemicals. The Living Water Garden is essentially a park that creates a wetland habitat, provides public access to the river, and renovates the waterfront.

The water flow enters the park through pumps powered by a waterwheel on the side of the river. The diverted river water is moved up a 20 -foot high hill into a settling pond with a water fountain in the center. Then it gushes through an aeration system made from a series of sculptures called flow forms. These sculptural forms aerate the water while

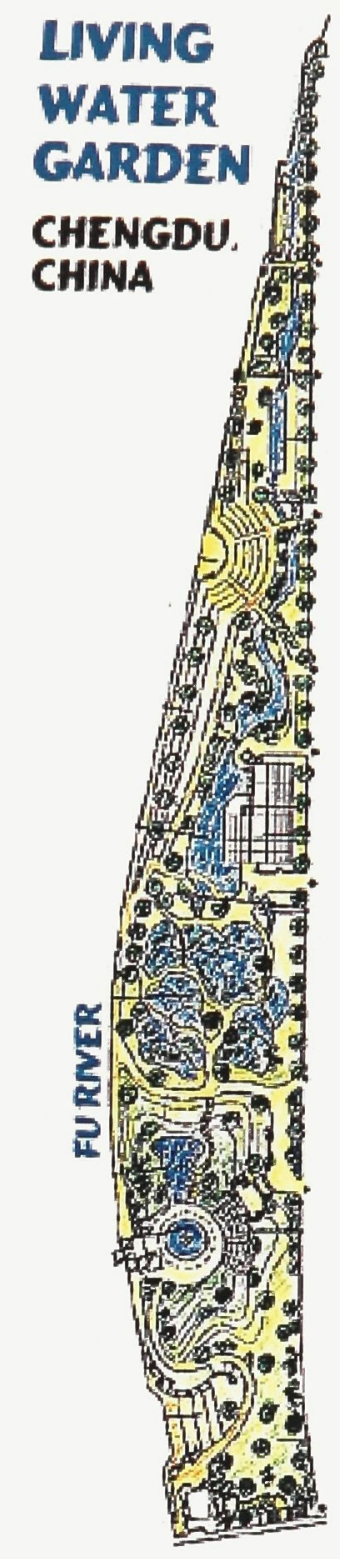

14: Living Water Garden Map displaying and educating the public. Later, the aerated water enters the reconstructed wetlands where seven different plants purify the water. After that, the water flows through two more sets of flow forms into ponds where it is further filtered with sand and gravel. Finally the cleaned water reaches a fountain that celebrates the process at the end of the park. 
One important aspect of this project that this thesis wishes to embrace is its clarity in demonstrating the water purification process. Each phase of the Living Water Garden's purification process is articulated differently. Visitors can clearly observe the progression of water throughout the park. Through explanatory signs and displays throughout the park people can understand the intricate process of water purification in detail. This further emphasizes the educational purpose of the project. Another significant aspect is the sensitivity that this project has with respect to local traditions and culture. The parkland of the Living Water Garden resembles the form of a fish, an important symbol of regeneration in Chinese culture. The designed flow forms and sculptures throughout the park are inspired by local culture and traditions and made with local craftsmanship and expertise. It also reinforces the desires of this thesis to adopt the aspect of integration and cooperation between different professionals ranging from artists, to planners, to biologists and the multiple levels of government that have made this project possible.

On the other hand, there are important aspects of the project related to the sensitizing of the population to water issues that were not engaged by the Living Water Garden; particularly the lack of integration of the project into the mundane activities of daily life. The Living Water Garden is essentially a park, a tourist attraction, a place full of recreational activities that is separated from everyday activities. It remains as a destination place rather than one that is experienced by urban dwellers during the course of their daily lives. Not unlike the traditional wastewater treatment facility, the garden is an addition to the community, separated and hidden from view. The design itself demonstrates various extravagant and artful plays with water which has the effect of 
distancing the user from finding the poetry of water use in his/her everyday activities.

Furthermore, the project falls short in illustrating the full water cycle and the significantly negative impact humanity has had on the water resource to date. As such, the project lacks the demonstration of action and reaction in environmental concerns.

The water infrastructure plan proposed for the city of Cai Lay, Vietnam attempts to adopt the successful aspects of this case study in terms of clarity, sensibility, and collaboration while emphasizing the significance of integrating water remediation (both physical and spiritual) into everyday life. The intent is that the project will enable a positive transformation in the way that the population approaches water utilization.

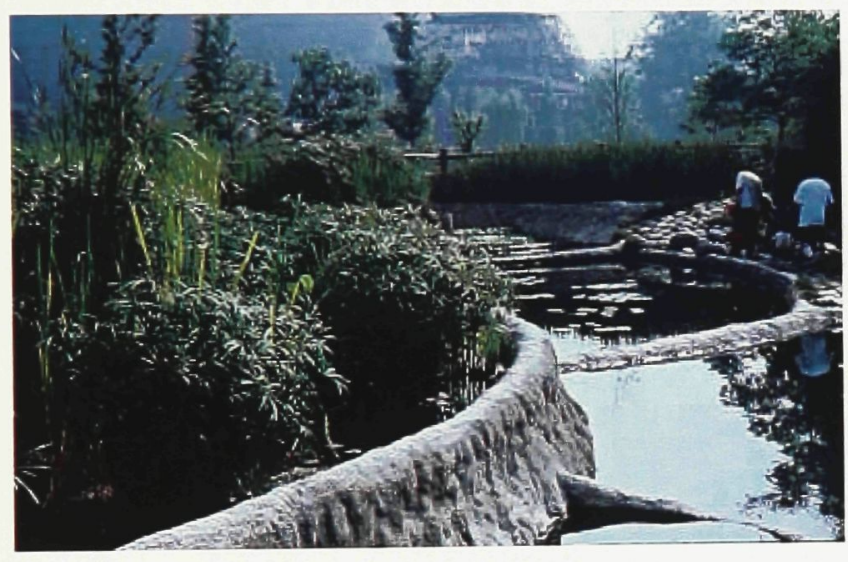

15: Constructed Wetlands

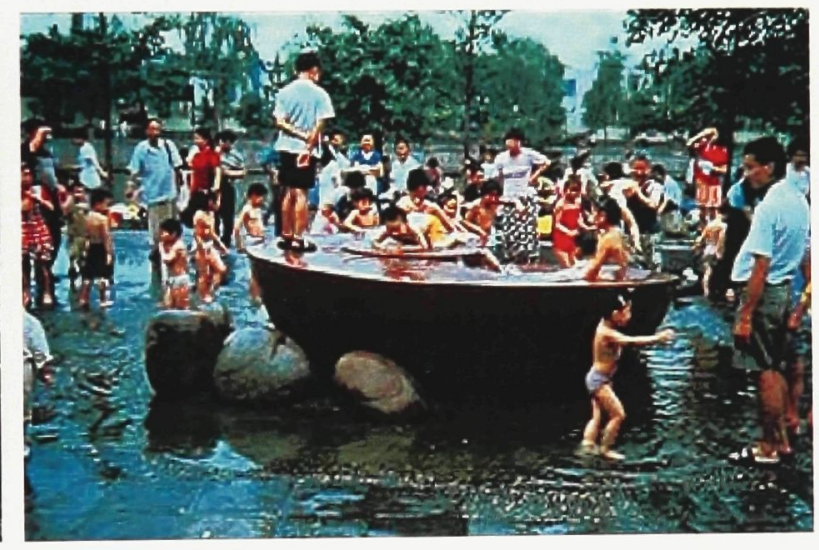

16: Clean Water Fountain

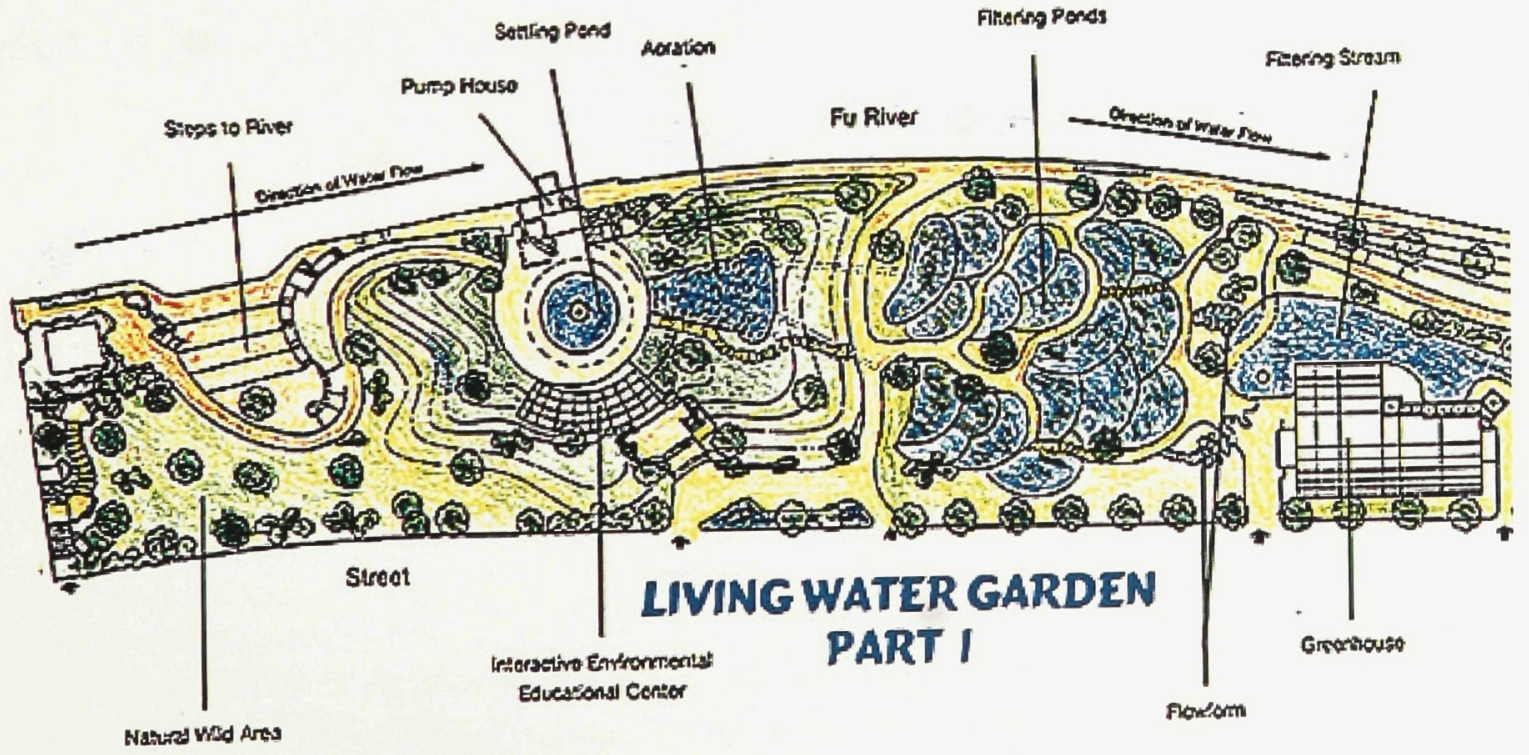

17: Living Water Garden Detailed Map 


\section{Site Research: Cai Lay, Vietnam}

\subsection{Geographical Background}

Cai Lay is located in the Mekong Delta region and is under the influence of tropical monsoon weather that is characterized by only two different seasons. The rainy season occurs from May to November with Southwest winds, and the dry season occurs from December to April with Northwest winds. The average temperature is 28 degrees Celsius with a difference of nearly 5 degrees between the coolest and hottest months. The average annual rainfall is 1437 millimeters, which is the lowest in the region of Mekong Delta. ${ }^{29}$ With its system of waterways and canals, Cai Lay's river (Ba Rai) plays a good part in alum water drainage from the Plain of Reeds through to Cau Sao and the Xang Canal. Ba Rai River also provides an escape for floodwater coming from the Plain of Reeds. The river width sometime reaches 185 meters with a maximum flow of discharge as high as 653 cubic meters per second. ${ }^{30}$ Although, the flow discharge is high, the quality of water is poor, as water from various small waterways contain much alum in them. The content of alum may get as high as a thousand milligrams per liter, and the $\mathrm{pH}$ reaches 3 to 4 , which is highly acidic. ${ }^{31}$ In the late rainy season, the alum content in

\footnotetext{
${ }^{29}$ Tien Giang Office of Agriculture and Rural Development Center of Rural Living Water and Environment Sanitation, Adjustment Annex Investment Report: Rural Living Water System in Tien Giang (My Tho: Provincial Office of Agriculture and Rural Development, 2002) 2.

${ }^{30}$ Tien Giang Office of Agriculture and Rural Development Center of Rural Living Water and Environment Sanitation, Adjustment Annex Investment Report: Rural Living Water System in Tien Giang (My Tho: Provincial Office of Agriculture and Rural Development, 2002) 2-3.

${ }^{31}$ Tien Giang Office of Agriculture and Rural Development Center of Rural Living Water and Environment Sanitation, Adjustment Annex Investment Report: Rural Living Water System in Tien Giang (My Tho: Provincial Office of Agriculture and Rural Development, 2002) 3.
} 
the river water lowers while at the same time, the impurity in the water gets as high as 300 milligram per liter. ${ }^{32}$

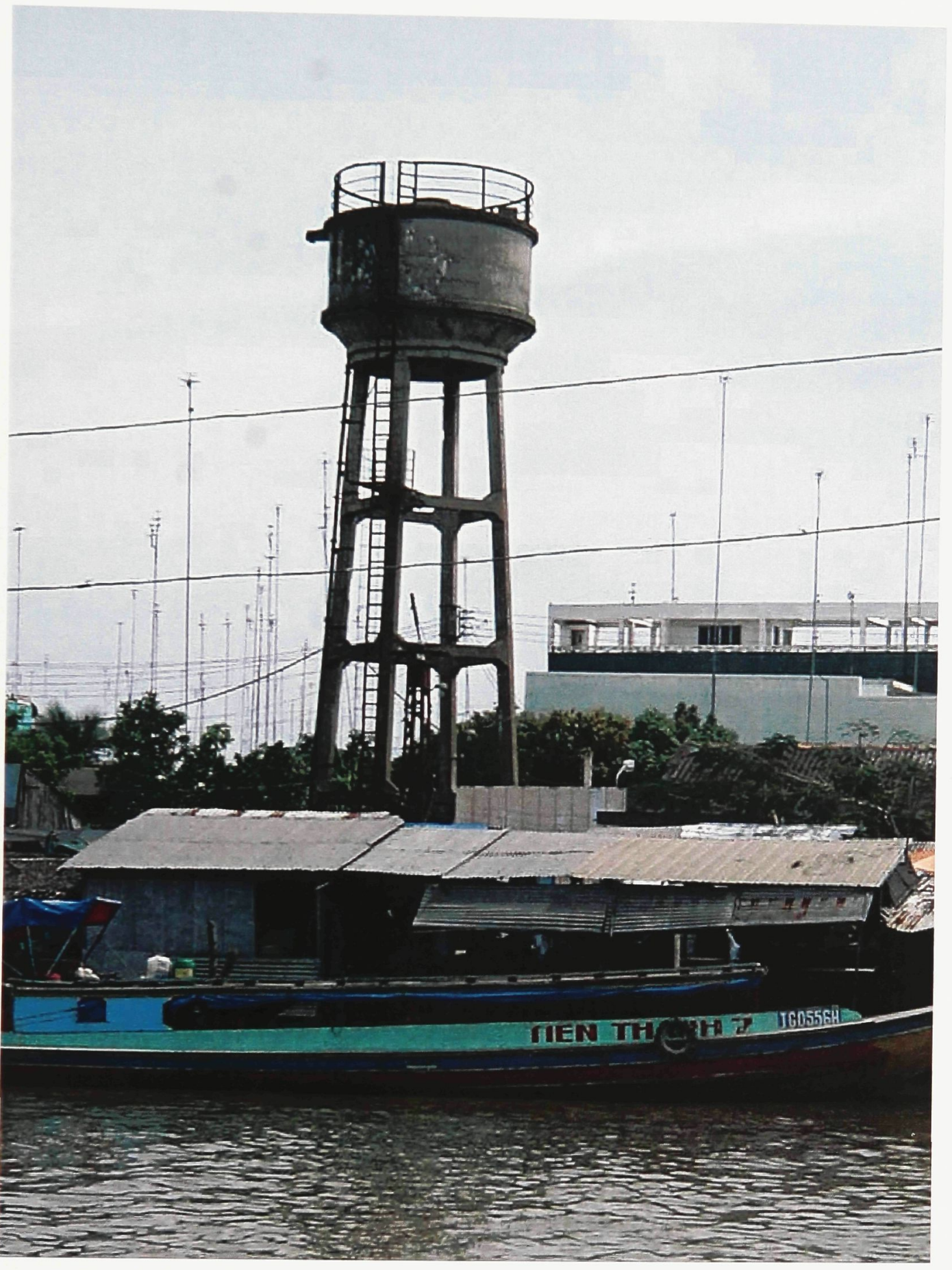

18: Water Tower

${ }^{32}$ Tien Giang Office of Agriculture and Rural Development Center of Rural Living Water and Environment Sanitation, Adjustment Annex Investment Report: Rural Living Water System in Tien Giang (My Tho: Provincial Office of Agriculture and Rural Development, 2002) 3. 


\subsection{The Current Water Resources for Living}

The current potable water resource for the majority of the population of Cai Lay is the underground water supply. However, water sources such as rainwater and surface water also contribute significantly to their everyday activities. The daily amount of water usage taken from each source is based on the nature of use and the time of year when they are most available.

Rainwater is the main water resource for the majority of the inhabitants of Cai Lay during the rainy months. Additional tanks are not available for every home in Cai Lay thus keeping rainwater for later use is a problem for many people in the city. According to the Provincial Office of Agriculture and Rural Development (POARD) only about 20 per cent of the population in Cai Lay can afford an adequate number of water tanks. Inhabitants who cannot afford the expenses are forced to turn to other water resources, usually on the ground, and usually polluted.

Surface water in Cai Lay is abundant but it is not safe for public use. The surface water of the city is polluted with dirt and alum water that originates from the Plain of Reeds. In addition, the water is contaminated because many kinds of waste such as garbage, bodies of dead animals, and human as well as animal waste are dumped into the river, which make the problem worse. As a result of these pollutants, water-borne diseases such as diarrhea, dysentery, intestinal worms and hepatitis are rife in the city, particularly amongst the poor. It is not recommended to use ground water for public use, as it is likely to cause health problems. In some situations, people have been forced to use this unclean water, as they were in the flood of 2000 and 2002. 
Rainwater use is limited and this water source is not always potable as it is collected from old leaf-shingle houses. As a result, there are many water-related diseases caused by unsafe drinking water, lack of sanitation and insufficient water for hygiene. It is a major problem for the city as the majority of illnesses within the city are waterrelated. According to Environment Canada, 80 per cent of illnesses in developing countries are water-related.

Recent years have seen big improvements in access to safe water and adequate sanitation. The city of Cai Lay began utilizing underground water sources with the aid of UNICEF. In 1990, UNICEF began a program with watering facilities that offered much needed services. Over the last decade, there have been 361 water distribution stations built in the province of Tien Giang. ${ }^{33}$ These stations were developed using the following model:

Borehole $\rightarrow$ Distribution pump system $\rightarrow$ Water Tower $\rightarrow$ Pipelines $\rightarrow$ Home use The water available underground is collected at boreholes by a system of pumps, and then driven to the water tower where it goes to individual homes in a system of pipelines.

All of the three existing water facilities are now providing potable water to 80 per cent of the population. When they operate in full power the percentage of people receiving water may reach up to 92 per cent according to the Adjustment Annex Investment Report (AAIR) of 2002. Households that cannot be provided with safe water have to utilize water from other available sources, which are not clean or safe, putting their health at risk. Therefore, UNICEF initiatives are greatly appreciated and effective.

\footnotetext{
${ }^{33}$ Tien Giang Office of Agriculture and Rural Development Center of Rural Living Water and Environment Sanitation, Adjustment Annex Investment Report: Rural Living Water System in Tien Giang (My Tho: Provincial Office of Agriculture and Rural Development, 2002) 3.
} 


\subsection{Water Consumption}

The system of water facilities in Cai Lay currently provides potable water to 4,869 households or approximately 24,345 people. According to water management officials, the water supply facilities produce an average of $2,250 \mathrm{~m}^{3}$ per day for the city center core, which is equivalent to 2,250,000 liters per day. The provincial standard states that there must be 100 liters of clean water per day supplied to every person in the province. The above findings show that the maximum capacity of the current water facilities can only provide for 22,500 people in the city's core. However, there are 24,345 people connecting to the potable water grid making the standard of water accessibility less than 93 liters/day/person when the facilities are in full operation. The results demonstrate the city of Cai Lay is well below the provincial standard and is also leaving one per cent of the population inaccessible to potable water.

According to the AAIR of 2002, the population growth rate in the province is estimated at two per cent. Thus, in the next ten years the number of people in Cai Lay will be as high as 29,865 . Using the Cai Lay provincial standard of 100 liters/day/person, the system will require an output volume of 2,986,500 liters/day or 2,987 $\mathrm{m}^{3}$ per day. Survey findings show that water is used during an average of 13 hours per day. Therefore, the pump station will have to be in operation for 13 hours everyday and the city should be aiming to supply $230 \mathrm{~m}^{3}$ per hour with all the water facilities combined. Over the next ten years, the city will require an additional $723 \mathrm{~m}^{3}$ per day or approximately 191,000 gallon per day of potable water from the proposed facility to accommodate all of the inhabitants of Cai Lay. (See Appendix $\mathrm{C}$ for detailed interview data of inhabitants on site.) 


\subsection{Site Remediation Opportunities}

It is generally assumed that water is an essential service, part of the urban infrastructure, and essential for the city to survive and for the people to prosper. Adequate infrastructure will provide the city the opportunity to support a high quality of life. It is important to recognize that effective total urban management is made up of primarily the social, economic, and intangible factors in the city. These lead to the quality of life where the infrastructure constitutes a necessary but insufficient condition. Essentially, the infrastructure is a starting point to make the other factors possible and it is therefore of utmost importance that the urban water system be given the care and attention it requires.

Findings through site research shows that clean water demand has not yet been met in Cai Lay, leaving a small percentage of the population with no clean water. In addition, there is exploitation of this precious resource. The majority of urban wastewater generated by human activities receives no treatment at all before being releasing into the river. In most cases, solid and liquid waste is dumped into the most convenient surface watercourse such as a canal or river. As a result, the numerous rivers and bodies of water around the community are polluted, including private ponds.

Furthermore, such environmental degradation places a disproportionate burden on women largely because of their social and economic roles, which expose them to greater numbers of environmental hazards. In Cai Lay, women have the primary responsibility for household chores and activities that keep them inside the house most of the time. They take primary responsibility for obtaining water and washing the family clothes. These activities can be hazardous where sanitation is poor, washing facilities are 
inadequate and water supplies are contaminated. In addition, they are usually responsible for caring for sick children and thus increasing their exposure to disease-causing organisms.

The provision of clean water will help reduce the health burden caused by many waterborne diseases, improve community life and facilitate a better environment for the city. The success of the proposed project will also help people recognize the importance of protecting the environment and existing water resources. 


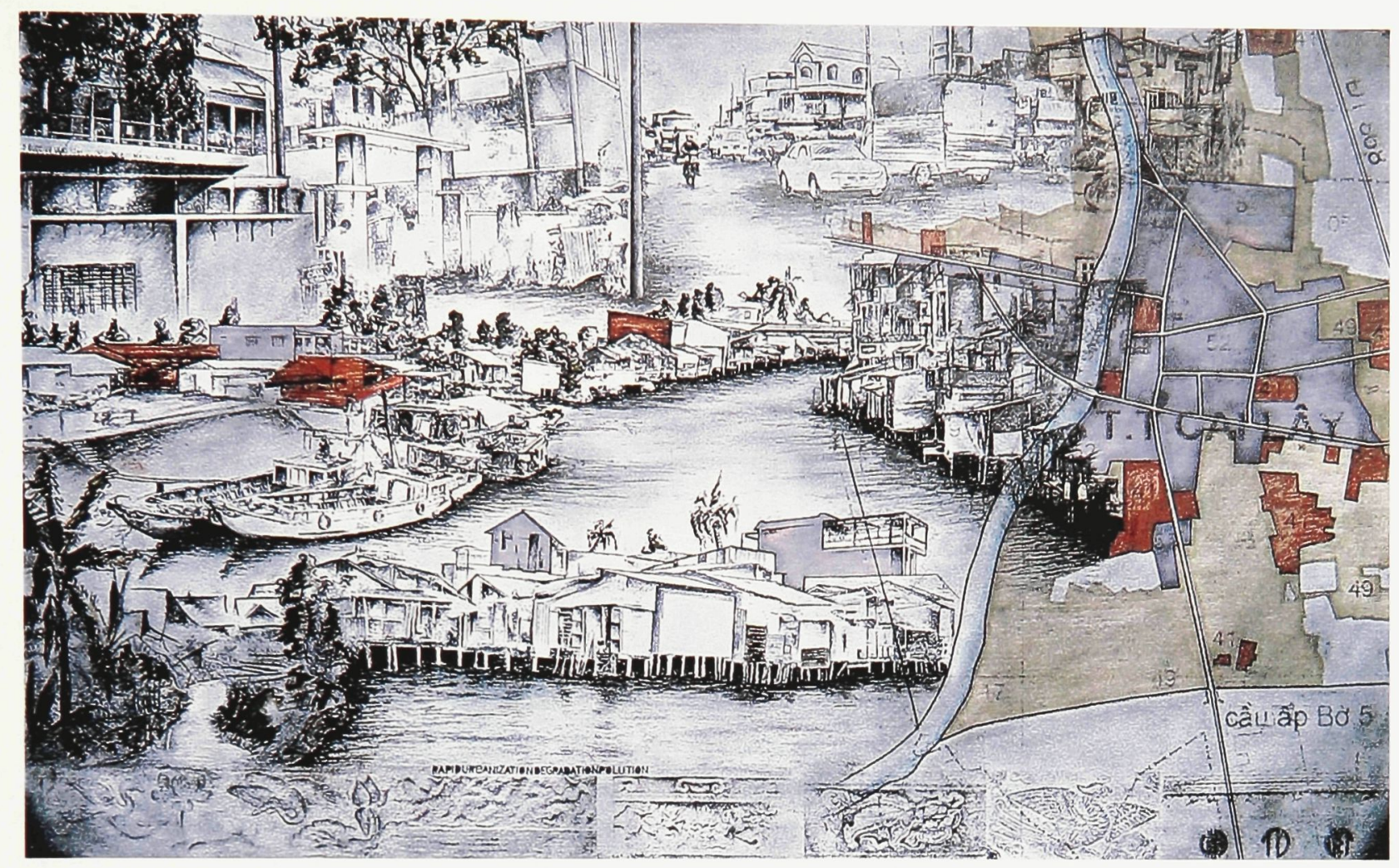

19: Site Analytical Drawing 1

This drawing describes the current topography of the site. It juxtaposes the traditional waterway of transporting goods with the new highway. 


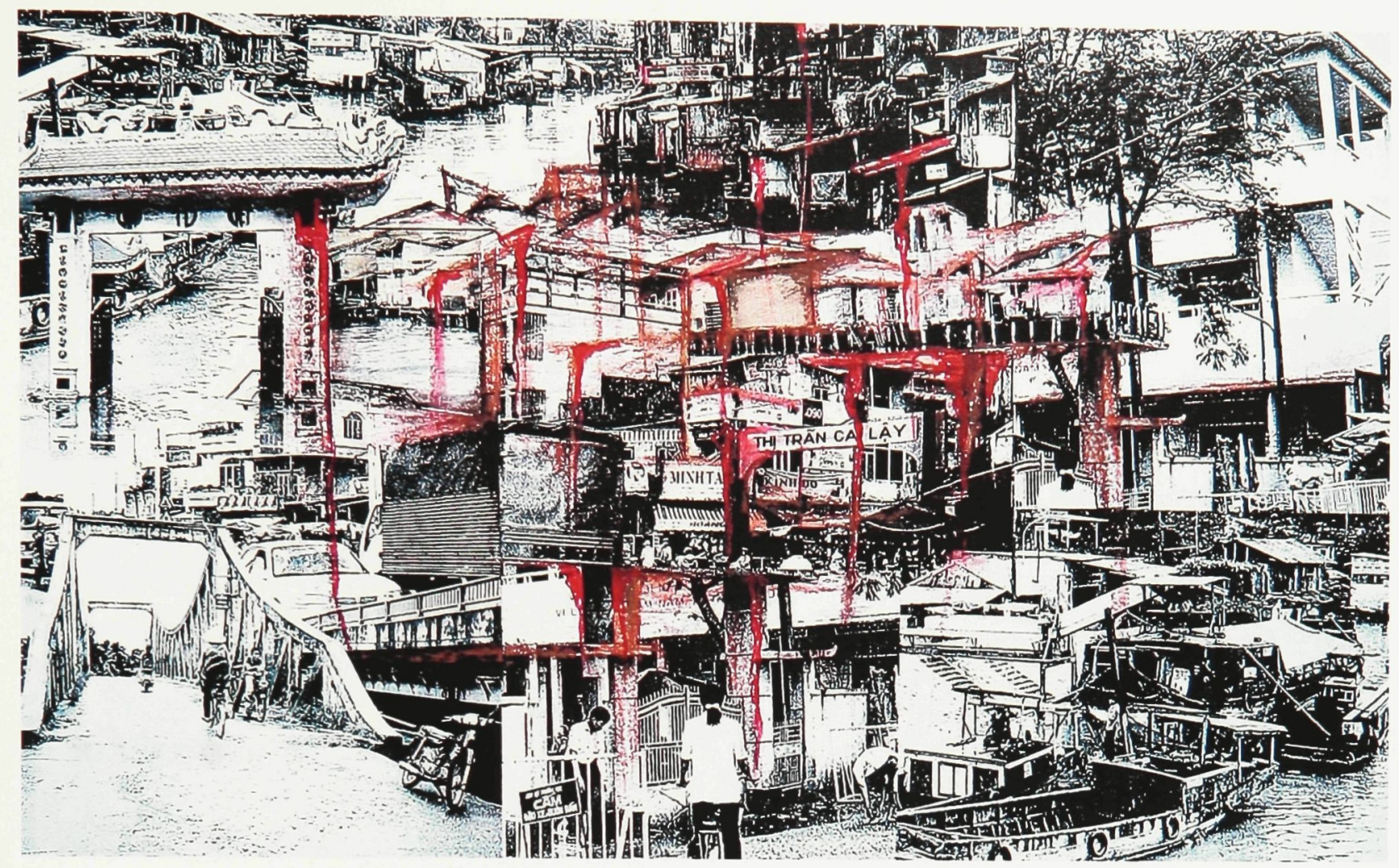

20: Site Analytical Drawing 2

The collage is an illustration of the eroding quality that water can give to the site.

This vibrant red colour is used to emphasize the process of erosion against the neutral background to reveal the essential intimate quality that it has. 


\section{Cultural Research: Cai Lay, Vietnam}

\subsection{Water Culture}

Water resources commonly have a high level of cultural and personal significance for communities, particularly those outside of large cities and towns. The importance of natural water sources to the Vietnamese in rural areas or in a small city such as Cai Lay is particularly high, as the water provides the focus for economic, social and cultural activities. Often it is the poor who are most heavily dependent on the natural water cycle, for irrigation of their farms and transportation of goods to the city.

Village ponds and bodies of water constitute vital elements in the ecology of Vietnamese rural communities. In the lengthy process of making these ponds inhabitable, residents typically obtain earth to lift the floors of their houses to save them from heavy rain and flooding. These ponds also contribute to the peasants' incomes by producing cattle feed and a supplementary fish breeding locale.

Ponds are sometimes connected to the natural water cycle such as canals and rivers and eventually become the haven for many fish species. Every four to six months, the peasants dam these ponds and drain the water to catch all the fish within them. The fish can be a source of food and income during the toughest time of the harvesting season. Generally, one of the ponds (where the public washroom is conveniently located) is dedicated to raising catfish. Other ponds also constitute a reliable source of water for daily use and increased cultivation.

Water lanes via rivers and canals are an important feature in Vietnam's transportation system, and are confined mostly to the Mekong Delta. The majority of the 
produce that reaches cities such as Cai Lay is transported by water. Consequently, the traditional local markets in small cities and towns are always located near the river waterfront.

A small percentage of the population in Vietnam currently lives on their boats moving from one place to the next, shipping goods for a living. The river is literally home for these people. However, the number of people who live directly on the river in Cai Lay is relatively few.

Fifteen years ago, the Ba Rai River in Cai Lay was much more than a place for trade and transportation. It was also a market and a playground. Its frontage was not privatized and so one could play anywhere along the river edge or wave a boat to shore whenever one wished to buy any sort of produce. The attitude regarding the market has changed and is gradually shifting toward major street intersections. Today, boats and canoes of goods have their specific retail destinations. Furthermore, occupations are becoming more specific where farmers now are no longer the vendors of their own goods but sell them through retailers. Meanwhile, children have withdrawn their activities from the river edge as debris build-up and pollution increases. The Ba Rai River is no longer the revered element that provided a space of spontaneous activity but has now become a feared, diseased and infected problem to be dealt with. 


\subsection{Traditional Water Puppetry}

Traditionally in Vietnam, village

festivals are cultural activities that mark either

the completion or the beginning of the

agricultural cycle. These events are the means

by which the peasants express their gratitude

and hopes for more abundant crops for the next

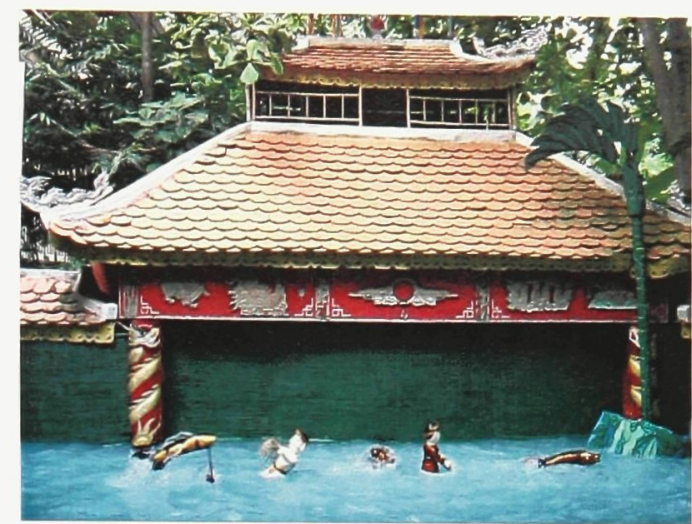

21: Water Puppet Theatre harvest season. These festivals feature traditional folk entertainment which reflects ancient religious beliefs as well as customs. In the Northern delta region, a puppet show on the surface of a lake or pond is one of the many festival highlights.

The exclusive theater of water puppetry is believed to have been invented when an ordinary puppet show was unexpectedly interrupted by one of Vietnam's many floods. The puppeteers suddenly began performing shows in the available water. Over the years, different villages have developed their own personal water puppet plays to appropriately mark certain battles or events throughout history.

Historically, several literary works by Phan Truong Nguyen ( $12^{\text {th }}$ century) and others by king Tran Thai Ton (1225-1258) appear to confirm that water puppetry was a courtly entertainment during the Ly and Tran dynasties. ${ }^{34}$ The scholar Nguyen Cong Bat also described a scene from the water puppetry show on the steel of Sung Thien Dien Linh archaeological artifacts in $1121 \mathrm{AD}$ at Doi pagoda, Ha Nam province. ${ }^{35}$ This steel inscription was from the time of King Ly Nhan Tong dynasty where it is historically

\footnotetext{
${ }^{34}$ Hong Huy Nguyen and Chinh Trung Tran, Vietnamese Traditional Water Puppetry, (Vietnam: The Gioi

Puplishers, 2001) 52.
${ }^{5}$ Hong Huy Nguyen and Chinh Trung Tran, Vietnamese Traditional Water Puppetry, (Vietnam: The Gioi Puplishers, 2001) 51-52.
} 
valued as a period of exceptionally cultural and aesthetic development of Vietnamese history. ${ }^{36}$

These historical documentations and inscriptions thoroughly validate that water puppetry was popularized in the court of the $11^{\text {th }}$ century. The existence of such records indicates that it must have existed even earlier in the rural villages where it was first performed.

The successive wars throughout Vietnam's history caused major destruction to national monuments and heritage. As a consequence, only a few examples of water puppet theatres survive. Such examples include the pavilion at Thay pagoda, built in the Le period (15331708) and the one at Dong temple, built in 1775.

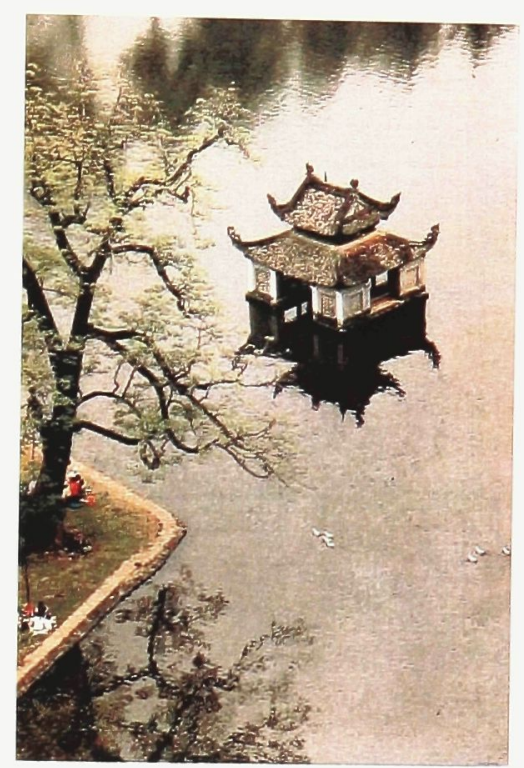

22: Thay Pagoda

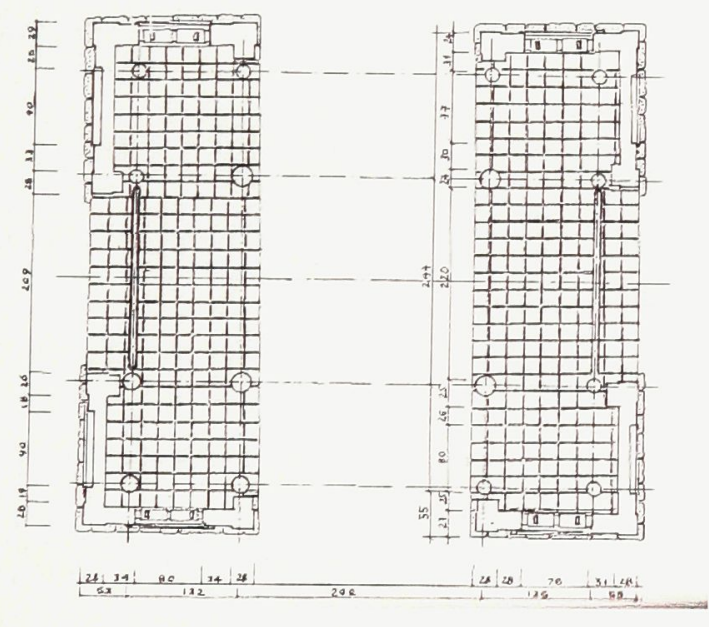

23: Thay Pagoda Plan

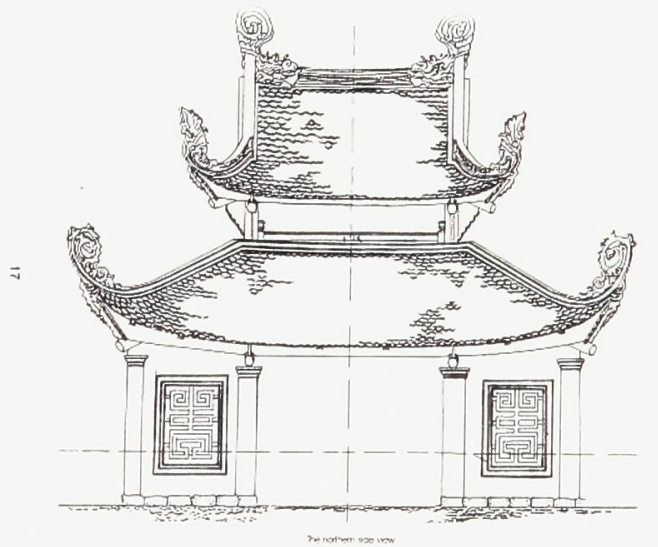

24: Thay Pagoda Elevation

\footnotetext{
${ }^{36}$ Hong Huy Nguyen and Chinh Trung Tran, Vietnamese Traditional Water Puppetry, (Vietnam: The Gioi Puplishers, 2001) 52.
} 
Another probable origin of water puppetry may have come from rural religious belief. Since the results of the peasant's labour depended heavily on seasonal rainfall, the offering of prayers to various deities for good crops was one of the earliest forms of religions that have been preserved virtually in its original form. The custom of water procession has been conserved with its many water-related objects and activities that are both tangible and abstract. Such activities include releasing a captured aquatic creature (carp) back into its environment, washing statues of various deities and Buddha, cleaning pagodas with water, prayers for rain and games which take place in water such as swimming contests, rowing competitions, and water puppetry. The rudimentary materials and simple handicraft techniques were always available within reach to develop this form of entertainment and also suggest its origin is from peasants in rural areas of Vietnam. Rural ecology of paddy fields, rivers, canals, lakes and ponds adequately provided a favorable environment which influenced and facilitated the development of water puppetry requiring little effort to find or invent. As such, it is a form of folk entertainment that is harmonious with nature and successfully derived from the natural environment.

The scenes in water puppetry are very short, typically lasting from one to seven minutes. Each scene reinterprets a certain rural activity and aspect of life in a modest and simple way. A scene is created by means of manipulating several distinctive gestures to the puppets that typify the mundane aspects of life. It is uniquely interpreted with its simplicity and familiar images of life by the puppeteers in such a way to entertain and arouse emotions in the audience. For instance, a fisherman, armed with a basket trap, streams onto the scene while the fish are washed aside and try to escape. Astonishing 
scenes can be contrived through puppet control techniques. Perhaps one of the most popular and shocking scenes is when Khuong Linh Ta's head is severed. The character then runs after the drifting head, scoops it up and carries it off. Many of these scenes involve fast-moving action creating breathtaking events which hold the attention of the audience, then develop and comes to a sudden climax. The scenes are never strictly based on any script and the performance does not unfold according to any plot. The same scenes can be expressed differently depending on the technical capacity of each guild. There are no compulsory standards regarding content or method of performance for any single scene. Different guilds perform the same scenes differently but they can also add or remove details from a scene.

According to the program of the show, a single scene can be performed separately or included in a group of scenes based on the theme. Groups of scenes are performed based on the contents of one principle scene where a number of individual vignettes can be performed in sequence in the form of sketches. For examples, the "farming" group of scenes can consist of six different scenes that include ploughing, harrowing, grass cutting, hoeing, rice transplanting and tending buffalo scenes.

Individual scenes are generally drawn from already existing excerpts from traditional Tuong and Cheo plays. Those excerpts that are adapted to water puppetry are often full of action. Since the puppets are limited in the capacity of various expressions, performing shows with full stories and scripts are usually beyond the capacities of the puppets. However, these excerpts from traditional plays are no strangers to the peasants, who understand the content without requiring much explanation. 
Similarly to other forms of puppetry, water puppetry originally consisted of acting without words. The gestures of the puppets are perfected first, then the words of the character are composed, deliberately reminding the audience of the stories behind the gestures. The main literary aspects of water puppetry derived from folk poetry and folk songs. Rhyming texts from folk literature describe work and everyday activities in words that are usually simple, cheerful and full of potent messages that are common to the community.

The fast and upbeat atmosphere of water puppetry animations are often accompanied by the use of percussion instruments. These instruments are usually drums, bells, gongs, horns, and shells. Occasionally, firecrackers are used in celebrative moments such as the opening scenes and finales of the festival. Although there is no distinctive music of its own in water puppetry scenes, there are songs in some scenes with rhythm playing the primary role.

Traditionally, age is regarded as an indicator of a man's status in the community. Life and inherited experience was the only way of accumulating knowledge, thus the older the person, the more he/she was respected by the community. Only with the permission of the head of the family, who granted the right and ownership of land, house or garden as well as authority over family members, could people take part in village affairs and support their activities as a member of the guild through their own effort, time, and family resources. Therefore, the title of a water puppetry artist was used to designate a person who participated directly in this genre of theatre and did not specifically denote a profession, income or social background. Water puppetry was never a means for supporting one's existence. Most often, the guild is gathered together by the 
people with an interest in it and contributes to their own funding which can be handed down from one generation to the next. In fact, the first and foremost role of a water puppetry guild is to take part in traditional village festivities, and latter recognized as an organization working for the public benefit.

There were few women engaged in water puppetry because they were regarded as not physically fit enough to stand for long periods in muddy water and to manipulate the puppets. Historically, very few women held the position of head of their family and, more specifically, it was feared that they might disclose the secrets of water puppetry troupe to their husbands' families.

Similar to other professional organizations in Vietnamese society, the practice of keeping professional secrets has long restricted the possibility of exchanges among puppetry guilds from village communities. At the same time, this traditional fabric of society has stimulated and resulted in a diversity of form, control techniques and mechanisms within each guild itself.

The potent messages of water puppetry are often moral issues and lessons for the youngster but also underline that one should always be content. This traditional idiom often reminds us that one can easily be happy with three meals a day, and these water puppetry scenes are enacted to illustrate just that. These stories embody the collective memory of the community. They act as the hinge between past and future. The fact that they unfold on a fluid stage is of undeniable significance. 


\section{Design Proposal}

\subsection{Urban Renewal Objectives}

Research cited can be categorized into three primary objectives for the urban renewal strategy in Cai Lay, Vietnam:

1. To provide adequate and affordable water supply for all citizens.

2. To eliminate the exploitation of water resources.

3. To propagate the awareness, education, and appreciation of water as a resource to the general public.

The practical urban planning strategy utilizes the existing infrastructure and builds the necessary water treatment features for a self-sustaining community with access to a safe, adequate and affordable water supply, as well as proper hygiene and sanitation. The strategy is to redirect all open-sewage trenches, which currently dump directly into the $\mathrm{Ba}$ Rai River, toward the new natural wastewater cleaning garden at the South end of the river waterfront. This new natural water treatment garden will provide the anticipated capacity of potable water for the city. It will be integrated with other community programs and residential units and will accommodate all inhabitants currently on site.

In addition, the project proposes to redevelop the waterfront, where the new natural wastewater treatment garden will be located. Through site interviews and surveys, findings show that the majority of the waterfront dwellings are squatter communities that represent one of the major sources of pollution in the Ba Rai River. The existing problematic residential units are to be relocated and integrated into the city grid. The waterfront area then becomes an opportunity to reinterpret and redevelop a more sustainable approach to inhabiting the waterfront involving the cessation of direct 
dumping of wastewater into the river, but also providing infrastructure to minimize future burdens on the river. Moreover, the new structures will celebrate and highlight the significance of water in daily life.

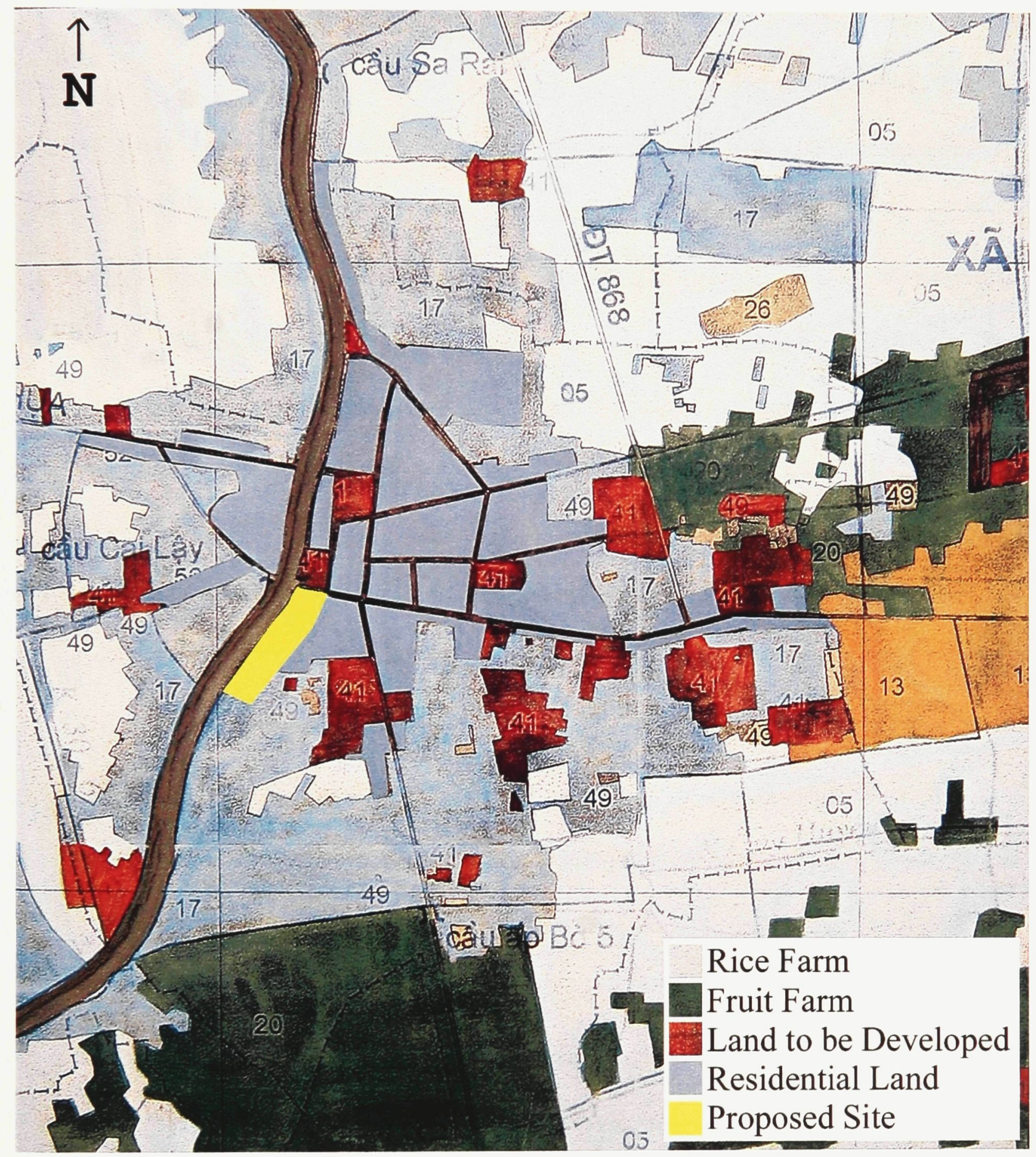

25: Site drawing of land uses (1:5000) 


\subsection{Site Remediation}

This project involves converting Cai Lay's parched and polluted landscape into a public garden rich in greenery, by taking processed water from the local sewage system and further purifying it within the public garden using natural cleaning methods. The theme of the project is to make a public space defined as an infrastructural landscape insertion, which uses techniques such as urban energy recycling and waste processing to minimize the burden on the environment. It is made up of a system of water branches that are remediated from the old and polluted open sewage systems. The water branching system is completed by gentle slopes which bridge the differences in height between the canal channels. Through the process of constant reticulation and the action of natural elements such as the sun, vegetation and soil, the water undergoes various purification operations, including sterilization, decomposition and filtration. This naturally purified water is then used to irrigate the neighbouring vegetation, and to regenerate the Ba Rai River.

Through differences in their shape, material, depth and water flow, a diverse range of locales are created which are conducive to a variety of activities. Essentially, the continuous canal channel replaces the traditional ponds where open sewage and polluted bodies of water are transformed into a natural purifying canal that is shared by all community members. As a result, each dwelling is responsible for one section of the canal for raising fish or as a source of water for daily uses such as irrigation. The essence of the project is the process of remediation of a polluted city and the provision of an essential basic element for survival. Once the landscape has been created and the supply of water has begun, this area will continue to mature and undergo continual 
transformation as people utilize it and the newly-planted vegetation grows and changes over time.

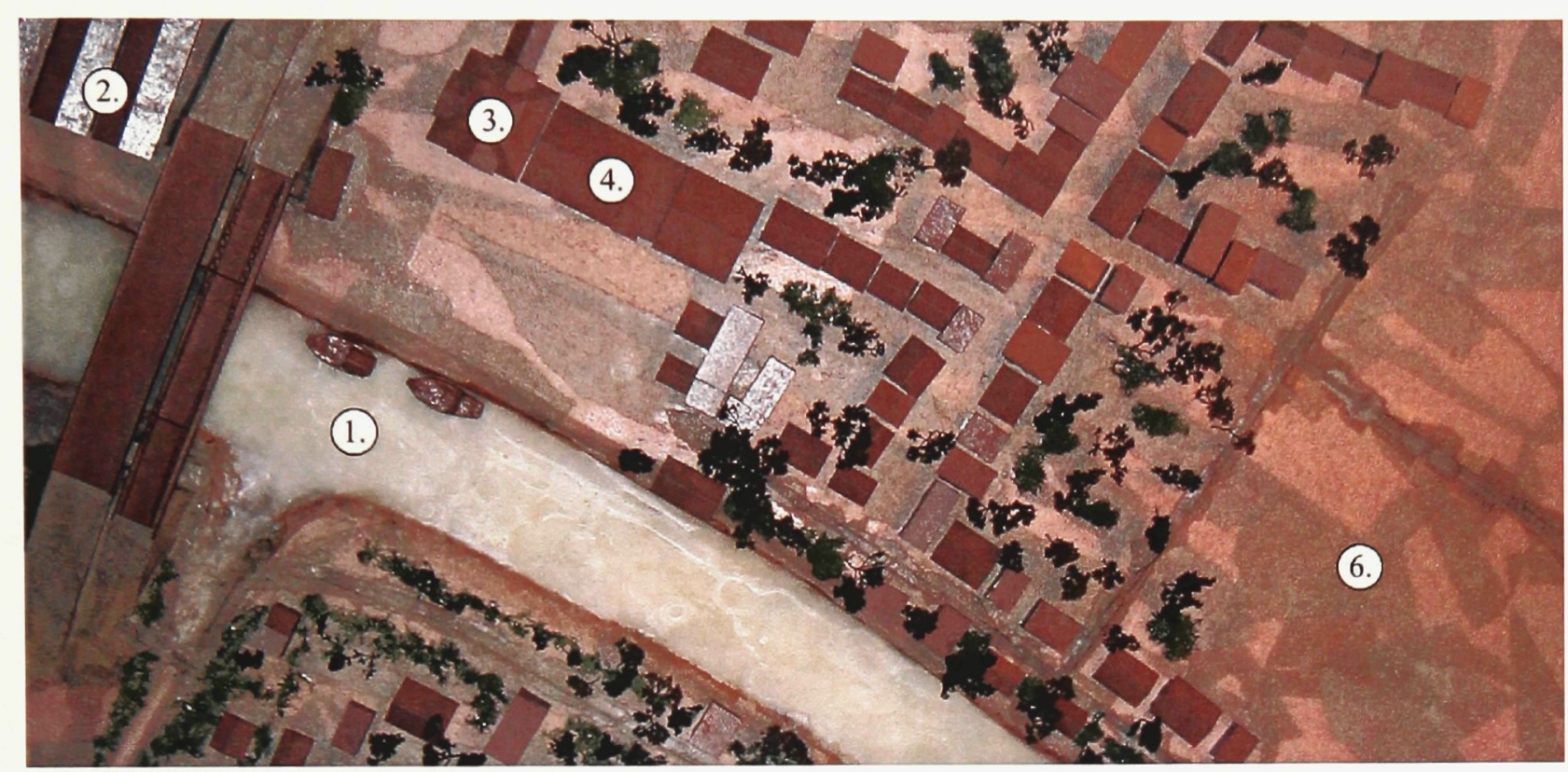

26: Site Model (1:250)
1. Ba Rai River
5. New Temple
9. Proposed Open
2. Old Market
6. Rice Farm
Market Space
3. Old Temple
7. Water Puppet Theatre
10. The Living Machine
4. Ice Factory
8. Proposed Market
11. Drainage Mill 


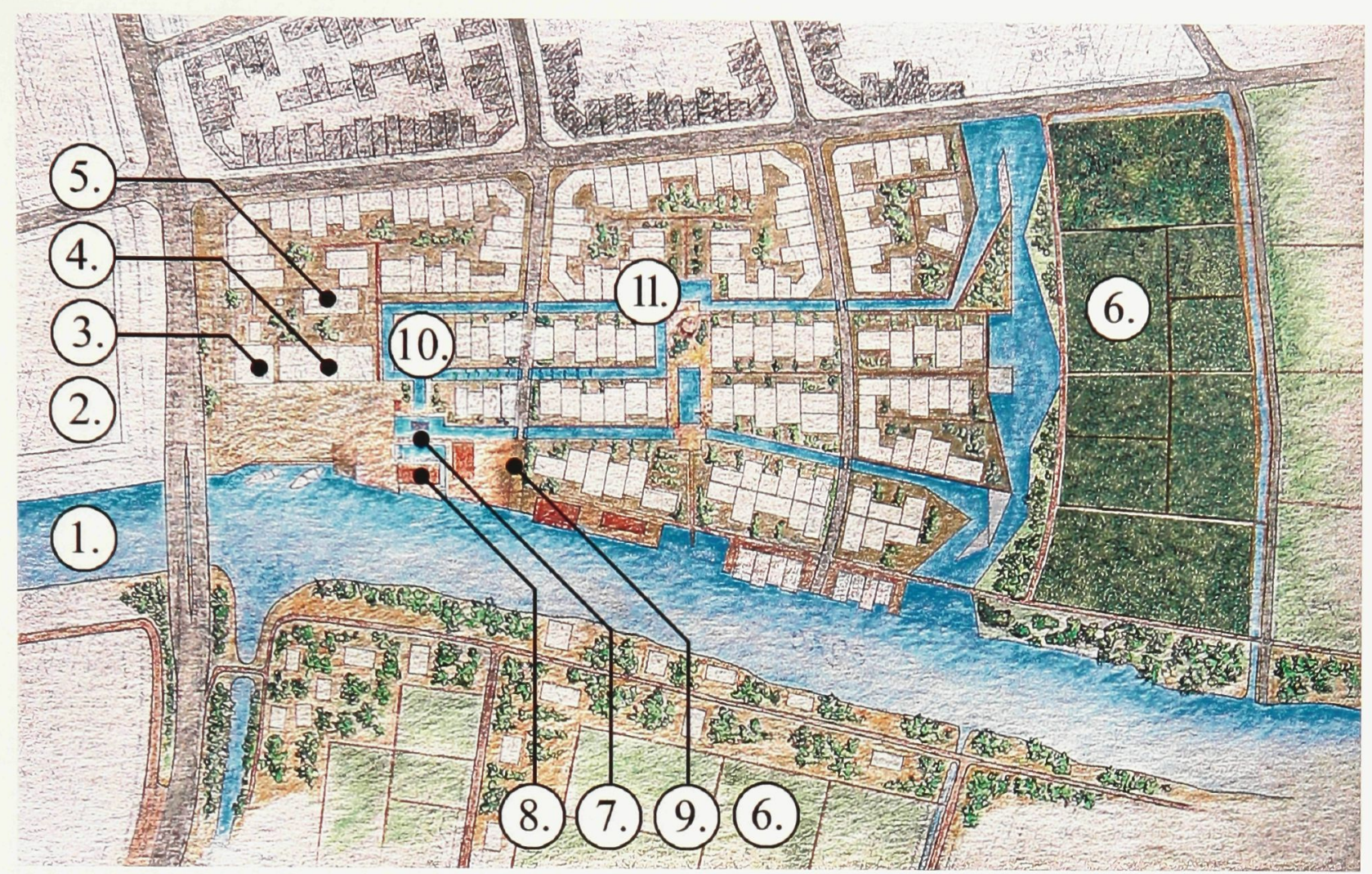

27: Proposed Site Plan (1:1000)

1. Ba Rai River

2. Old Market

3. Old Temple

4. Ice Factory
5. New Temple

6. Rice Farm

7. Water Puppet Theatre

8. Proposed Market
9. Proposed Open Market Space 10. The Living Machine 11. Drainage Mill 


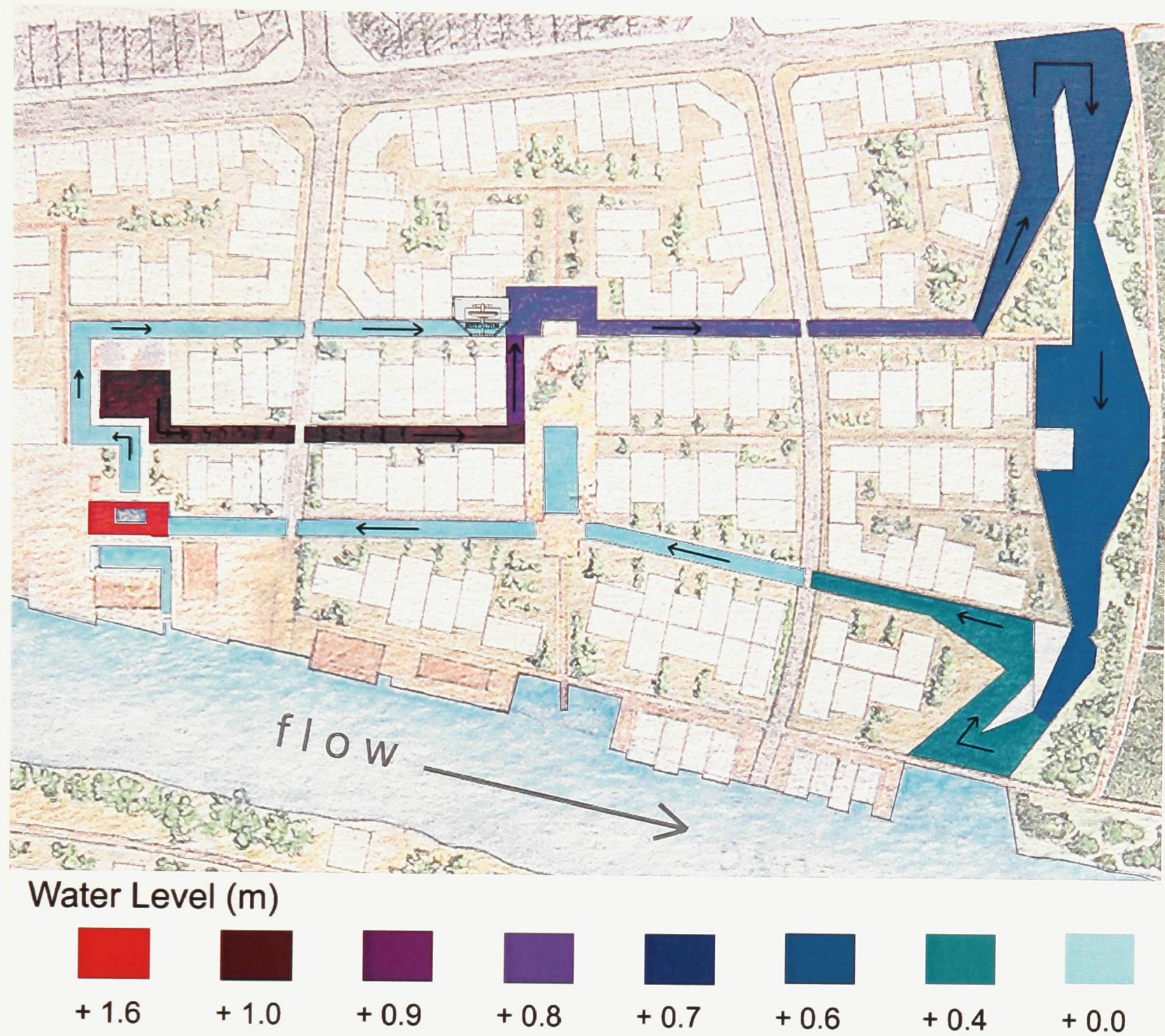

28: Water Level Diagram 


\subsection{Development of the River Waterfront}

The practical and obvious reasons for development on a river waterfront are for access to readily available drinking and cooking water, cleansing, irrigation, and the importance for transportation and food. As a result, the waterfront land represents prime real estate with abundant opportunities for development.

Many developed countries have experienced a popular movement to return decaying waterfronts to productive use. This redevelopment trend forms part of a clearly defined cycle of waterfront development: growth, deterioration, and then re-use. However, in developing countries such as Vietnam, the end cycle is often deterioration and abandonment, rather than re-use. The reasons for this are lack of financial support and funding for a complete environmental cleanup. Another concern for revitalizing these sites is that banking and other financial institutions are normally reluctant to lend money to develop the properties because of liability concerns. Therefore, it is absolutely crucial to implement sustainable solutions for the problem to become financially feasible for the community.

The waterfront of Cai Lay River, which was once revered and cherished, has been neglected, abused, and subjected to all forms of exploitation. The river waterfront has become inaccessible to many communities due to extremes of illegal encroachments from impoverished squatter settlements. Aggravated river and shoreline pollution also exists due to inappropriate land uses and due to improper solid and liquid waste disposal. Consequently, the river waterfront has lost its value, and the recognition of its potential has been considerably clouded. Therefore it is essential to devise methods and programs to revive the river waterfront in order to provide the proper environment for the needs of 
the population. Furthermore, a healthy community demands the rational use and improvement of its natural environment. Some of the direct benefits of restoration of the river waterfront would be reduction of congestion and improved employment, tourist and commercial development.

The successful waterfront development must be capable of making a contribution to the betterment of the health of the community. First, the air, land, sediments and water should be free of contaminants. Secondly, the diversity and productivity of ecological communities should be protected and restored. Finally, the waterfront development must contribute to the creation of an economy, community, and ecosystem that is sustainable.

The proposed waterfront development will be expanded along the southeast shoreline. This expansion of the docking area then becomes an opportunity to reinterpret and redevelop a more flexible space that is fluid and continuous along the shoreline. With the addition of an open market place and a water puppet theatre, the waterfront can provide a space of spontaneous activity. An additional alternative service road will reduce vehicles congestion but also provide an access route to the natural water treatment garden of the community.

Every year, the waterfront is piled with sandbags to prevent flooding of the community. This method gradually fails because the shore does not have adequate foundations causing landslides and debris to accumulate on the river bank. Elevated sandbag piles on the river's edge also disengage people's activities from the water as it becomes unapproachable. As a result, the redevelopment of the waterfront can improve in areas such as landslide prevention, boating area safety, docking variety, and infrastructure connectivity to minimize debris released into the river. Through 
differences in their shape, material, depth and water edge conditions, a diverse range of locales emerge along the waterfront that support and enable its engagement by the community.

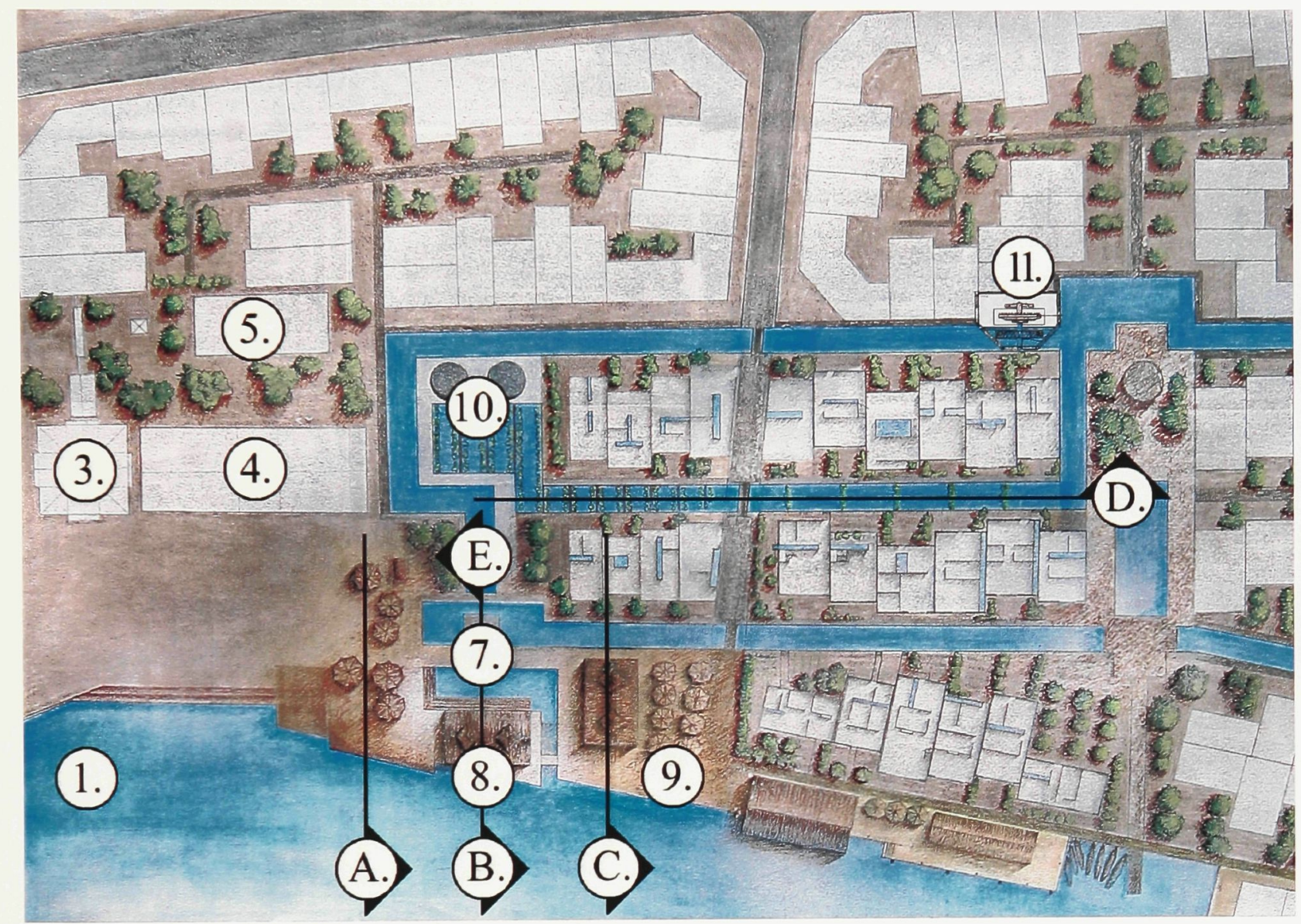

29: Proposed Waterfront Plan (1:250)

1. Ba Rai River

2. Old Market

3. Old Temple

4. Ice Factory
5. New Temple

6. Rice Farm

7. Water Puppet Theatre

8. Proposed Market
9. Proposed Open Market Space

10. The Living Machine

11. Drainage Mill 


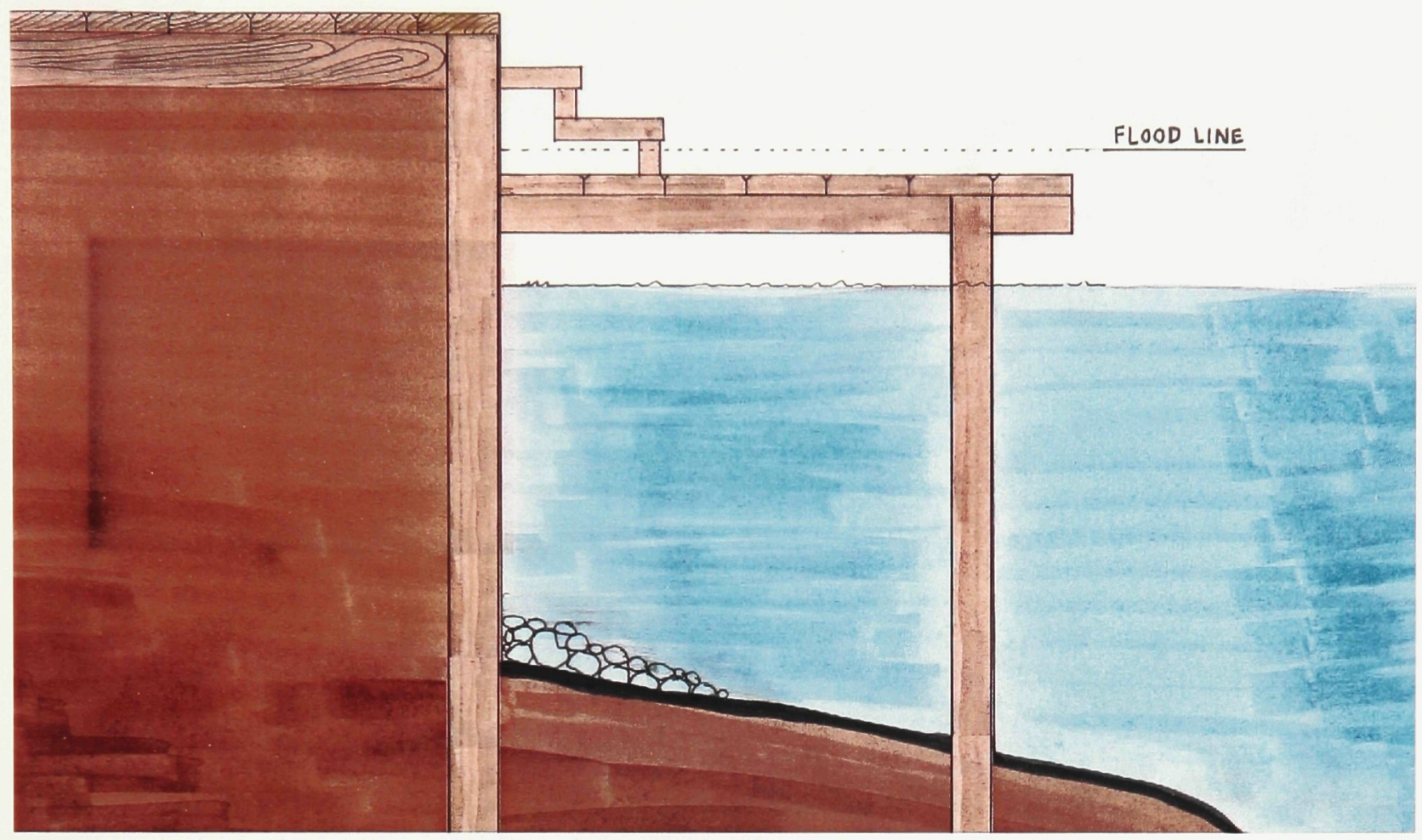

30: Proposed Foundation Section (1:10)

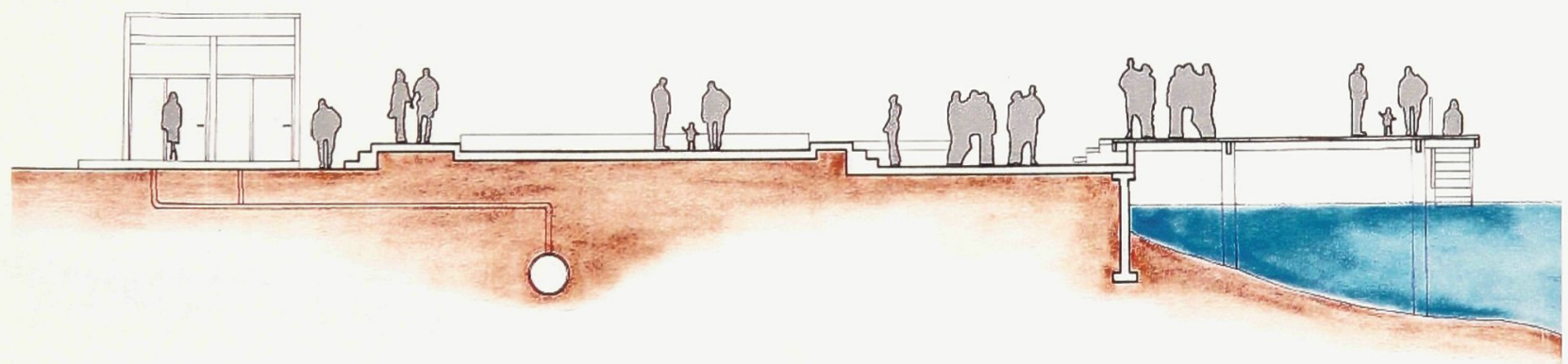

31: Section A - Washroom and Dock (1:50) 


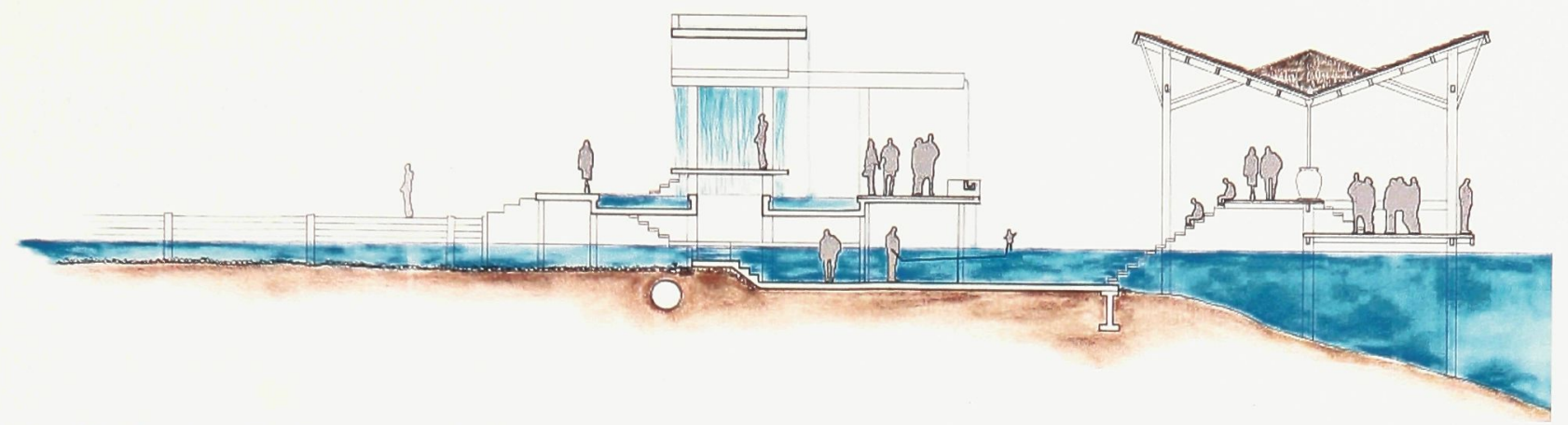

32: Section B -Theatre and Market (1:50)

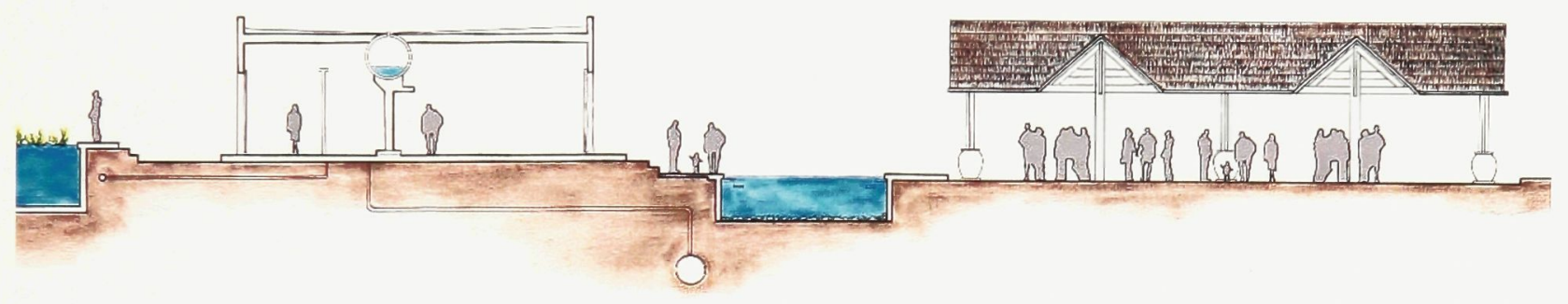

33: Section C - House and Market (1:50)

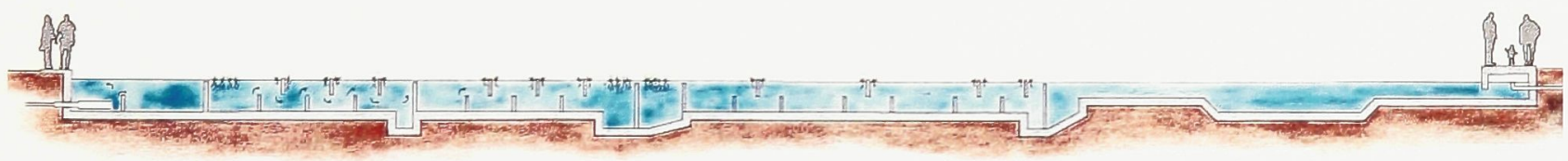

34: Section D - Water Reclamation (1:50) 


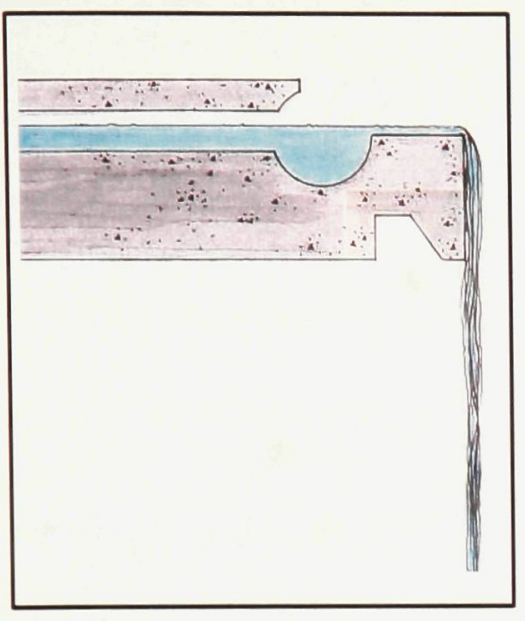

35: Detail-Water Spout (1:5)

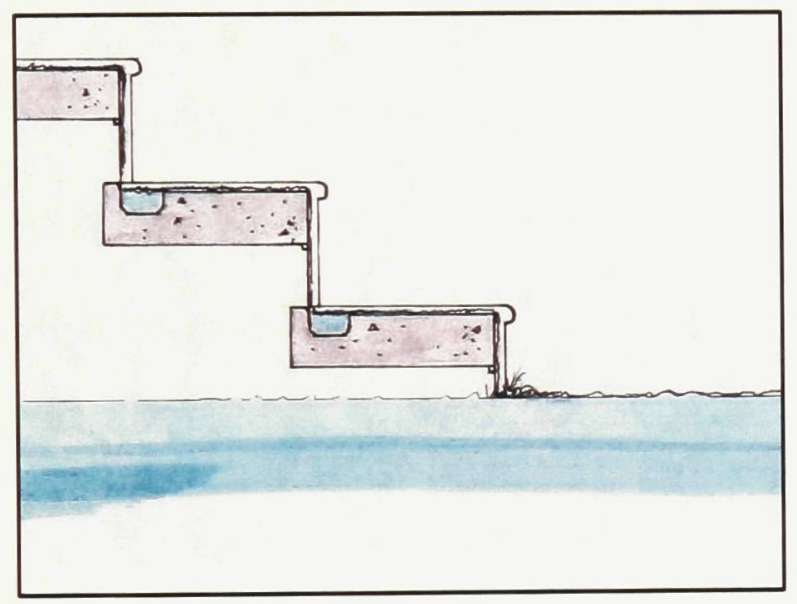

37: Stair with Water (1:20)

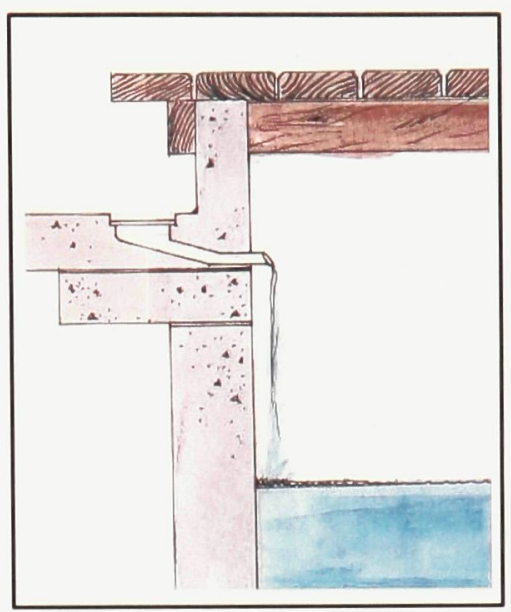

36: Detail - Dock with Water (1:20)

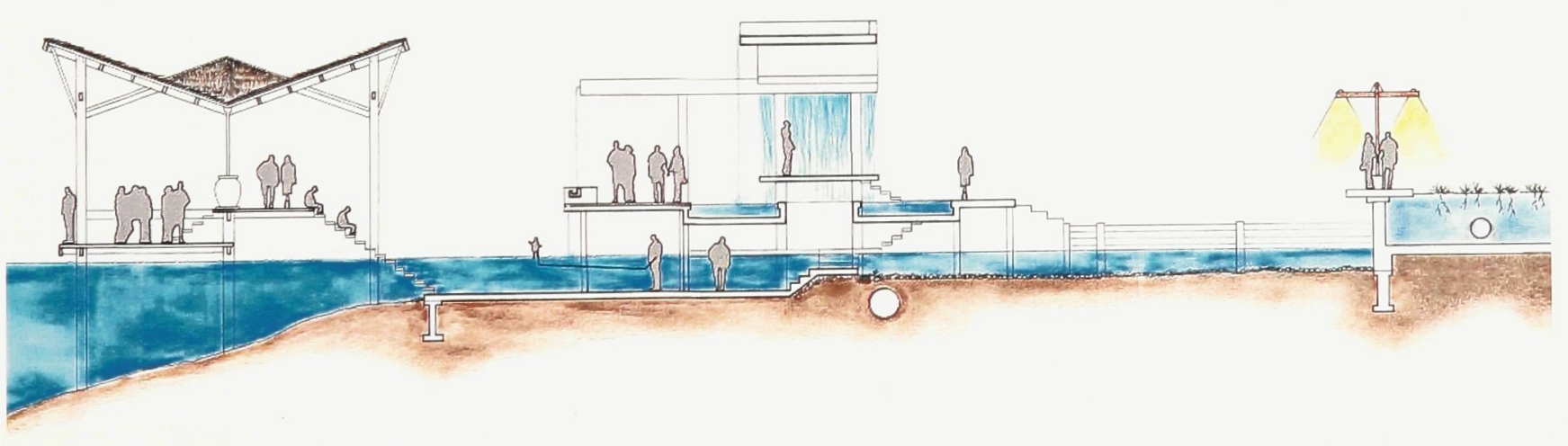

38: Section E - Market/Theatre/Pathway (1:50) 


\subsection{The Water Puppet Theatre}

The architectural setting for water in the city of Cay Lai should deal with the traditional symbolic meanings of water, and in particular, the positive symbols that stand in stark contrast to the current exploitation of this precious resource in most parts of the world. It is this juxtaposition that constitutes the foundation for the architectural intention. Considerations have been made regarding the fundamental symbolism of water as a design element, and the examination of specific uses of water in a wide spectrum of architectural structures.

In the case of Cai Lay, the integration of a tradition of water puppetry theater evokes positive educational perspectives on the importance of water resources for both children and adults. As we have seen, water puppetry is performed as a spectacle for all members of the community. As a result the theater is designed as a multi-purpose theater where community members can change according to their needs and desires.

The art of water puppetry has roots that date back to the tenth century. Over the years, different villages have developed their own personal water puppet plays to mark certain battles or events. Similarly, modern plays can illustrate the significance of water and its meaning to the survival of the city.

With this history in mind, the architectural program juxtaposes a traditional water puppetry theater with a natural wastewater treatment garden. The natural wastewater treatment garden deals directly with the current water problems as a remediation strategy for the city. As a catalyst for an urban renewal strategy for the city, a traditional water puppetry theater can engage and educate the community, encouraging people to 
reconsider their relationship to water and see how important it is to protect their environment and water resources.

This theatre is the focal point of the entire community and marks the pivotal moment when this life-giving substance is celebrated as purified water and is given back to the river. It becomes part of the water playground area as it located in the middle of the public swimming pool area. Essentially, the theatre is a water fountain that trickles water downwards, giving form to the theatre shelter as it carves the silhouette of the traditional puppet theatre as a backdrop and eventually acting as the stage backdrop for the puppets. The open market also extends onto the stage of the theatre when the theatre is not in use. Fundamentally, the theatre is a stage for the intersections of everyday life activities as market life juxtaposed with festive activities.

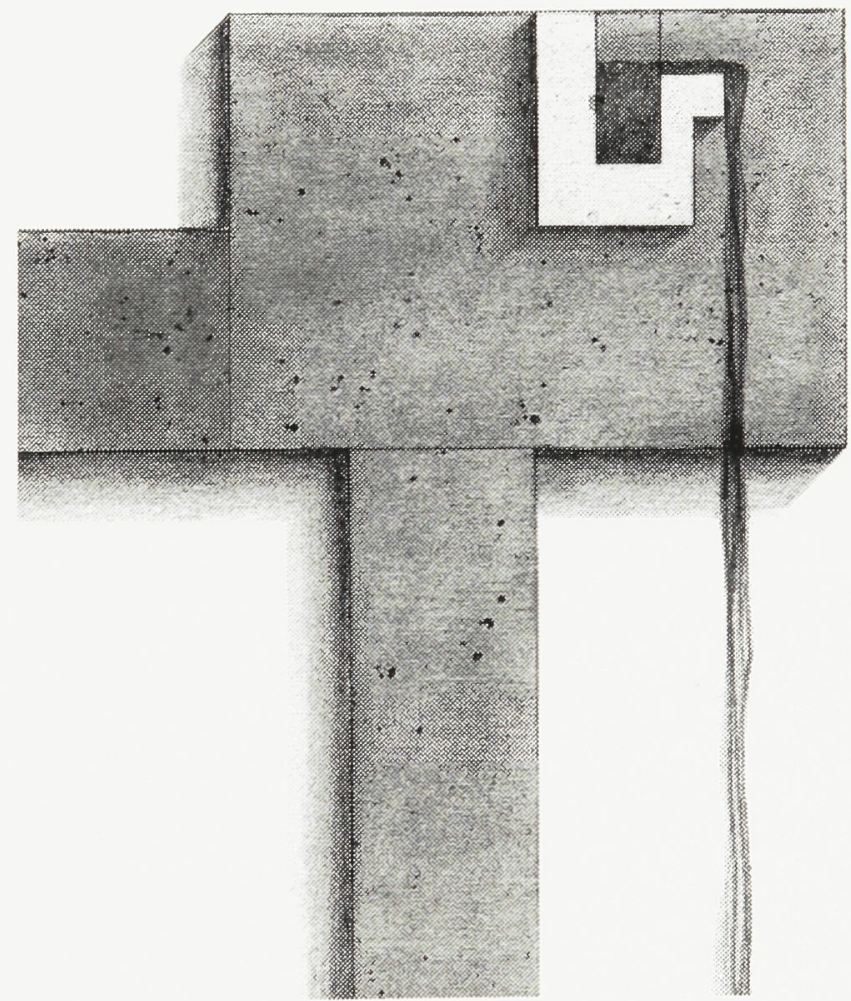

39: Detail Section - water screen (1:10) 


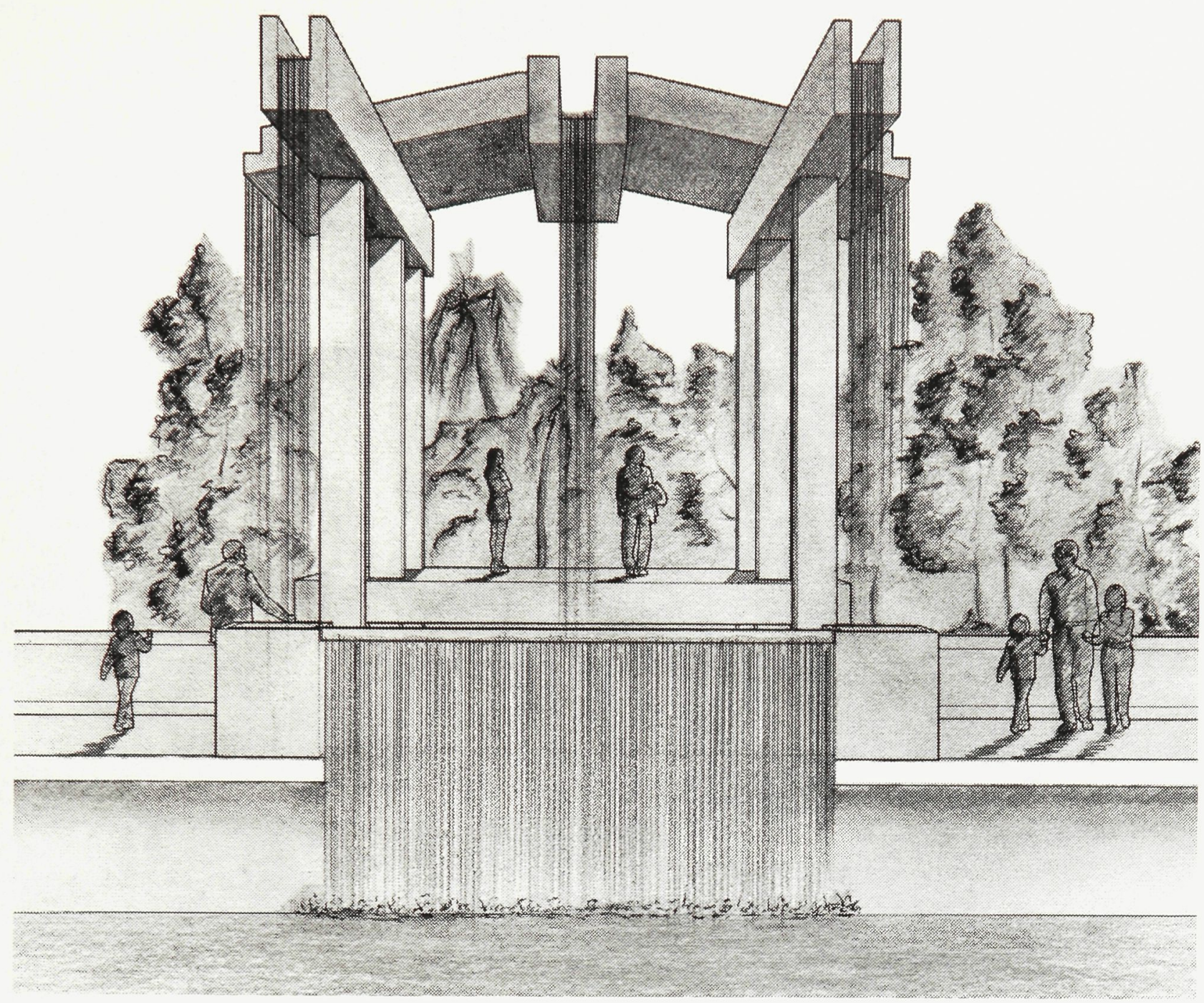

40: Water Puppet Theatre Elevation 

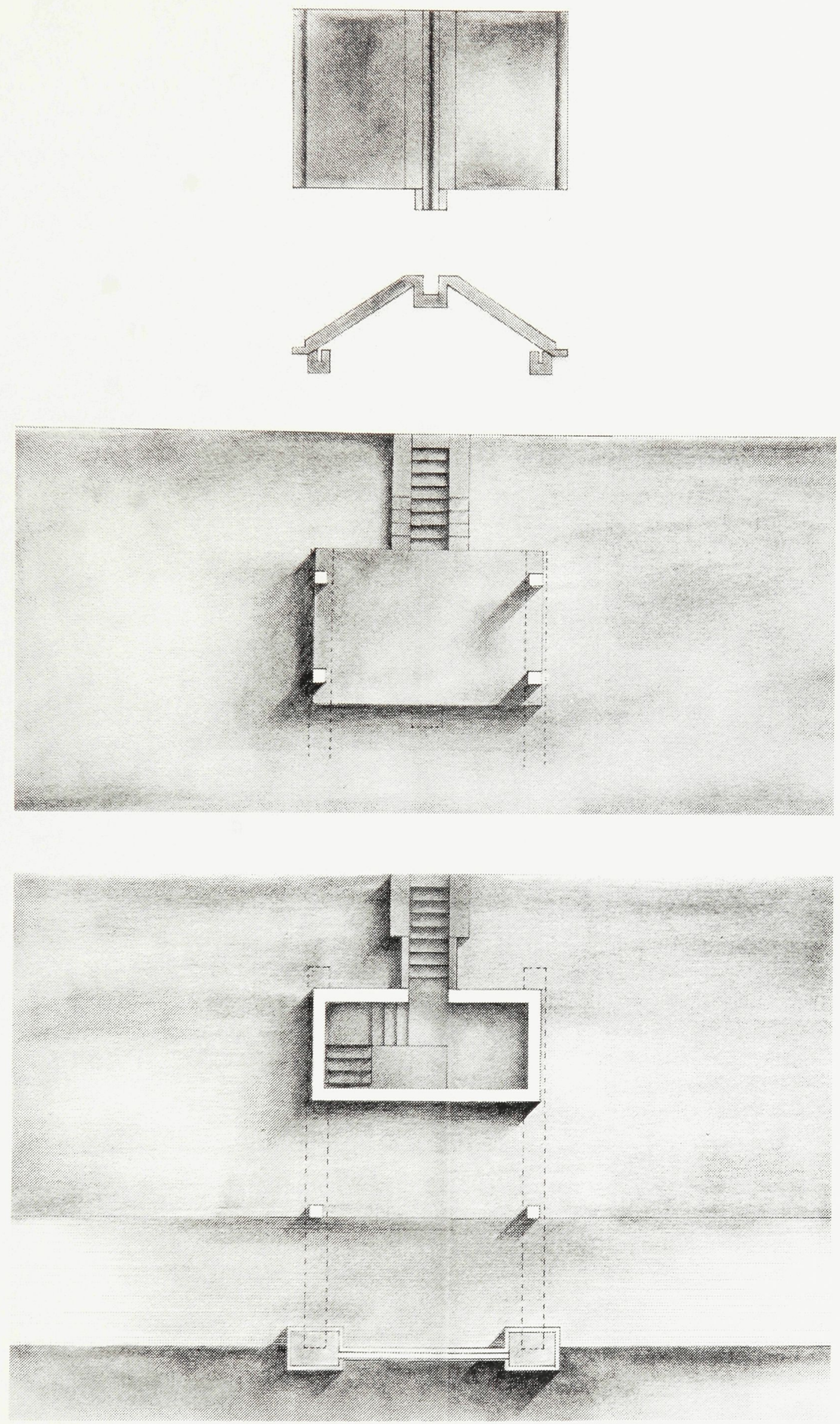

41: Water Puppet Theatre Plan (1:50) 


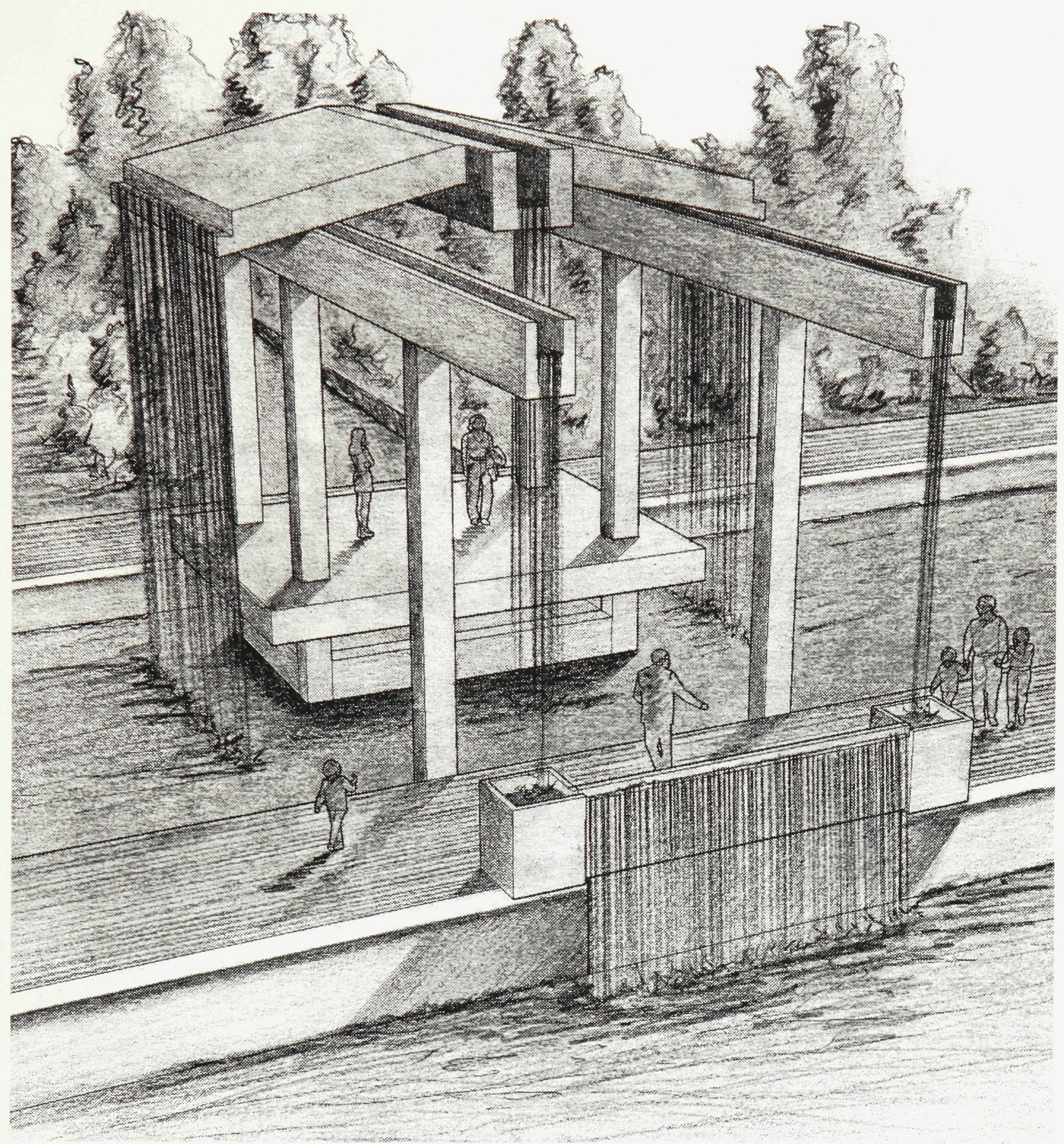

42: Water Puppet Theatre Perspective 


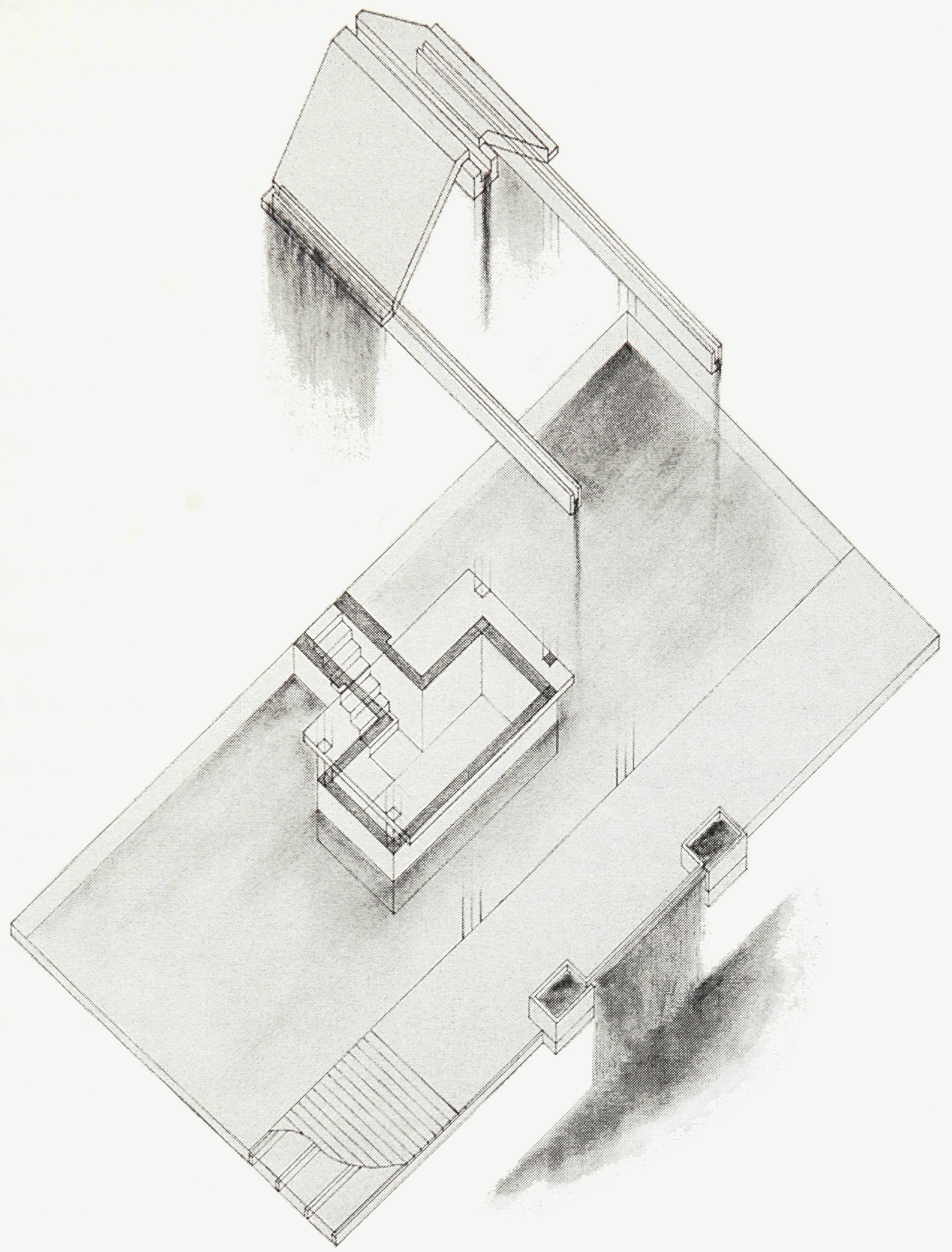

43: Water Puppet Theatre Axonometric Drawing 


\subsection{The Residential Infrastructure}

In Vietnamese landscape painting, rivers and waterfalls are a favored subject and are portrayed with great care. The rural landscape portrayals always romanticize the life near water and all its water activities. As such, water designs are mainly influenced by paintings and sketches, similar to those of the Chinese culture. The process of developing the proposed designs remains true in the area of naturalistic effects. Rather than accurately measuring and drawing up a plan and elevation the designs are extrapolated through a series of vignettes, idealized landscape paintings and sketches.

The role of design for Cai Lay focuses mainly on cultural aesthetic standards, and the role of water in the cultural and social life of the site. In terms of the propositions for the newly redesigned dwellings, water is the main concern. The architectural proposition is therefore the space in which water and architecture meets. These new dwellings surrounded by the natural water treatment garden are prototypes for living with an intimate relationship with water and the water cycle. The "architecture" of the community resides in the roof design that is conceived to collect and celebrate the gift of water from the sky, and in the design of the kitchen, bathing and planting areas where the supply and removal of water intersect with the activities of everyday life. As such, the architect provides the narrative skeleton around which the rest of the house is elaborated.

The residential arrangements suggested in this investigation, are merely examples of what might occur. The unique ways in which the infrastructure will be interpreted will help the inhabitants to reconsider and personalize their relationship to water. 


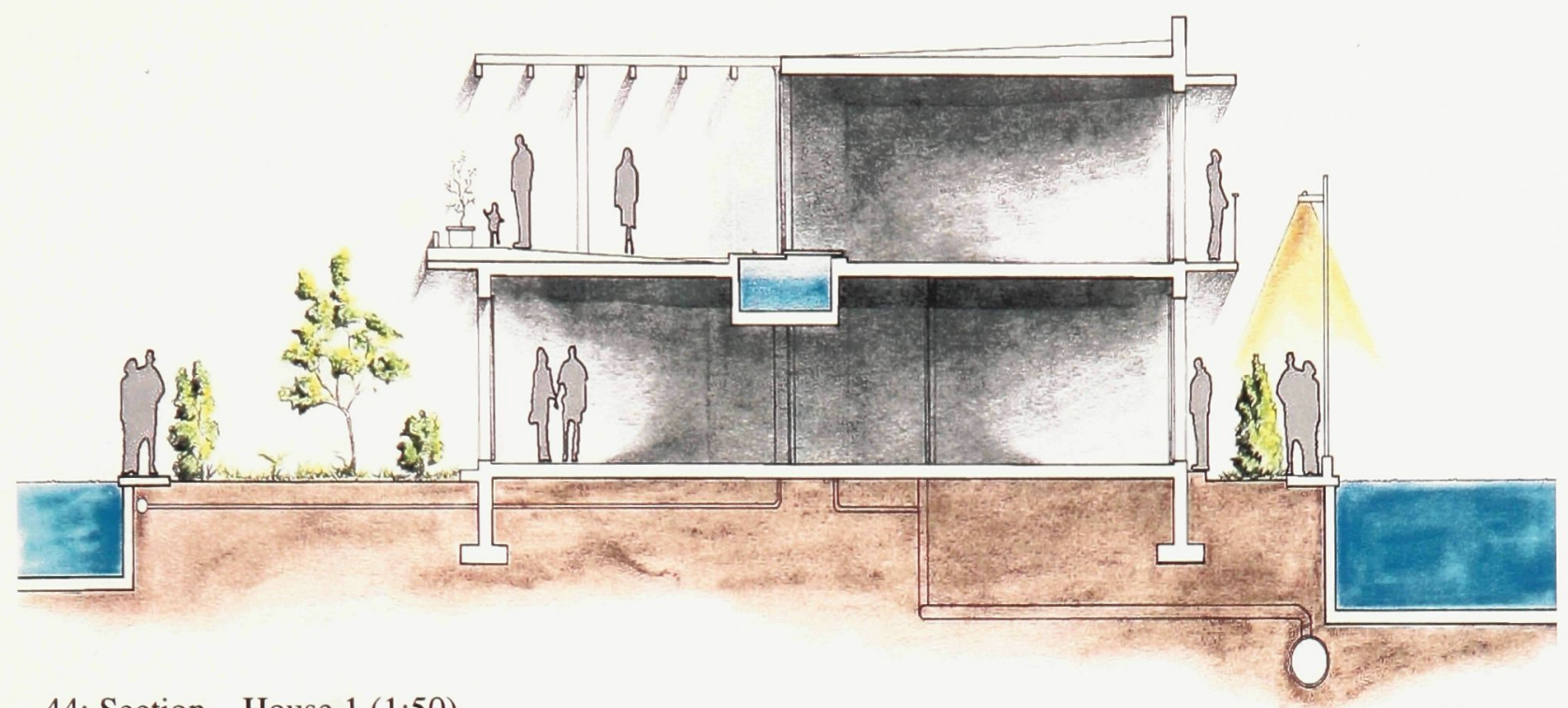

44: Section - House 1 (1:50)

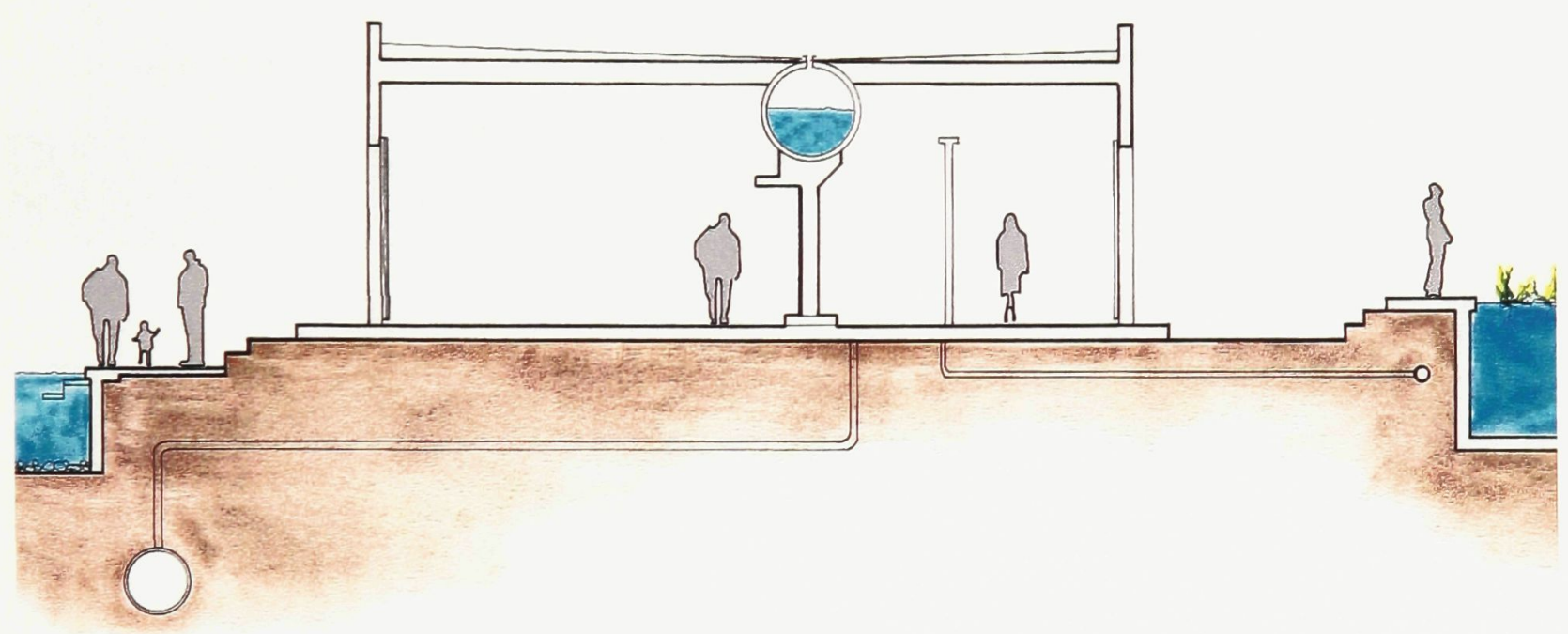

45: Section - House 2 (1:50) 
69

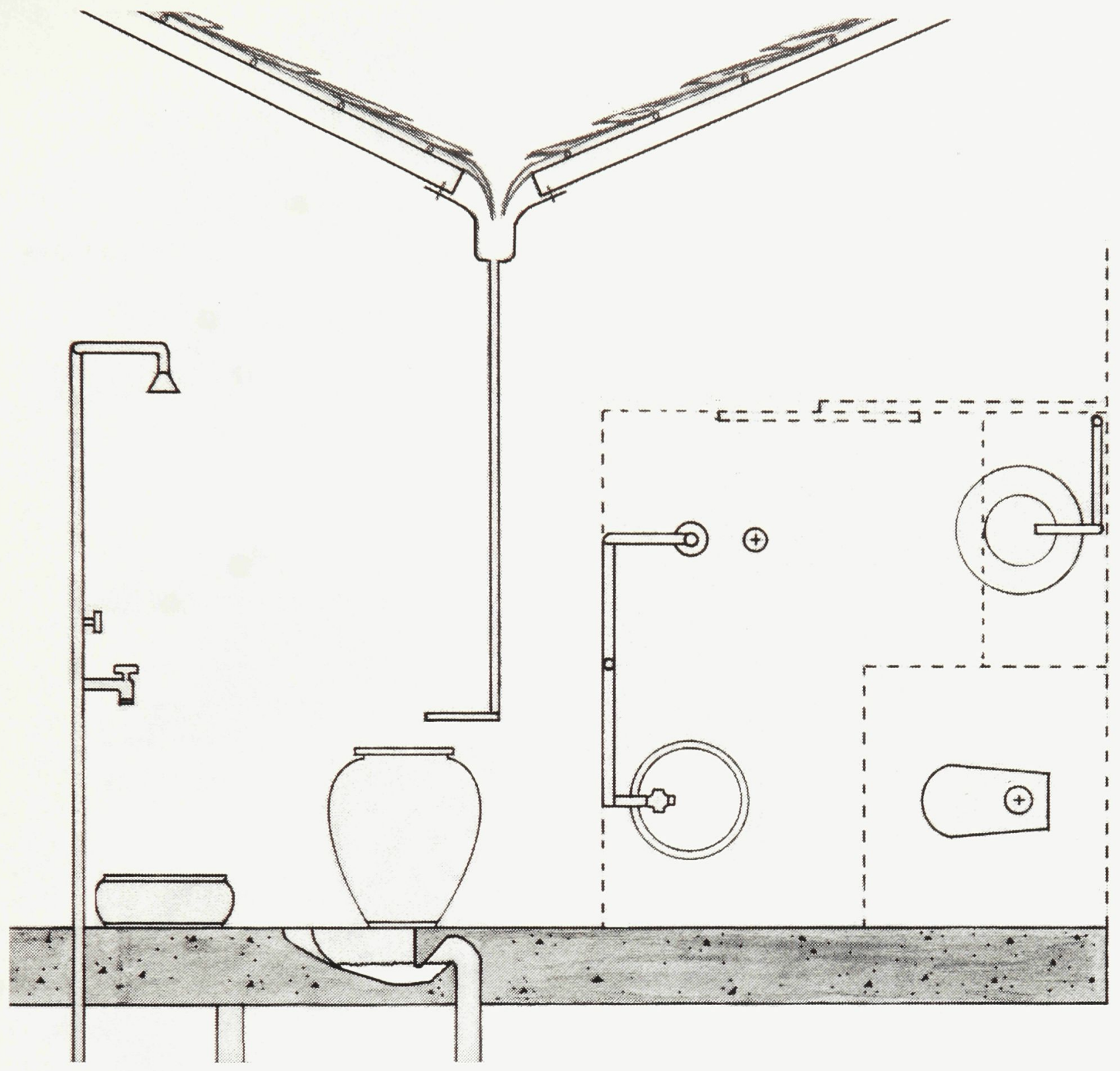

46: Proposed Plumbing (1:20) 


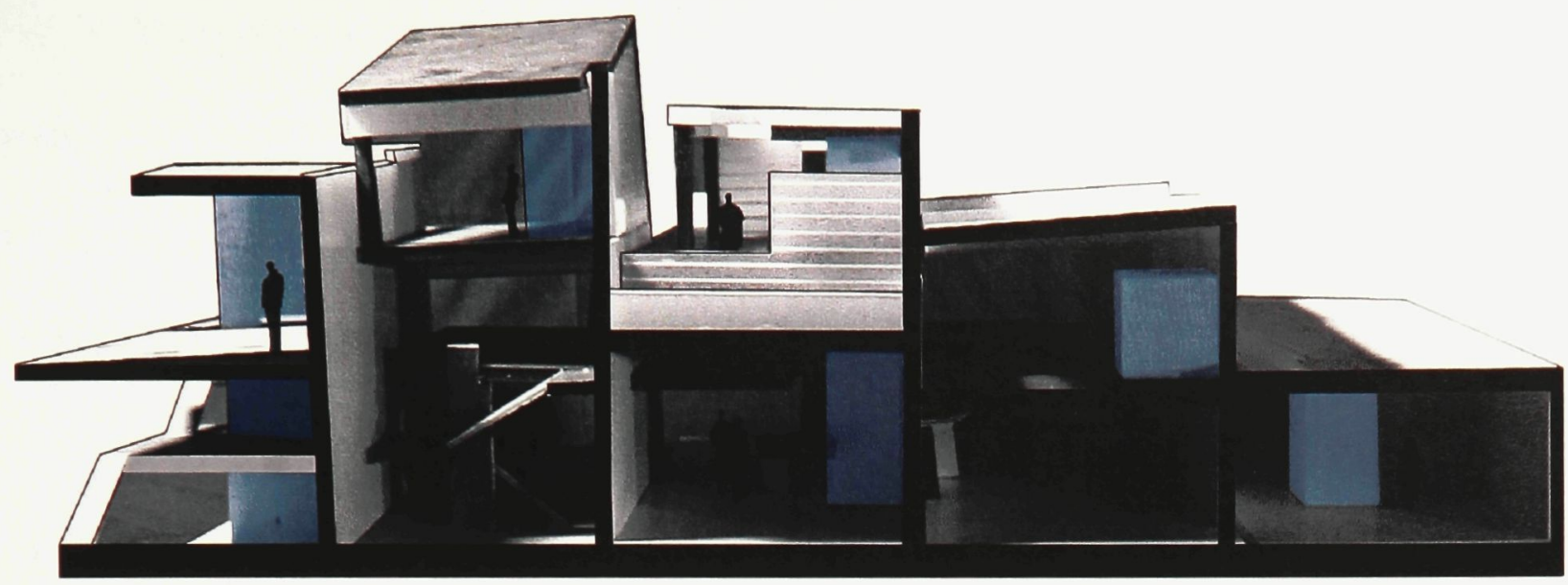

47: Water Placement and Collection Studies

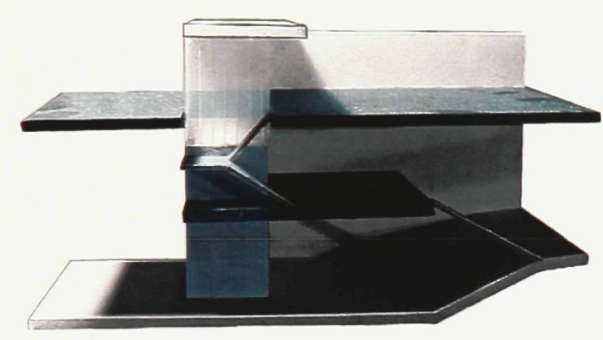

48: Conceptual House Model 1

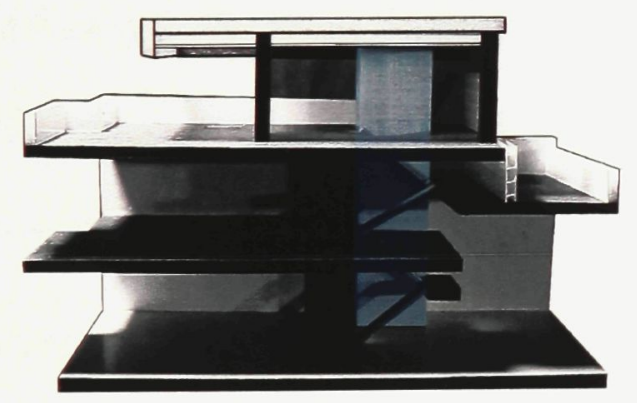

50: Conceptual House Model 3

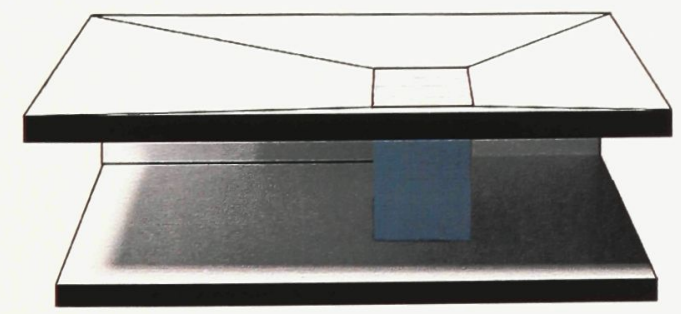

52: Conceptual House Model 5

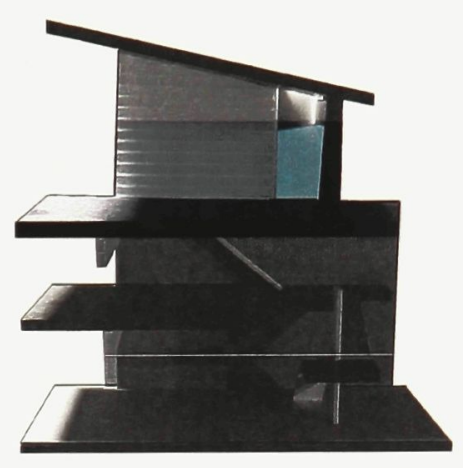

49: Conceptual House Model 2

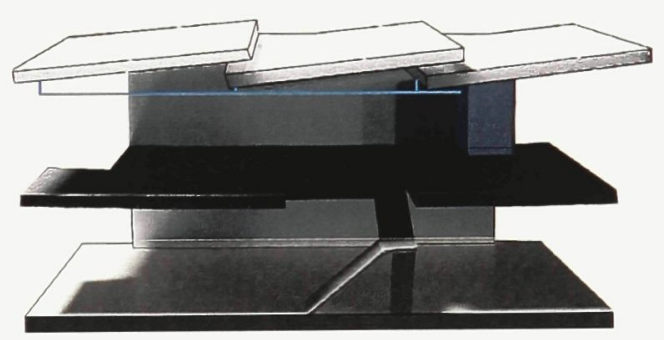

51: Conceptual House Model 4 
This painting tries to capture the water movement through building details. It began as an analytical painting of architectural details of the site.

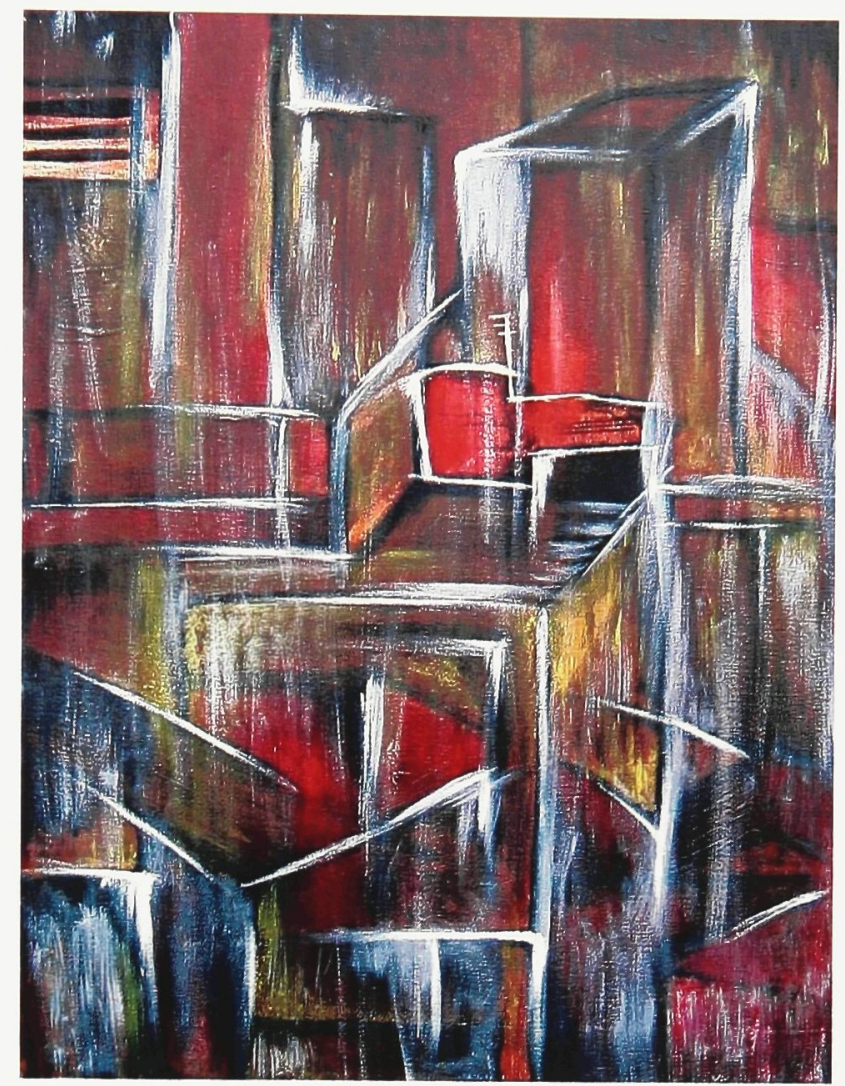

53: Analytical Painting 1

The scene describes mankind's intimacy with water. It was inspired by Kisho Kurokawa's comment that "mankind was born to the oceans, and will have to return there...,37

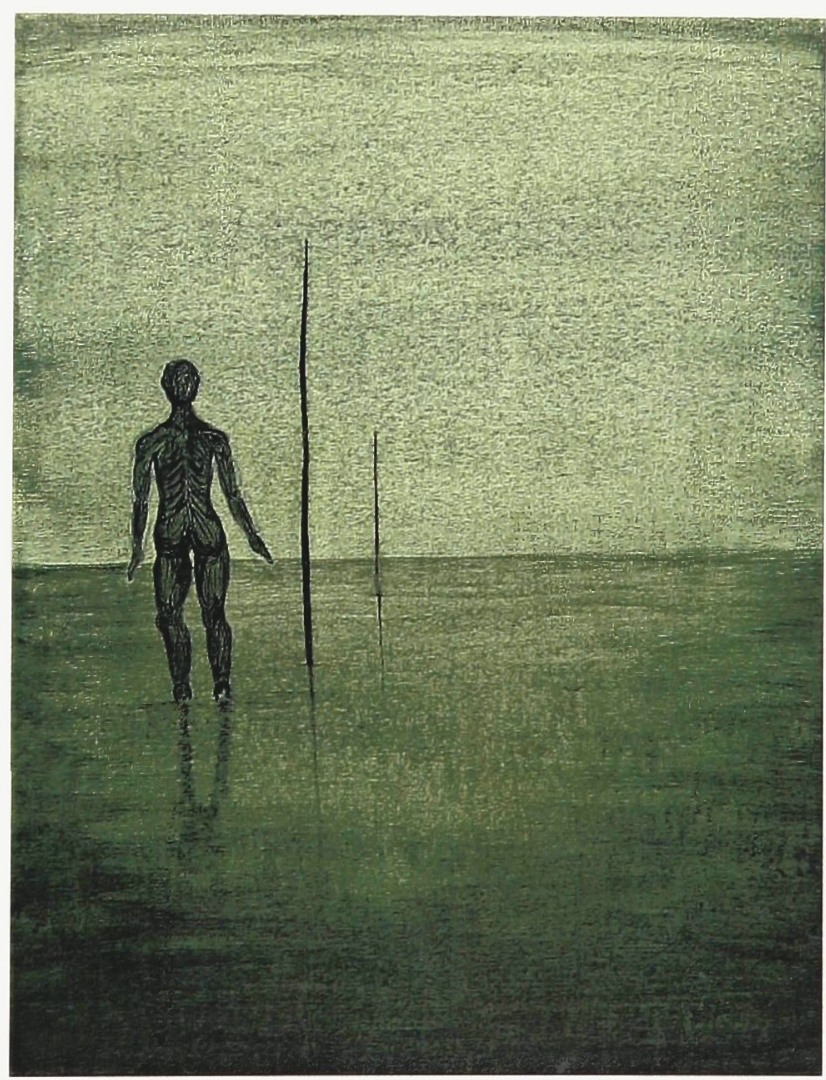

54: Analytical Painting 2

${ }^{37}$ C. J Lim, Realms of Impossibility: Water, (Canada: John Wiley \& Sons Inc., 2002) 44. 
The painting is an impression of

Ha Long Bay of northern Vietnam. It is a washed painting with only one single tone illustrates the formless quality of water and the transcendental process of transforming from a liquid into a vapor.

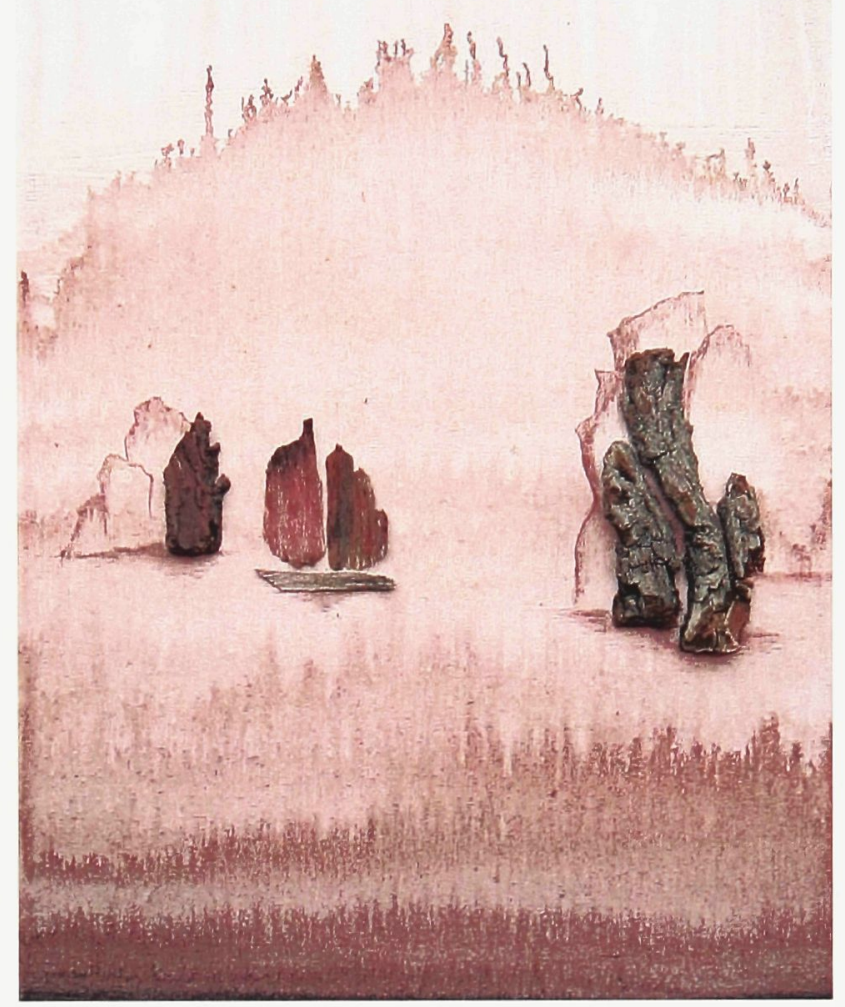

55: Analytical Painting 3

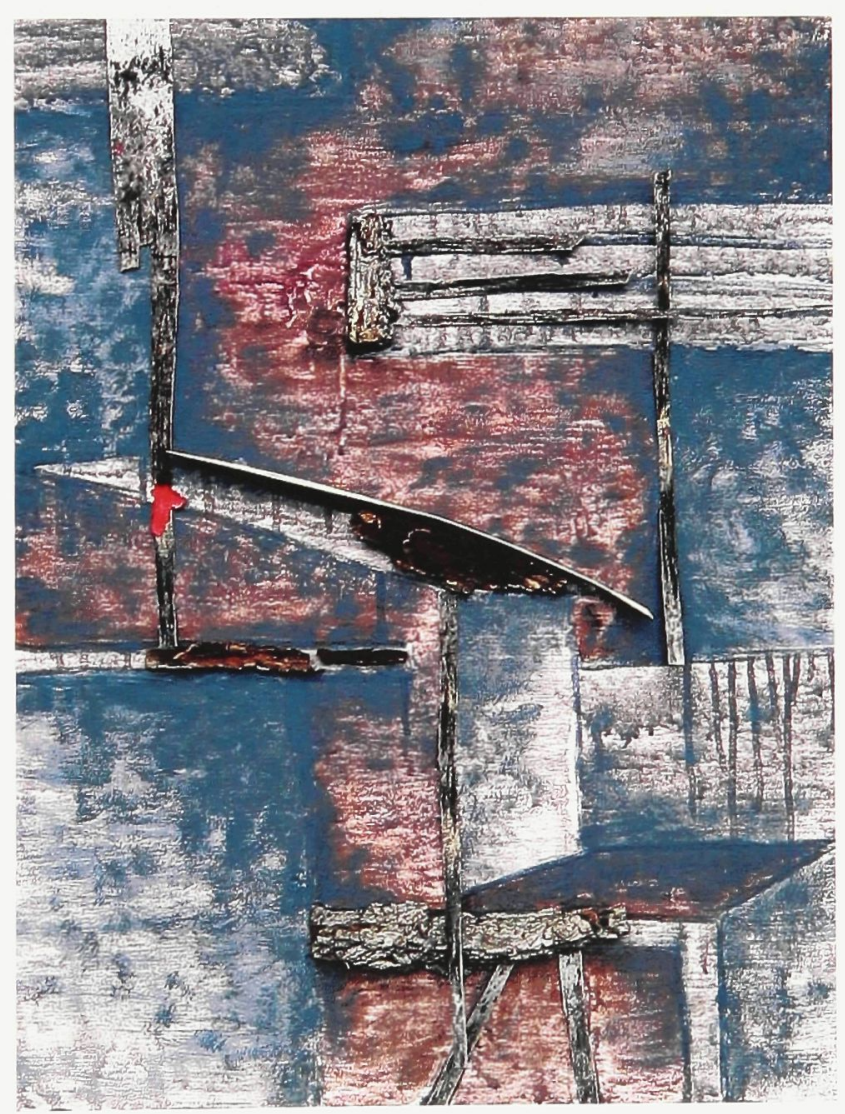

56: Analytical Painting 4
The water eroding the stains of vernacular materials can give the impression of time and also creates a tactile imagery and intimacy to the space. 
This is a layered-painting of architectural possibilities within the natural water treatment process. These range from architectural details to playful water features.

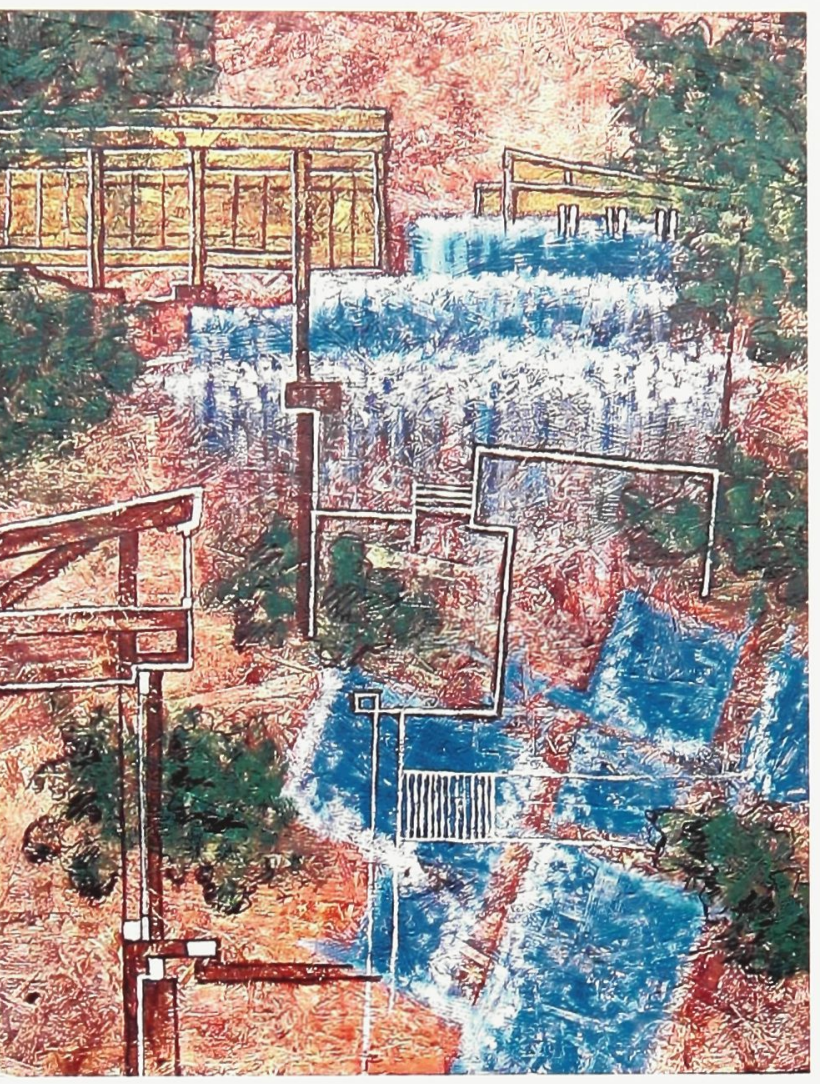

57: Analytical Painting 5

This detail describes how the dock engages the natural water treatment system. It illustrates how plants will grow and continue to take shape in the process of water reclamation.

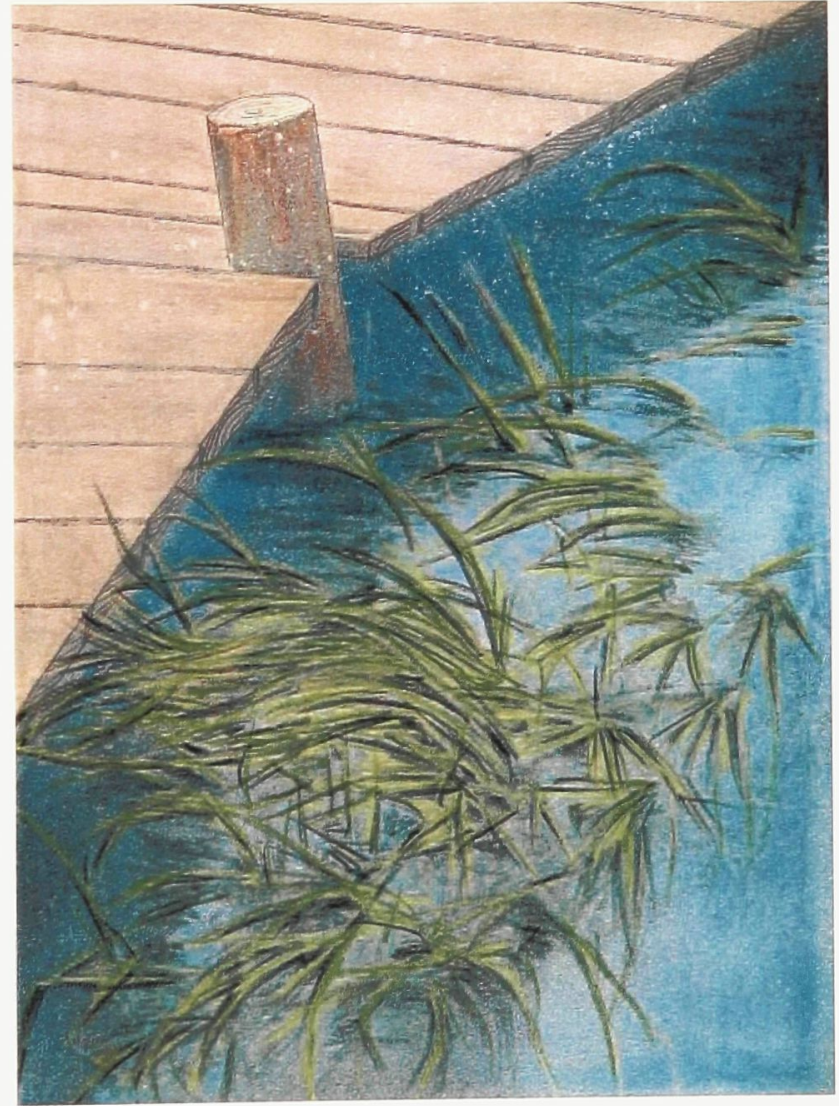

58: Moment 1 
The moment exemplifies the everyday life activities bordering the natural water treatment process.

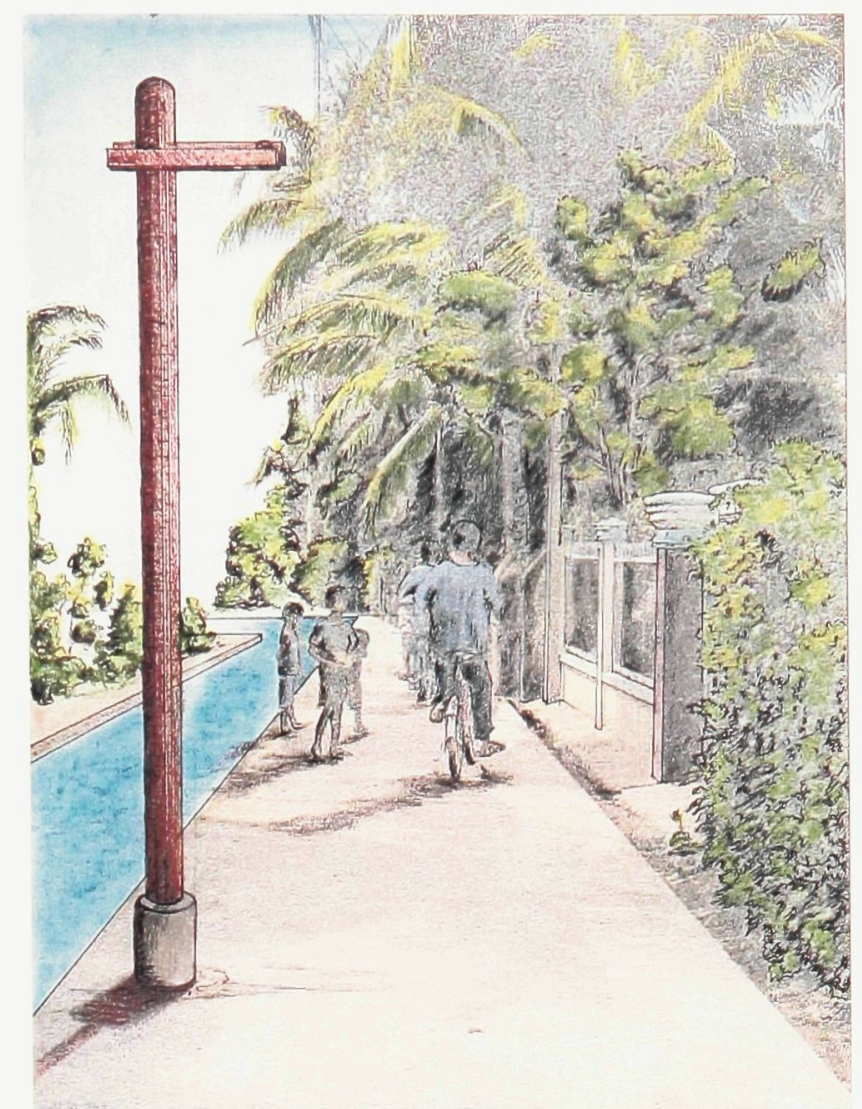

59: Moment 2

This is an illustration of an inhabitant obtaining water from the canal for daily irrigation.

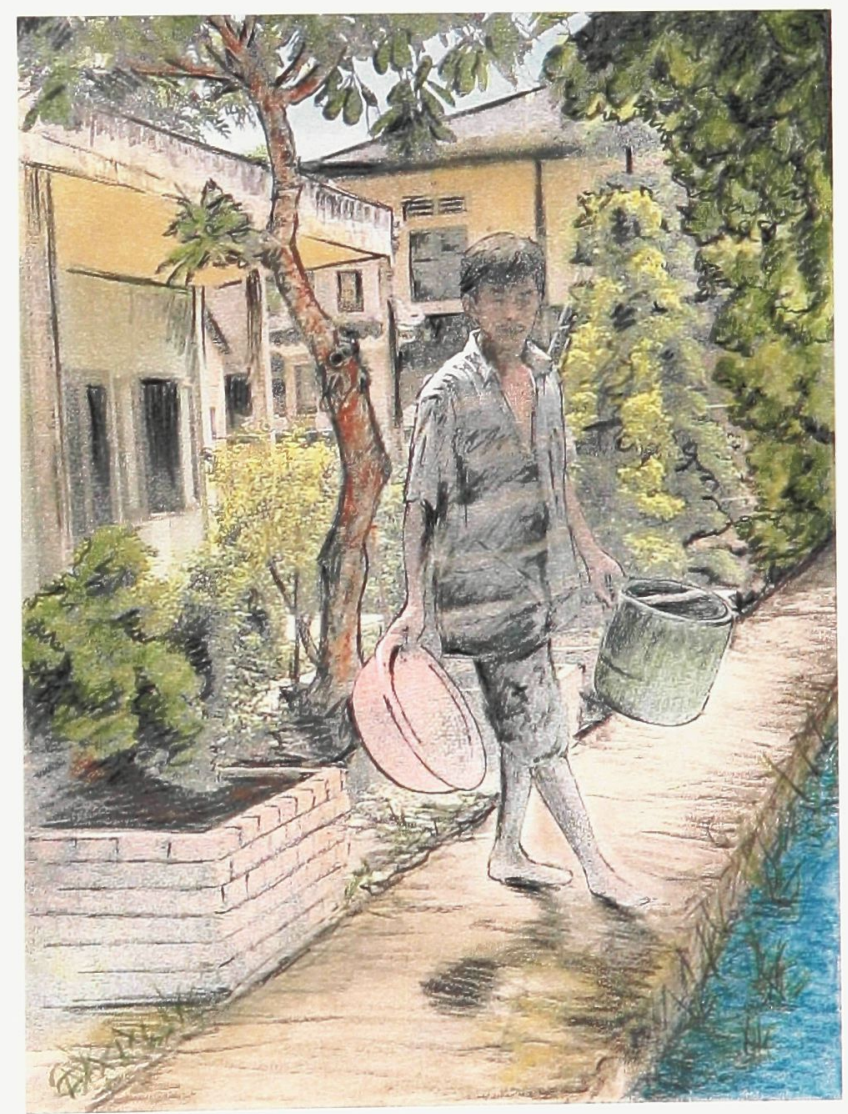

60: Moment 3 
This stair is a proposed moment for the termination of an alleyway when it reaches the water edge.

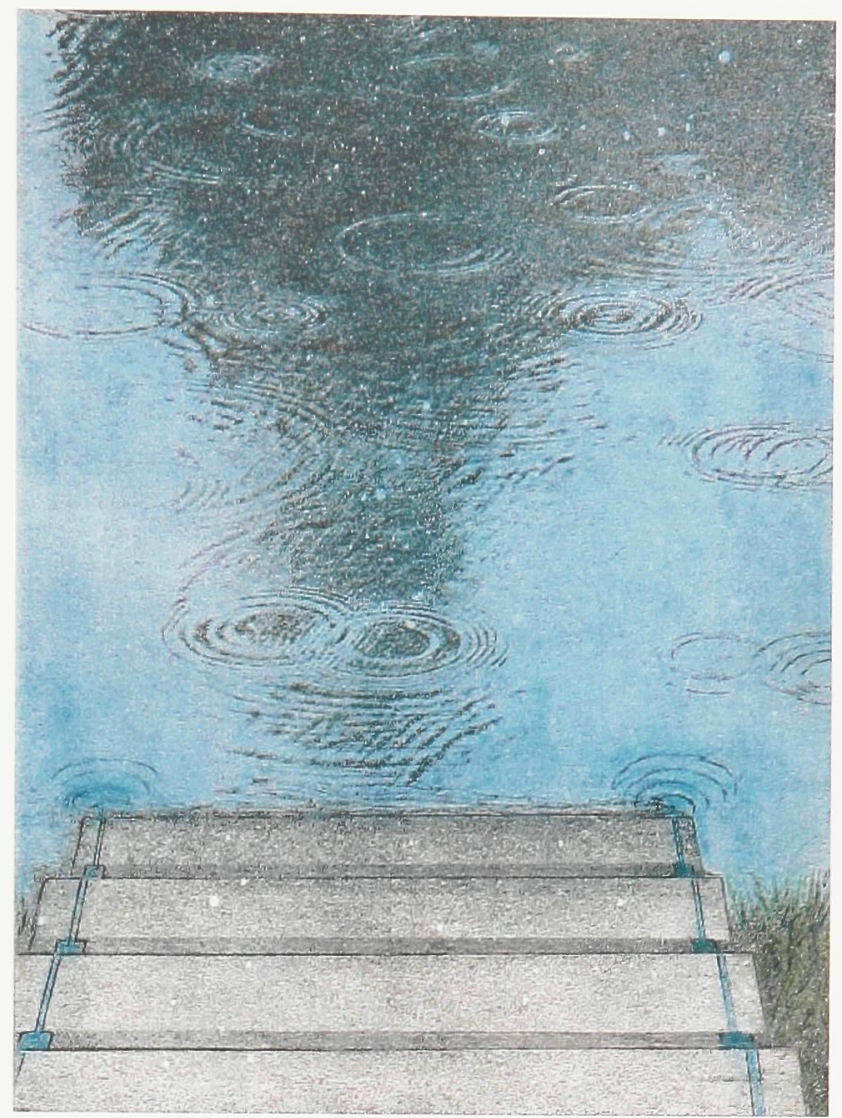

61: Moment 4

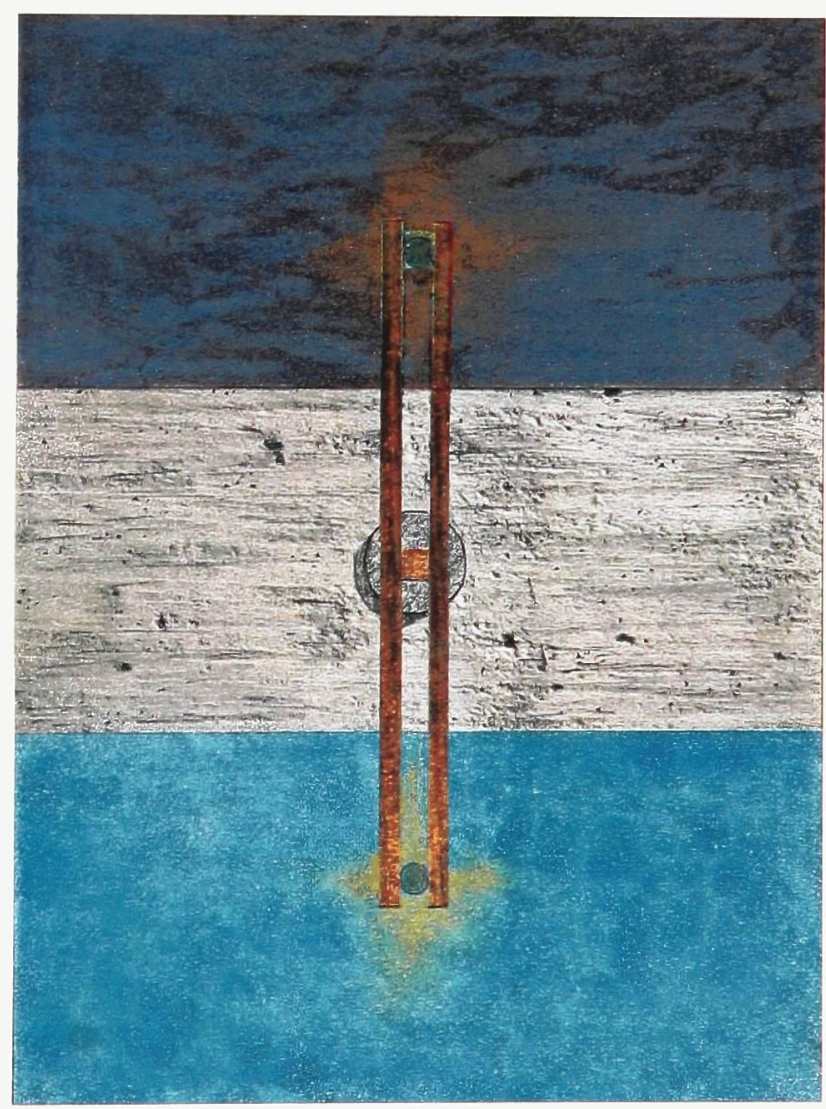

62: Moment 5 


\section{Conclusions}

The present-day water crisis continues to grow because of our failure to recognize the full extent of our interconnectedness with nature and to deal effectively with it as a public issue. Water problems concern not only science and technology but also the ideals, myths, and meaning that we associate with nature. Undeniably, water has a tangible physical hold on the lives of every one of us, therefore designs involving water and architecture must remind people of this enormous impact that water has on our lives.

Charles Moore comments on the significant use of water in architecture as follows:

"Architects use materials and forms to communicate ideas. When we make places that include water in our designs, we cannot ignore the role that history and symbolism play in fortifying connections among people, water and nature. Perhaps the greatest lesson of our century has been that people need connection to the past, and myths or religions, to help make some sense of our increasingly complex world.",38

The critical analysis and water infrastructure plan proposed for the city of Cai Lay, Vietnam, through its various elements and considerations have attempted to accomplish just that.

While the focus of this thesis has been on Vietnam, where the water crisis is severe, North American architects would do well to learn from this situation and take preemptive action by showing leadership in the area of water integration in all projects

\footnotetext{
${ }^{38}$ Charles W. Moore, Water and Architecture, (New York: Harry N. Abrams, Inc., 1994) 199.
} 
that they undertake. The fact is that if water is neither used well nor used often in our architecture, then surely some of the difficulty can be traced to our confusion over what sort of attitude toward this resource we are trying to express. Furthermore, the current utilization of water in architecture implicitly reflects the thoughtless attitude the architectural profession has had to date towards the water crisis (that allegedly causes the deaths of millions every year). It is crucial therefore that architects take a leadership role in developing an effective way to incorporate water's history, symbolism, and physical nature into their designs. 


\section{Appendix A}

\section{The Living Machine Fact Sheet}

Source: Living Machines, Inc., September 2004. Web Site:

http://livingmachines.com 


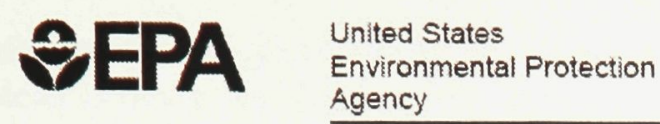

Wastewater Technology Fact Sheet

The Living Machine ${ }^{\mathrm{E}}$

\section{DESCRIPTION}

The Living Machine ${ }^{8}$ is an emerging wastewater treatment technology that utilizes a series of tanks, which support vegetation and a variety of other organisms. The Living Machine ${ }^{\text {t }}$ was conceived by Dr. Jom Todd, President of the non-profit organization Ocean Arks International, and gets its name from the ecologically-based components that are incorporated within its treatment processes (microorganisms, protozoa, higher animals such as snails, and plants). The Living Machine has sometimes been referred to as the "Advanced Ecologically Engineered System" or AEES. The Living Machine ${ }^{\varepsilon}$ is now designed and marketed by Living Machines. Inc. of Taos, New Mexico.

The Living Machine ${ }^{*}$ is a second generation design. Dr. Todd developed the Living Machine ${ }^{\mathrm{TM}}$ design concept after working on a number of similar small pilot-scale facilities, now referred to as Solar Aquatics ${ }^{\mathrm{IM}}$ and marketed by Ecological Engineering Associates of Marion, Massachusetts.

The Living Machine incorporates many of the same basic processes (e.g., sedimentation, filtration, clarification, adsorption, nitrification and

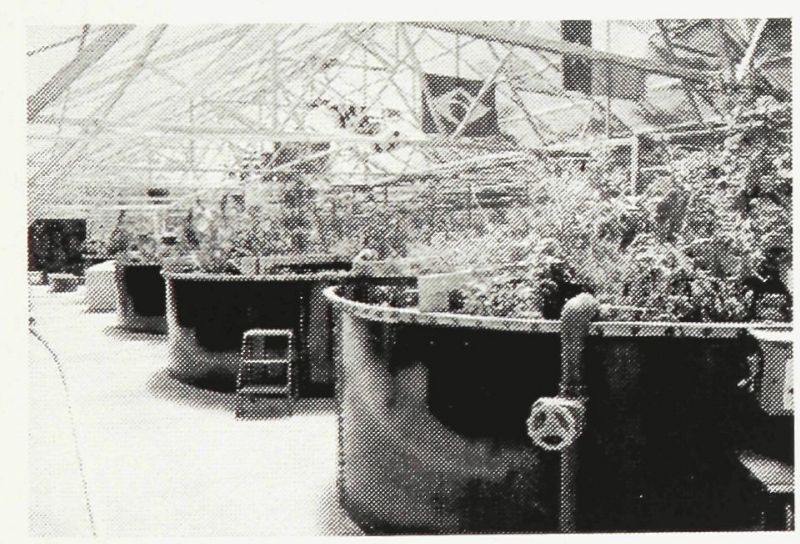

Source: U.S. EPA., 2001

FIGURE 1 THE OPEN AEROBIC TANKS OF THE LIVING MACHINE® IN SOUTH BURLINGTON, VT denitrification. volatilization. and anaerobic and aerobic decomposition) that are used in conventional biological treatment systems. What makes the Living Machine ${ }^{\mathbb{v}}$ different from other systems is its use of plants and animals in its treatment process, and its unique aesthetic appearance. While these systems are aesthetic appealing, the extent to which the plants and animals contribute to the treatment process in current Living Machine designs is still being verified (U.S. EPA, 2001). In temperate climates, the process is typically housed within a large greenhouse. which protects the process from colder temperatures

Living Machines. Inc. describes the Living Machine $^{8}$ as being a wastewater treatment system that:

- Is capable of achieving tertiary treatment;

- Costs less to operate than conventional systems when used to achieve a tertiary level of treatment; and

- Doesn't typically require chemicals that are harmfil to the environment" as a part of its treatment process (Living Machines, Inc., 2001).

Several federally-funded Living Machine demonstration systems have been constructed, the largest of which handled design flows of up to 80,000 gpd. As configured for these demonstrations. these systems treated municipal wastewaters at various strengths, and reliably produced effluents with five-day biochemical oxygen demand $\left(\mathrm{BOD}_{\hat{\xi}}\right)$, total suspended solids (TSS), and Total Nitrogen $\leq 10 \mathrm{mg} /$, Nitrate $\leq 5 \mathrm{mg} / \mathrm{L}$, and Ammonia $\leq 1 \mathrm{mg} / \mathrm{L}$ (U.S. EPA, 2001 and see Table 1). With regard to phosphons removal, the Living Machine $e^{\text {process }}$ is capable of about 50 percent removal with influents within the 5-11 mg I range (U.S. EPA. 2001). In addition to 
the demonstration projects, the Living Machine ${ }^{\&}$ technology is being used by a variety of municipal and industrial clients, where similar performance has been reported.

\section{Treatment Process}

A typical Living Machine comprises six principle treatment components, after influent screening. In process order (see Figure 1), these are (1) an anaerobic reactor, (2) an anoxic tank, (3) a closed aerobic reactor, (4) aerobic reactors, (5) a clarifier. and (6) "ecological fluidized beds" (EFBs). While the open aerobic reactors and EFBs are found in almost all Living Machines ${ }^{\text {s }}$, the other components are not always utilized in the treatment process. The specific components used are selected by the designers depending upon the characteristics of the wastewater to be treated and the treatment objectives. Sometimes additional process components may be added if considered necessary by the designers. For example, the demonstration system in Frederick, Maryland utilized a "Final Clarifier" and a high-rate subsurface flow (SF) wetland as the last two components of its treatment train.

\section{Anaerobic Reactor (Step 1)}

When it is employed the anaerobic reactor serves as the initial step of the process. The reactor is similar in appearance and operation to a septic tank, and it is usually covered and buried below grade. The main pupose of the anaerobic reactor is to reduce the concentrations of $\mathrm{BOD}_{5}$ and solids in the wastewater prior to treatment by the other components of the process. When necessary, gases are passed throngh an activated carbon filter to control odor.

Raw influent enters the reactor, which acts as a primary sedimentation basin. Some of the anaerobic reactors used have an initial sludge blanket zone, followed by a second zone for clarification. Additionally, strips of plastic mesh netting are sometimes used in the clarification zone to assist with the trapping and settling of solids, and to provide surface area for the colonization of anaerobic bacteria, which help to digest the solids. Sludge is typically removed periodically via perforated pipes on the bottom of the reactor, and wasted to a reed bed or other biosolids treatment processes. Gasses produced are passed through an activated carbon filter or biofilter for odor control.

Anoxic Reactor (Step 2)

The anoxic reactor is mixed and has controlled aeration to prevent anaerobic conditions, and to encourage floc-forming and denitrifying microorganisms. The primary pupose of the anoxic reactor is to promote growth of floc-forming microorganisms, which will remove a significant portion of the incoming $\mathrm{BOD}_{5}$.

Mixing is accomplished through aeration by a coarse bubble diffuser. These diffusers are typically operated so that dissolved oxygen is maintained
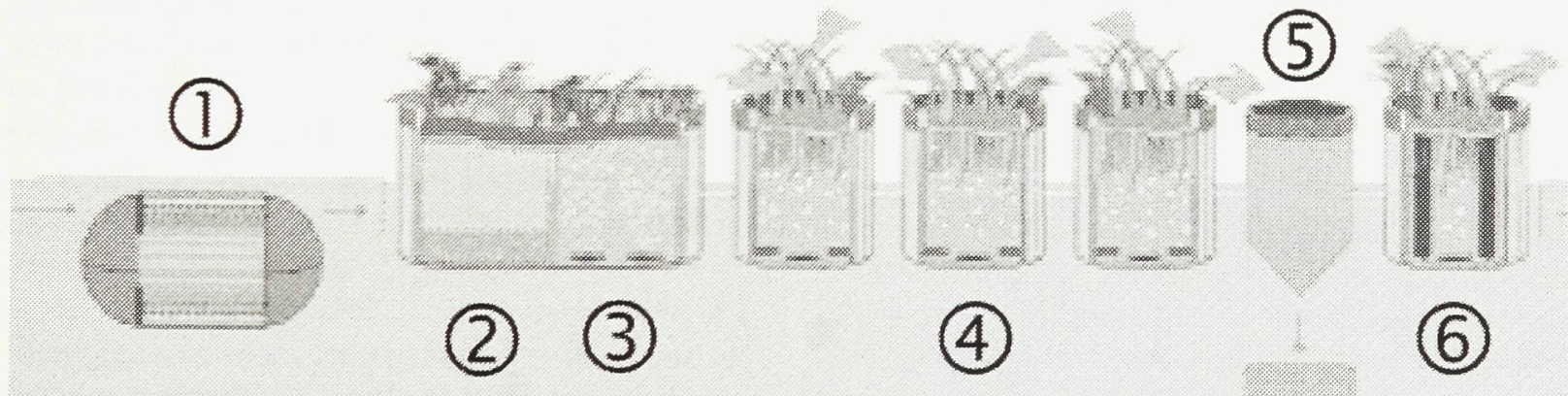

Source: Living Machines inc., 2001

FIGURE 1 THE COMPONENTS OF THE LIVING MACHINE®: (1) ANAEROBIC REACTOR, (2) ANOXIC REACTOR, (3) CLOSED AEROBIC REACTOR, (4) OPEN AEROBIC REACTORS, (5) CLARIFIER, AND (6) "ECOLOGICAL FLUID BED" 
below $0.4 \mathrm{mg} / \mathrm{L}$. The space over the reactor is vented through an odor control device, which is usually a planted biofilter. Additionally, an attached growth medium can be placed in the compartment to facilitate growth of bacteria and microorganisms.

Settled biosolids from the clarifier (Step 5), and nitrified process water from the final open aerobic reactor (Step 4) are recycled back into this reactor. The purpose of these recycles is to provide sufficient carbon sources to the anoxic reactor to support denitrification without using supplemental chemicals, such as methanol.

\section{Closed Aerobic Reactor (Step 3)}

The purpose of the closed aerobic reactor is to reduce the dissolved wastewater $\mathrm{BOD}_{5}$ to low levels, to remove further odorous gases, and to stimulate nitrification.

Aeration and mixing in this reactor are provided by fine bubble diffusers. Odor control is again achieved by using a planted biofilter. This biofilter typically sits directly over the reactor and is planted with vegetation intended to control moisture levels in the filter material

\section{Open Aerobic Reactors (Step 4)}

Next in the process train are the open aerobic reactors, or aerated tanks. They are similar to the closed aerobic reactor in design and mechanics (i.e., aeration is provided by fine bubble diffusers): however, instead of being covered with a biofilter. the surfaces of these reactors are covered with vegetation supported by racks. These plants serve to provide sumface area for microbial growth, perform mutrient uptake, and can serve as a habitat for beneficial insects and microorganisms. To what extent the plants enhance the performance treatment process in the Living Machine ${ }^{2}$ is still being verified (U.S. EPA, 2001). However, with the variety of vegetation present in these reactors, these untts (along with the Ecological Fluidized Beds Step 6) set the Living Machine ${ }^{\sqrt{x}}$ apart from other treatment systems in terms of their unique appearance and aesthetic appeal.
The aerobic reactors are designed to reduce $\mathrm{BOD}_{5}$ to better than secondary levels and to complete the process of nitrification. The size and number of these reactors used in a Living Machine ${ }^{6}$ design are determined by influent characteristics, effluent requirements, flow conditions, and the design water and air temperatures.

\section{Clarifier (Step 5)}

The clarifier is basically a settling tank that allows remaining solids to separate from the treated wastewater. The settled solids are pumped back to the closed aerobic reactor (Step 3), or they are transferred to a holding tank, and then removed for disposal. The surface of the clarifier is often covered with duckweed, which prevents algae from growing in the reactor.

\section{Ecological Fluidized Betls (Step 6)}

The final step in the typical Living Machine process are the "ecological fluidized beds" (EFBs). These are polishing filters that perform final treatment of the wastewater, and one to three are used in series to reduce $\mathrm{BOD}_{5}$. TSS and nutrients meet final effluent requirements.

An EFB consists of both an imer and outer tank. The imer tank contains an attached growth medium, such as crushed rock, lava rock, or shaped plastic pieces. The wastewater flows into the EFB in the annular space between the imner and outer tanks and is raised by air lift pipes to the top of the inner ring that contains the media. The bottom of the inner tank is not sealed, so the wastewater percolates through the gravel media and returns to the outer anmular space, from where it is again moved back to the top of the gravel bed. The air lifts also serve to aerate the water and maintain aerobic conditions.

The unit serves as a fixed bed, downflow, granular media filter and separates particulate matter from the water. Additionally, the microorganisms that occupy the gramular media surfaces provide any final nitrification reactions.

As sludge collects on the EFB, it reduces its ability to filter. This would eventually clog the bed completely. Therefore additional aeration diffusers 
beneath the gravel bed are periodically tumed on to create an upflow airlift, reversing the flow direction. This aeration is intended to "fluidize" the bed and release the trapped sludge (hence the name of this unit). This sludge is washed over and accumulated at the bottom of the outer amular space where it can be collected manually, and wasted along with the biosolids from the anaerobic reactor. Consequently, the name "ecological fluidized bed" is somewhat misleading for this unit since, in its treatment mode, it acts like a typical, conventional, downflow coarse media contact filter unit. Only during backwash cleaning does the bed become partially fluidized.

After this last step, the wastewater should be suitable for discharge to surface waters or a subsurface disposal system. or reused for landscape inigation, toilet flushing, vehicle washing, etc. (Living Machines, Inc., 2001).

\section{APPLICABILITY}

The Living Machine $e^{6}$ is well suited for treating both municipal and some industrial wastewaters. As with most treatment systems using plants, it can require a larger footprint than more conventional systems, and its requirement for a greenhouse in more temperate climates can impact costs. However, its unique and aesthetically pleasing appearance make it an ideal system in areas that oppose traditional treatment operations based on aesthetics (i.e., smell and appearance). The designers also stress the educational benefits of the

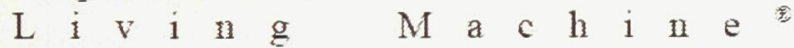
(http//www livingmachines.com/htm planet $2 . \mathrm{htm}$ ) in raising awareness of wastewater treatment methods and benefits.

\section{ADVANTAGES/DISADVANTAGES}

\section{Advantages}

- Capable of treating wastewaters to $\mathrm{BOD}_{5}$, TSS, and Total Nitrogen $\leq 10 \mathrm{mg} / \mathrm{L}$, Nitrate $\leq 5 \mathrm{mg} \mathrm{L}$, and Ammonia $\leq 1 \mathrm{mg} / \mathrm{L}$.

- Offers a unique, aesthetically pleasing environment for treating and recycling wastewater. This may be helpfin when attempting to locate the treatment system in areas where the public opposes traditional wastewater treatment operations for aesthetic reasons

\section{Disadvantages}

- The Living Machine has only been shown to remove about 50 percent of influent phosphorous (with influents in the range of $5-11 \mathrm{mg} / \mathrm{L}$ ). The removed phosphorus appears to be primarily associated with the incoming solids.

- The process requires a greenhouse for reliable operation in the cold weather of more temperate climates, adding to system costs.

\section{DESIGN CRITERIA}

Every Living Machine system is designed by Living Machines, Inc. based upon the expected wastewater volume and content, as well as the treatment requirements and local climate. Once these factors are known, the designers then determine whether a greenhouse is necessary, what types of reactors are needed, how many of each type of reactor are required, and what capacity is required to achieve the suitable residence times.

\section{PERFORMANCE}

The Living Machine ${ }^{\mathfrak{E}}$ has reliably achieved treatment goals of $\mathrm{BOD}_{5}$, TSS, and Total Nitrogen $\leq 10 \mathrm{mg} / \mathrm{L}$, Nitrate $\leq 5 \mathrm{mg} / \mathrm{L}$, and Ammonia $\leq$ $1 \mathrm{mg} /$. Table 1 shows the results of independent evaluations of two demonstration systems. The Living Machine demonstration project in Frederick, Maryland was designed to treat 40,000 gpd of screened and degritted wastewater. It employed a single anaerobic reactor for primary solids digestion, then three parallel treatment trains, each comprised of two open aerobic reactors, a clarifier, three "ecological fluidized beds." a final clarifier, and a small. high-rate subsurface flow wetland. The demonstration project located in South Bulington, Vermont was designed to treat 80,000 gpd of screened and degritted wastewater, 
TABLE 1 PERFORMANCE OF THE FREDERICK AND BURLINGTON LIVING MACHINES $^{8}$

\begin{tabular}{|c|c|c|c|c|c|c|c|c|}
\hline \multirow[b]{2}{*}{ Parameter } & \multicolumn{4}{|c|}{ FREDERICK } & \multicolumn{3}{|c|}{ BURLINGTON } & \multirow[b]{2}{*}{$\begin{array}{c}\text { Effluent } \\
\text { Goal }\end{array}$} \\
\hline & $\begin{array}{l}\text { Influent } \\
\text { mg/L }\end{array}$ & $\begin{array}{c}\mathrm{GH} \\
\text { Influent } \\
\text { mg/L }^{\mathrm{a}}\end{array}$ & $\begin{array}{c}\text { Effluent } \\
\text { mg/L }\end{array}$ & $\begin{array}{c}\% \\
\text { Removal }\end{array}$ & $\begin{array}{l}\text { Influent } \\
\text { mg/L }\end{array}$ & $\begin{array}{c}\text { Effluent } \\
\text { mg/L }\end{array}$ & $\begin{array}{c}\% \\
\text { Removal }\end{array}$ & \\
\hline $\mathrm{BOD}_{5}$ & 230 & 156 & 4 & 97 & 227 & 5.9 & 97 & $<10$ \\
\hline$C O D$ & 944 & 378 & 21 & 94 & 556 & 35.9 & 94 & -- \\
\hline TSS & 381 & 70 & 2 & 97 & 213 & 5.3 & 98 & $<10$ \\
\hline $\mathrm{NH}_{3}$ & $\cdot$ & 22 & 1.2 & 94 & 16.3 & 0.4 & 98 & $<1$ \\
\hline $\mathrm{NO}_{3}$ & - & 20.8 & 10 & 52 & $15.9^{b}$ & 4.9 & 69 & $<5$ \\
\hline $\begin{array}{l}\text { TN (tota: } \\
\text { nitrogen) }\end{array}$ & - & 44 & 11 & 75 & 29.3 & 5.6 & 81 & $<10$ \\
\hline $\begin{array}{l}\text { TP (total } \\
\text { phos- } \\
\text { phorus) }\end{array}$ & 11 & 7.7 & 6 & 45 & 5.0 & 2.0 & 67 & $<3$ \\
\hline
\end{tabular}

a Effluent from the anaerobic reactor at Frederick into the reactors contained within the greenhouse.

b Assumes that all removed ammonia is converted to nitrate.

Source: U.S. EPA, 2001

and employed five open aerobic reactors (though one of these was later converted to an anoxic reactor), a clarifier, and three "ecological fluidized beds."

In these instances, the Living Machine ${ }^{a}$ was capable of $\mathrm{BOD}_{5}$ and TSS removal in excess of 95 percent. While the Frederick system did not consistently achieve its goal of $<5 \mathrm{mg} / \mathrm{L}$ for Nitrate, the Burlington Living Machine ${ }^{\text {sid. The }}$ Living Machine reliably demonstrated about 50 percent removal of Total Phosphorous (TP), although the Burlington system had a low influent TP concentration (U.S. EPA, 2001)

While the Frederick Living Machine ${ }^{\mathbb{E}}$ achieved quite good colifom removal $(<200 \mathrm{MPN} / 100 \mathrm{~mL})$, the Burlington system's effluent was above 1,000 MPN $100 \mathrm{~mL}$. Consequently. disinfection may be required as an additional step depending upon system configuration and effluent requirements.

\section{OPERATION AND MANTENANCE}

\section{Routine Activities}

The routine operation and maintenance (O\&M) requirements for Living Machines ${ }^{2}$ are similar to the requirements for a conventional wastewater treatment plant, with a few additional requirements. These additional requirements include cleaning the inlet/outlet structure: cleaning the screen and tank; removing and disposing sludge; and maintaining and repairing machinery. Other requirements are vegetation management, including routine harvesting to promote plant growth, and removal of accumulated plant litter. Additionally, it may be necessary to manage fish and snail populations, and control mosquitoes and flies (if applicable).

\section{Residuals Management}

The Living Machine produces residuals comparable in quantity to conventional treatment systems. However, some of these residuals are biosolids, while others are in the form of plant 
TABLE 2 PRESENT WORTH COMPARISON OF "LIVING MACHINES" AND CONVENTIONAL SYSTEMS

\begin{tabular}{lccc}
\hline \hline Process & $40,000 \mathrm{gpd}$ & $\mathbf{8 0 , 0 0 0 \mathrm { gpd }}$ & 1 million gpd \\
\hline $\begin{array}{l}\text { "Living Machine" with } \\
\text { greenhouse }\end{array}$ & $\$ 1,077,777^{1}$ & $\$ 1,710.280^{1}$ & $\$ 10,457,542^{2}$ \\
$\begin{array}{l}\text { "Living Machine" without } \\
\text { greenhouse } \\
\text { Conventional System }\end{array}$ & $\$ 985,391$ & $\$ 1,570,246$ & $\$ 9,232,257$ \\
\hline \hline
\end{tabular}

(1) Cost difference is less than 20 percent

(2) Cost difference is greater than 20 percent

Source: U.S. EPA. 2001.

material. Analyses at the Frederick demonstration system showed that plant residuals could be composted and used for many agricultural or horticultural purposes. The biosolids would likely require stabilization and treatment to reduce pathogens and indicator organisms before they would meet Part 503 limits for sewage sludge (U.S. EPA. 2001).

\section{Costs}

Since the Living Machine is designed, marketed and trademarked by Living Machines, Inc., precise cost data are proprietary. However, a cost comparison with "conventional" treatment systems was performed as a part of an independent U.S. EPA evaluation of the Living Machines $\mathrm{R}$ (U.S. EPA, 2001). Table 2 summarizes the results of this cost comparison.

This analysis concluded that Living Machines are typically cost competitive with more conventional wastewater treatment systems at flow volumes up to $1.000,000 \mathrm{gpd}$, if they are located in a warm climate where a greenhouse is not necessary. However, if the climate cannot support the plants year-round and a greenhonse must be constructed. construction costs will increase. Addition of a greenhouse structure makes the Living Machine cost competitive with more conventional systems up to flow rates of around $600,000 \mathrm{gpd}$.

\section{REFERENCES}

\section{Other Related Fact Sheets}

Other EPA Fact Sheets can be found at the following web address:

http://www.epa.gov/owm/mtb/mtbfact.htm

1. Living Machines, Inc., 2001. Web Site: http/ /www livingmachines com

2. Massachusetts Foundation for Excellence in Marine and Polymer Sciences, Inc., Boston, MA, Ocean Arks International, Living Technologies, Inc.. 1997. Advanced Ecologically Engineered System, South Burlington, Vermont.

3. U.S. EPA, 2001. The "Living Machine" Wastewater Treatment Technology: An Evaluation of Pefformance and System Cost. EPA 832-R-01-004.

\section{ADDITIONAL INFORMATION}

Living Machines, Ine

125 La Posta Road

8018 NDCBU

Taos, New Mexico 87571

http://www livingmachines com 
The mention of trade names or commercial products does not constitute endorsement or recommendation for use by the U.S. Environmental Protection Agency.

Office of Water

EPA 832-F-02-025

October 2002

For more information contact:

Muncipal Technology Branch U.S. EPA

ICC Building

1200 Pemisylvania Ave., NW

$7^{\text {th }}$ Floor, Mail Code $4201 \mathrm{M}$

Washington. D.C. 20460

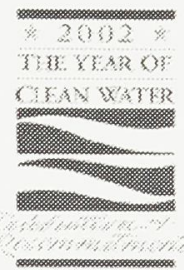




\section{Appendix B}

\section{Site Interview Data}

\begin{tabular}{|c|c|c|c|c|c|}
\hline $\begin{array}{c}\text { Interviewee } \\
\text { ID } \\
\end{array}$ & $\begin{array}{c}\text { Num. of } \\
\text { person/f } \\
\text { amily } \\
\end{array}$ & Water source & $\begin{array}{c}\text { Water } \\
\text { Disposal }\end{array}$ & $\begin{array}{c}\text { Water used/mth } \\
\left(\mathrm{m}^{\wedge} 3\right)\end{array}$ & $\begin{array}{l}\text { Garbage } \\
\text { Disposal }\end{array}$ \\
\hline 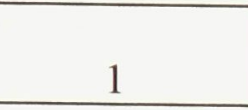 & 5 & $\begin{array}{l}\text { Well-water and } \\
\text { filtered water }\end{array}$ & River & 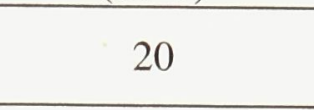 & Garbage-cart \\
\hline 2 & 2 & Filtered water & River & 7 & Garbage-cart \\
\hline 3 & 3 & Filtered water & River & 8 & Garbage-cart \\
\hline 4 & 5 & Filtered water & Drain & 30 & Garbage-cart \\
\hline 5 & 4 & Filtered water & Drain & 30 & Garbage-cart \\
\hline 6 & 7 & Filtered water & River & 60 & Garbage-cart \\
\hline 7 & 7 & Filtered water & River & 20 & Garbage-cart \\
\hline 8 & 2 & Filtered water & River & 20 & Garbage-cart \\
\hline 9 & 2 & Filtered water & River & 10 & Garbage-cart \\
\hline 10 & 4 & $\begin{array}{l}\text { Rain-water and } \\
\text { filtered water }\end{array}$ & River & 20 & Garbage-cart \\
\hline 11 & 5 & Filtered water & River & 18 & River \\
\hline 12 & 7 & $\begin{array}{l}\text { River-water } \\
\text { and filtered } \\
\text { water }\end{array}$ & River & 6 & River \\
\hline 13 & 7 & $\begin{array}{l}\text { River-water } \\
\text { and filtered } \\
\text { water }\end{array}$ & $\begin{array}{l}\text { Watered } \\
\text { the plan } \\
\text { and to } \\
\text { the river }\end{array}$ & 6 & Bury \\
\hline 14 & 8 & $\begin{array}{l}\text { Rain-water and } \\
\text { filtered water }\end{array}$ & River & 7 & River \\
\hline 15 & 2 & River-water & River & 20 & River \\
\hline 16 & 4 & $\begin{array}{l}\text { River-water } \\
\text { and filtered } \\
\text { water }\end{array}$ & $\begin{array}{l}\text { To the } \\
\text { river and } \\
\text { the pond }\end{array}$ & 8 & $\begin{array}{l}\text { Burn and } \\
\text { bury }\end{array}$ \\
\hline 17 & 5 & Filtered water & River & 12 & Burn \\
\hline 18 & 3 & Filtered water & Drain & 14 & Garbage-cart \\
\hline 19 & 10 & $\begin{array}{l}\text { River-water } \\
\text { and filtered } \\
\text { water }\end{array}$ & $\begin{array}{l}\text { To the } \\
\text { pond and } \\
\text { the drain }\end{array}$ & 5 & Bury \\
\hline 20 & 6 & Filtered water & Drain & 10 & Garbage-cart \\
\hline 21 & 3 & Filtered water & Drain & 8 & Garbage-cart \\
\hline 22 & 4 & Filtered water & Drain & 8 & Garbage-cart \\
\hline 23 & 6 & $\begin{array}{l}\text { River-water } \\
\text { and filtered } \\
\text { water }\end{array}$ & River & 5 & River \\
\hline 24 & 6 & River-water & River & 30 & River \\
\hline 25 & 6 & Filtered water & Drain & 10 & $\begin{array}{l}\text { Burn and } \\
\text { bury }\end{array}$ \\
\hline 26 & 4 & Filtered water & Drain & 6 & River \\
\hline 27 & 7 & Filtered water & Drain & 10 & River \\
\hline
\end{tabular}




\begin{tabular}{|c|c|c|c|c|c|}
\hline 28 & 7 & River-water & River & 20 & Bury \\
\hline 29 & 6 & Filtered water & Drain & 11 & River \\
\hline 30 & 3 & Filtered water & Drain & 9 & River \\
\hline 31 & 4 & Filtered water & Drain & 14 & River \\
\hline 32 & 8 & $\begin{array}{l}\text { River-water } \\
\text { and filtered } \\
\text { water }\end{array}$ & River & 6 & River \\
\hline 33 & 7 & Filtered water & River & 20 & River \\
\hline 34 & 11 & Filtered water & River & 40 & Garbage-cart \\
\hline 35 & 3 & $\begin{array}{l}\text { River-water } \\
\text { and rain-water }\end{array}$ & River & 6 & $\begin{array}{l}\text { Bury at the } \\
\text { garbage-hole }\end{array}$ \\
\hline 36 & 4 & Filtered water & River & 10 & River \\
\hline 37 & 1 & Filtered water & River & 4 & River \\
\hline 38 & 5 & Filtered water & River & 13 & River \\
\hline 39 & 2 & Filtered water & Drain & 5 & River \\
\hline 40 & 3 & Filtered water & Drain & 45 & River \\
\hline 41 & 4 & Filtered water & River & 10 & Garbage-cart \\
\hline 42 & 2 & Filtered water & River & 5 & Garbage-cart \\
\hline 43 & 8 & River-water & River & Unknown & River \\
\hline 44 & 6 & $\begin{array}{l}\text { Well-water and } \\
\text { filtered water }\end{array}$ & River & 50 & Garbage-cart \\
\hline 45 & 5 & Filtered water & River & 30 & Garbage-cart \\
\hline 46 & 4 & Filtered water & Drain & 18 & Garbage-cart \\
\hline 47 & 5 & Filtered water & River & 15 & Drain \\
\hline 48 & 7 & Filtered water & River & 40 & Garbage-cart \\
\hline 49 & 3 & Filtered water & Drain & 10 & Garbage-cart \\
\hline 50 & 3 & Filtered water & Drain & 15 & Garbage-cart \\
\hline 51 & 3 & Filtered water & Drain & 10 & Garbage-cart \\
\hline
\end{tabular}

Notes: Interviews are made randomly within the proposed area. All interviewees are head of their families. Garbage-cart is the city garbage removal service. 


\section{Source of Water Summary Chart}

\begin{tabular}{|l|c|}
\hline \multicolumn{1}{|c|}{ Source of water } & $\begin{array}{c}\text { Num. Of House } \\
\text { holder }\end{array}$ \\
\hline Well-water and filtered water & 2 \\
\hline City Filtered water & 36 \\
\hline River-water and rain-water & 1 \\
\hline Rain-water and filtered water & 2 \\
\hline River-water & 4 \\
\hline River-water and filtered water & 6 \\
\hline
\end{tabular}

\section{Source of Water}

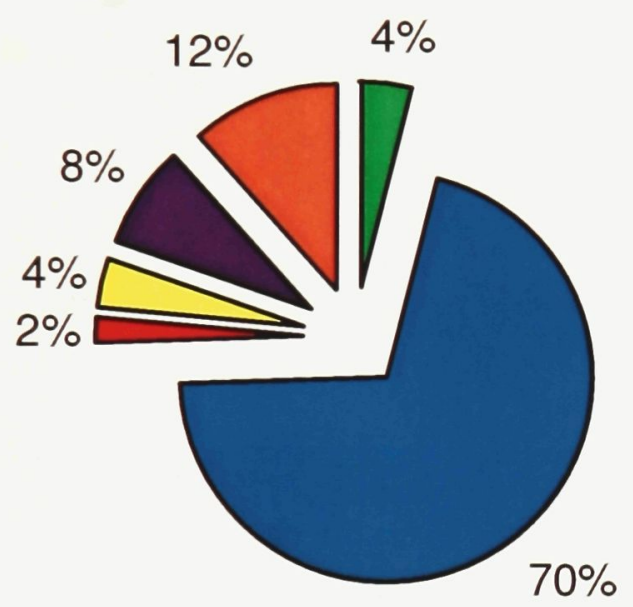

Well-water and filtered water

$\square$ Filtered water

$\square$ River-water and rainwater

$\square$ Rain-water and filtered water

River-water

River-water and filtered water 


\section{Water/Garbage Disposal Method Summary Chart}

\begin{tabular}{|l|c|l|c|}
\hline \multicolumn{1}{|c|}{ Water Disposal } & $\begin{array}{c}\text { Num. Of House } \\
\text { holder }\end{array}$ & \multicolumn{1}{|c|}{ Garbage Disposal } & $\begin{array}{c}\text { Num. Of } \\
\text { House holder }\end{array}$ \\
\hline Drain & 18 & Drain & 1 \\
\hline River & 30 & Garbage-cart (City Service) & 24 \\
\hline To the pond and the drain & 1 & Bury & 3 \\
\hline To the pond and the river & 1 & River & 19 \\
\hline $\begin{array}{l}\text { Watered the plan and to the } \\
\text { river }\end{array}$ & 1 & Bury at the garbage-hole & 1 \\
\hline & & Burn & 1 \\
\hline & & Burn and bury & 2 \\
\hline
\end{tabular}
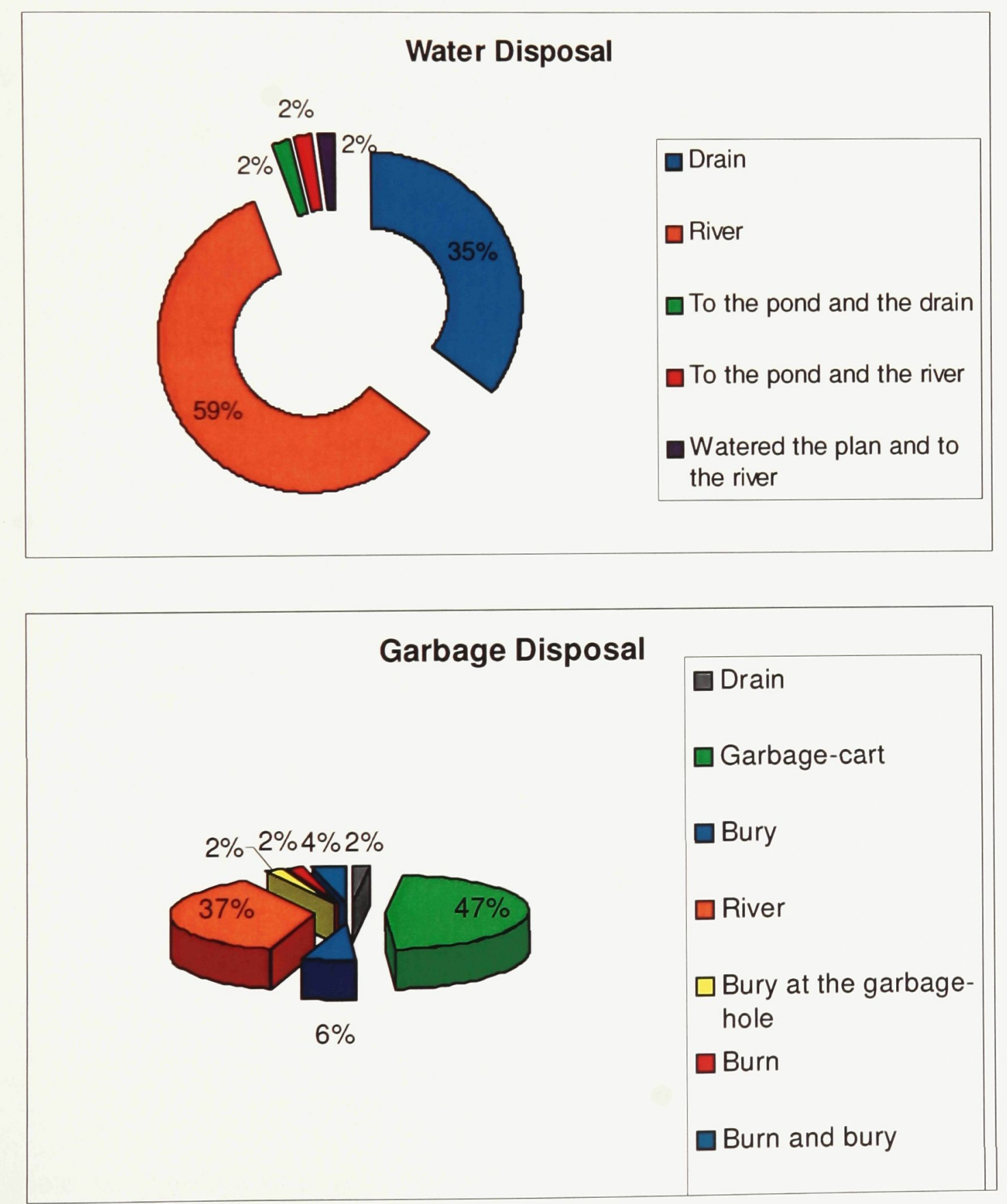


\section{Occupation}

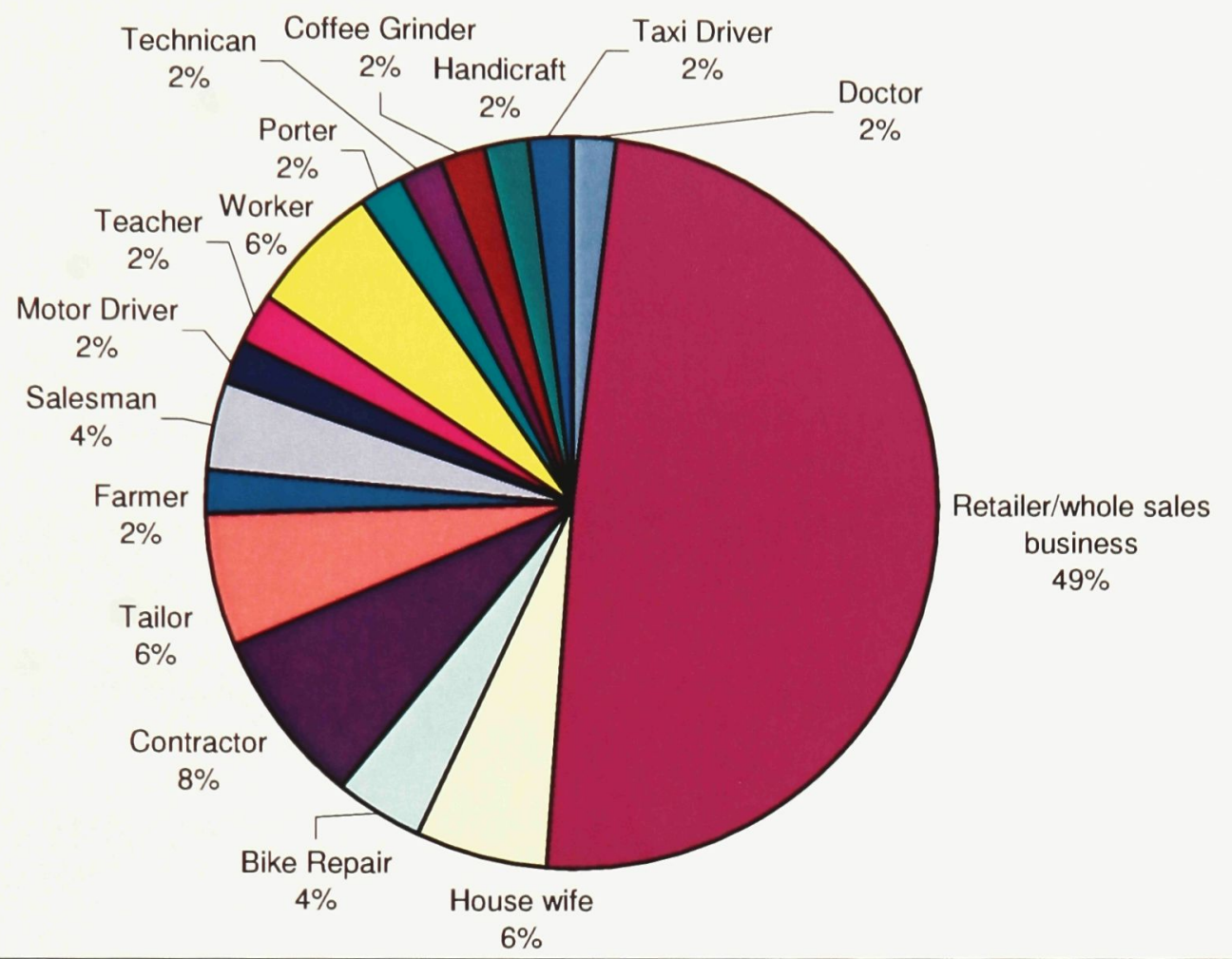

\section{Average Monthly Income/Occupation}

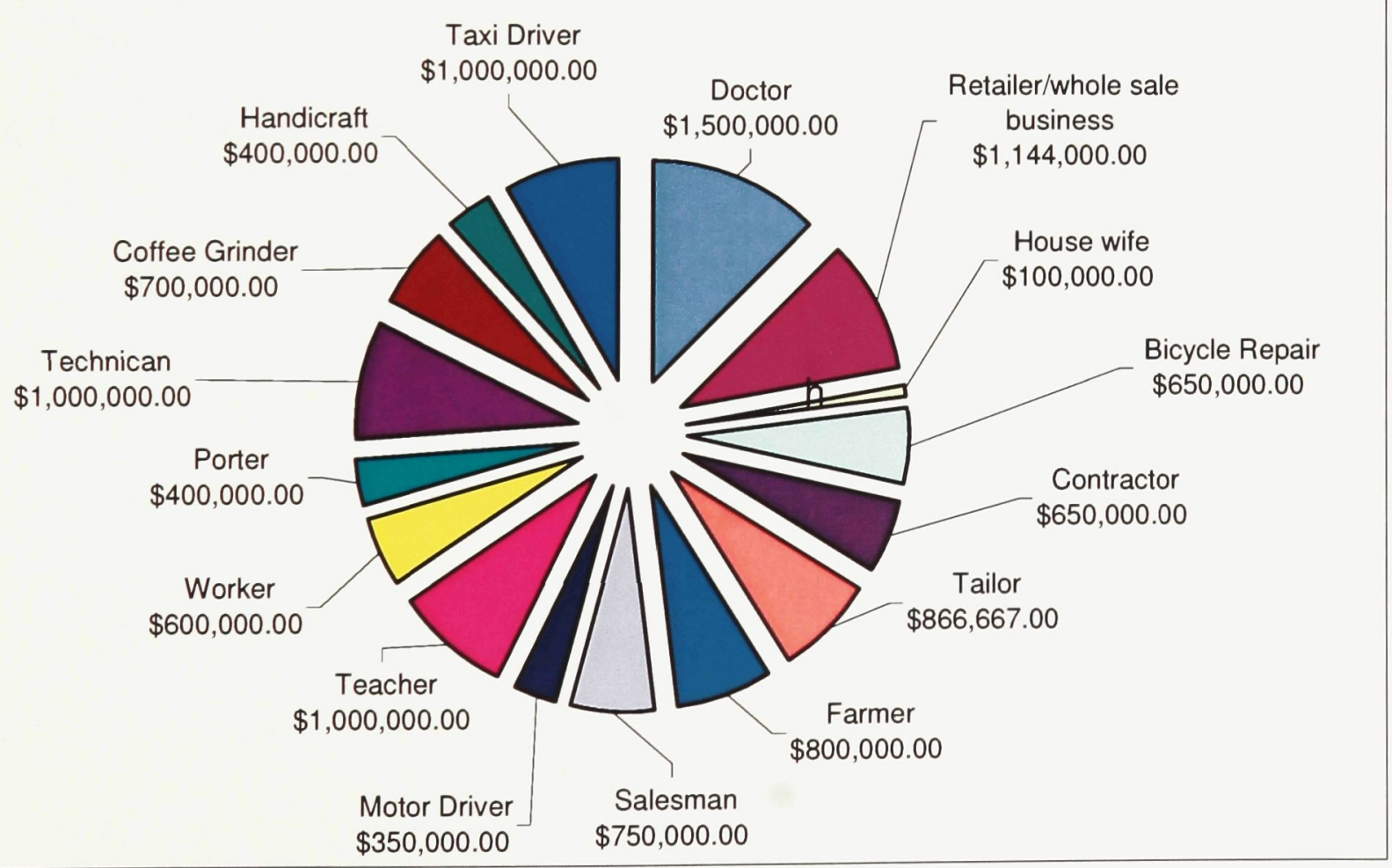

Note: the figures above are in Vietnamese Dong (12,500 Dong = 1 Canadian Dollar) 


\section{Works Cited}

Bachelard, Gaston. Water and Dreams: An Essay on the imagination of Matters. Trans. Edith R. Farrell. Dallas: The Dallas Institute of Humanities and Culture, 1983.

Barr, Stewart. Household Waste in Social Perspective: Values, attitudes, situation and behaviour. Aldershot: Ashgate, 2002.

Burgess Peter G. The Role of the Architect in Society. Pittsburgh: Carnegie-Mellon University, Dept. of Architecture, 1983.

Campbell, Craig S. Water in Landscape Architecture. New York: Van Nostrand Reinhold Company, 1978.

Chan, Wing-Tsit. A Source Book in Chinese Philosophy. Princeton, N.J.: Princeton University Press, 1963.

Cramer, James P. Design Plus Enterprise : Seeking a New Reality in Architecture.

Washington, D.C.: American Institute of Architects Press, 1994.

Diamond, Jared M. Collapse : How Societies Choose to Fail Or Succeed. New York: Viking, 2005.

Grigg, Neil S. Urban Water Infrastructure: Planning, Management, and Operations. New York: Wiley, 1986.

Nguyen, Huy Hong, and Chinh Trung Tran. Vietnamese Traditional Water Puppetry. Vietnam: The Gioi Puplishers, 2001.

Illich, Ivan. $\mathrm{H} 2 \mathrm{O}$ and the Waters of Forgetfulness: Reflection on the History of "Stuff". Dallas: Dallas Institute of Humanities and Culture, 1985.

Lim, C. J. Realms of Impossibility: Water. Canada: John Wiley \& Sons Inc., 2002.

McKirahan, Richard D. Philosophy Before Socrates: An Introduction with Texts and Commentary. Cambridge: Hackett Publishing Company, 1994.

Moore, Charles W. Water and Architecture. New York: Harry N. Abrams, Inc., 1994.

Nietzsche, Friedrich Wilhelm. Philosophy in the Tragic Age of the Greeks. Trans. Marianne Cowan. Chicago: Regnery, 1962.

Pelletier, Louise, Alberto Pérez Gómez, and Institut de recherche en histoire de l'architecture. Architecture, Ethics, and Technology. Montréal; Buffalo: Institut de recherche en histoire de l'architecture, Canadian Centre for Architecture, McGill University; Montreal; McGill-Queen's University Press, 1994. 
Raskin, Eugene. Architecture and People. New Jersey: Prentice-Hall, Inc., 1974.

Spector, Tom. The Ethical Architect : The Dilemma of Contemporary Practice. New York: Princeton Architectural Press, 2001.

Tanahashi, Kazuaki. Moon in a Dewdrop: Writings of Zen Master Dōgen. New York: North Point Press, 1985.

The Ministry of Environment and Natural Resource. Vietnam Environment Monitor 2003: Water. World Bank Report. Ho Chi Minh City, Vietnam.

The Living Water Garden. Keepers of the Waters website. 14 February 2005 $<$ http://keepersofthewaters.org/lwg.cfm>.

Tien Giang Office of Agriculture and Rural Development Center of Rural Living Water and Environment Sanitation. Adjustment Annex Investment Report: Rural Living Water System in Tien Giang. My Tho: Provincial Office of Agriculture and Rural Development, 2002.

United States Environment Protection Agency. Wastewater technology fact Sheet: The Living Machine. EPA, 2001.

Vitruvius. The Ten Books on Architecture. Trans. Morris Hickey Morgan. New York: Dover Publications, 1960. 


\section{Selected Bibliography}

Abel, Chris. Architecture and Identity: Responses to Cultural and Technological Change. $2^{\text {nd }}$ ed. Oxford; Boston: Architectural Press, 2000.

Aswathanarayana, U. Water Resources Management and the Environment. Lisse: A.A. Balkema, 2001.

Bachelard, Gaston. The Poetics of Space. Boston: Beacon Press, 1964.

Bell, Bryan. Good Deeds, Good Design: Community Service Through Architecture. New York: Princeton Architectural Press, 2003.

Billitewski, Bernd. Waste Management. New York, N.Y.: Springer, 1997.

Delight [Dujiangyan, China]. Vol. 216., 2004.

Diamond, Jared M. Guns, Germs, and Steel : The Fates of Human Societies. 1st Norton pbk. ed. New York: W.W. Norton \& Co., 1999.

Donahue, John M., Barbara Rose Johnston. Water, Culture, and Power: Local Struggles in a Global Context. Washington, D.C.: Island Press, 1998.

Gandy, Matthew. Recycling and the Politics of Urban Waste. London: Earthscan, 1994.

Harbison, Robert. The Built, the Unbuilt, and the Unbuildable: In Pursuit of Architectural Meaning. 1st MIT Press ed. Cambridge, Mass.: MIT Press, 1991.

Harries, Karsten. The Ethical Function of Architecture. Cambridge, Mass.: MIT Press, 1997.

Hegewald, Julia A. B. Water Architecture in South Asia : A Study of Types, Development, and Meanings. Vol. 24. Leiden; Boston: Brill, 2002.

Jellicoe, Susan, and Geoffrey Alan Jellicoe. Water: The use of Water in Landscape Architecture, [by] Susan and Geoffrey Jellicoe. London: A. and C. Black, 1971.

Kharbanda, Om Prakash and E.A. Stallworthy. Waste Management: Towards a Sustainable Society. Aldershot, Hants: Gower, 1990.

Reid, George W. Appropriate Methods of Treating Water and Wastewater in Developing Countries. Michigan, USA: Ann Arbor Science Publishers, 1982.

Russ, Thomas H. Redeveloping Brownfields: Landscape Architects, Planners, Developers. New York: McGraw-Hill, 2000. 
Shady, Aly M. Management and Development of Major Rivers. Calcutta: Oxford University Press, 1996.

Soesilo, J. Andy and Stephanie R. Wilson. Site Remediation Planning and Management. Boca Raton: CRC Press, c1997.

Stephenson, David. Water Resources Management. Netherlands: A.A Balkema Publishers, 2003.

Wylson, Anthony. Aquatecture : Architecture and Water. London: Architectural Press, 1986. 